\title{
A Multigenerational Home: \\ Designing Architecture that Facilitates Multigenerational Care
}

\author{
by \\ Brea Mann-Lewis \\ A thesis submitted to the Faculty of Graduate and Postdoctoral Affairs in partial fulfillment of \\ the requirements for the degree of
}

Master of Architecture

in

Architecture

Carleton University

Ottawa, Ontario

(C) 2014

Brea Mann-Lewis 

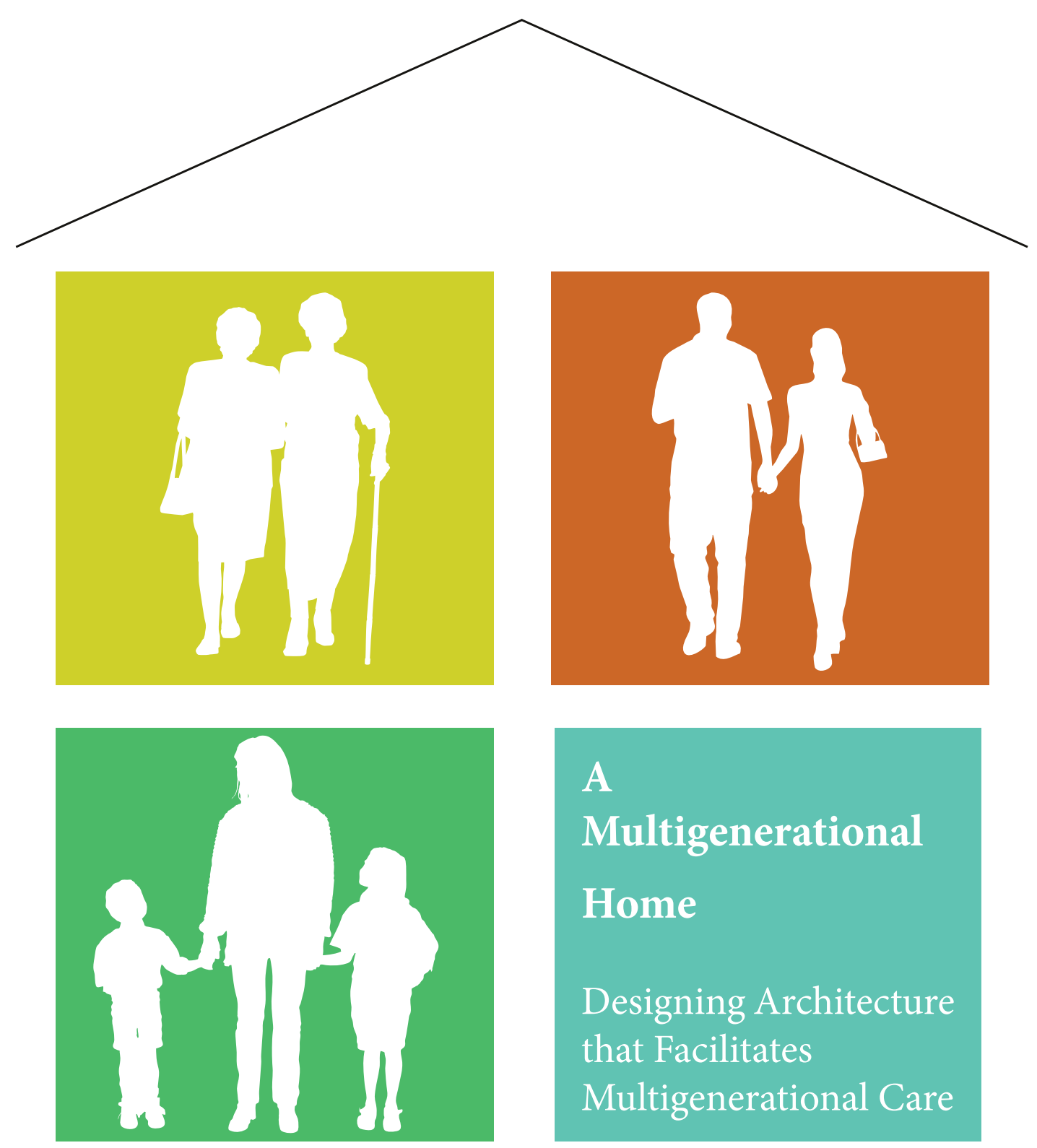


\begin{abstract}
Canada is facing an unprecedented demographic shift over the next 50 years; the senior population will be the largest it has ever been, which will put a great strain on the availability of senior housing. Consequently, issues of affordable housing with access to care immediately need to be addressed through an architectural intervention. There is a lack of choice of housing for low income seniors who need or wish to have minimum to moderate care and assistance in the home. This intervention of a multigenerational building provides a home for children, adults, and seniors to live together and to facilitate care between all residents. By providing both housing for all generations, and shared spaces to be used between all residents, all ages can participate and receive the necessary care while simultaneously creating a community within a shared building.
\end{abstract}




\section{Acknowledgments}

Thank you to everyone who has contributed to the success of my thesis: Federica for your exemplary supervision and guidance, my friends for providing an endless amount of support and my family for paying my OSAP. 


\section{Table of Contents}

Abstract

Acknowledgments

List of Illustrations

Introduction

Seniors and Families in Ontario

Retirement Homes

Long-Term Care Facilities

Low Income Seniors

Missing Option for Low Income Seniors

Multigenerational Care

Precedent Analysis

Design of a Multigenerational Home in Ottawa, Ontario

Conclusion

Post Script (Appendix II)

Bibliography 


\section{List of Illustrations}

Illustrations are creations of the author unless sourced otherwise.

Figure 1. Torre Julia front elevation. Accessed from http://www.archdaily.com/283113/

Figure 2. Torre Julia front entrance. Accessed from http://www.archdaily.com/283113/

Figure 3. Armstrong Place Senior Housing facade. Accessed from http://www.archdaily. com/153359/armstrong-place-senior-housing-david-baker-partners/

Figure 4. Armstrong Place Senior Housing courtyard. Accessed from http://www.archdaily. com/153359/armstrong-place-senior-housing-david-baker-partners/

Figure 5. Kidosaki House floor plans. Accessed from http://archinect.com/people/proj ect/21750526/regenerate-multigenerational-house/23030017

Figure 6. Kidosaki House entrance. Accessed from http://thisis3d.com/2011/03/10/kidosa ki-house-in-osaka-japan/

Figure 7. Miss Sargfabrik facade. Accessed from http://sieplcoatesstudio.weebly.com/ miss-sargfabrik.html

Figure 8. Miss Sargfabrik exterior living space. Accessed from http://www.bkk-3.com/ BUILDINGS/MISS-FACADE/miss-facade.html

Figure 9. Steinacker Residential Complex facade. Accessed from http://sieplcoatesstudio.wee bly.com/steinacker-residential-complex.html

Figure 10. Steinacker Residential Complex courtyard. Accessed from http://www.hsp-ar 
chitekten.ch/hsp_referenzen.php?read_article $=11$

Figure 11. Social Housing Complex - Wiesbaden exterior living space. Accessed from http:// sieplcoatesstudio.weebly.com/housing-development.html

Figure 12. Social Housing Complex - Wiesbaden facade. Accessed from http://sieplcoatesstu dio.weebly.com/housing-development.html

Figure 13. Courier Place front elevation. Accessed from http://www.jamboreehousing.com/ index.php?option=com_content\&view=category\&layout=blog\&id= 16\&Itemid=\&properties $=$ detail\&property_id $=62$

Figure 14. Courier Place site plan. Accessed from http://4.bp.blogspot.com/_ iFIDdxibrTg/TIpKyToiu9I/AAAAAAAAESs/Ecp3cIlvHOI/s1600/Courier+Place+site +plan1.jpg

Figure 15. Diagram showing the relationship between senior and family to form multigenerational care.

Figure 16. Floor plan of the multigenerational unit with the family, shared and senior space breakdown.

Figure 17. Floor plan of the senior unit.

Figure 18. Floor plan of the family unit.

Figure 19. Building axonometric describing the internal programs of residential private, residential shared and community space.

Figure 20. Diagram showing the relationship between family units, multigenerational units 
and senior units in the building.

Figure 21. Diagram axonometric depicting the relationship between residential units. 38

Figure 22. View from the gymnasium looking onto the west facade.

Figure 23. Floors two through three which include senior residential units and shared spaces. The shared spaces include a library on the second floor and a meeting room on the third floor.

Figure 24. Diagram showing the unit bedroom breakdown on floor two through three.

Figure 25. Floors four through six which include multigenerational residential units and shared spaces. The shared spaces include a shared kitchen on the fourth floor, a daycare on the fifth floor and a gymnasium room on the sixth floor.

Figure 26. Diagram showing the unit bedroom breakdown on floor four through six.

Figure 27. Floors seven through nine which include family residential units and shared spaces. The shared spaces include an open to below space to the gym on floor seven, a kids only area on floor eight and an exterior green space on floor nine.

Figure 28. Diagram showing the unit bedroom breakdown on floor seven through nine.

Figure 29. Site map of the greater Little Italy area showing the site, bus routes, educational facilities and public green spaces. Please note, the Ottawa Hospital - Civic Campus is located just south west of the map. Base map accessed from Google Maps.

Figure 30. Current condition of the site as a City of Ottawa infrastructure testing area.

Figure 31. Site map showing the locations of the O-Train, the Ottawa River Pathway and 
Figure 32. View of north facade.

Figure 33. Basement parking plan.

Figure 34. Ground floor plan including the CCAC office and farmers' market.

Figure 35. View of the west facade including the farmers' market.

Figure 36. Diagram of the brick materiality of the residential facade.

Figure 37. View of the entrance to the farmers' market, residential units and the CCAC office. $\quad 58$

Figure 38. View from the Ottawa River Pathway towards the south facades.

Figure 39. Diagram of the multigenerational units' development of the wall from a physical barrier to a moveable and interactive wall.

Figure 40. Diagram of the creation of a retractable wall between the family and senior shared space.

Figure 41. Diagram of the creation of rotating walls in order to provide additional private space.

Figure 42. Diagram of the creation of permanent walls to divide the shared space into smaller, more private spaces.

Figure 43. Diagram of the creation of a panel and track system, hung from the ceiling,to create smaller private areas within the shared space.

Figure 44. Diagram of the movement of the panel and track system through the shared space.

Figure 45. Elevations of the seven panels including a privacy panel, a handrail panel, a fold out table 
panel, a high level of visibility panel, a storage panel, a fold out chair panel, and a low visibility panel as read from left to right

Figure 46. Plan of a typical residential floor in a closed condition with a multiple senior unit to the west, two multigenerational units, and a kids only shared space

Figure 47. Plan of a typical residential floor in an open condition with a multiple senior unit to the west, two multigenerational units, and a kids only shared space

Figure 48. Diagram of the movement through the building. Yellow represents vertical movement, orange represents movement on one floor, and green represents movement on the alternating floor

Figure 49. Diagram of the movement through the building. Yellow represents vertical movement, green represents movement from the stairs, and orange represents movement to residential units

Figure 50. Section of the building showing residential units, stairs, shared spaces, the CCAC office, residential entrance, farmers' market, and parking

Figure 51. Plan of the ground floor in a closed condition including the farmers' market, residential entrance, and the CCAC office

Figure 52. Plan of the ground floor in an open condition including the farmers' market, residential entrance, and the CCAC office 


\section{Introduction}

Presently, the population of senior citizens aged 65 and over ${ }^{1}$ is the largest it has ever been in Canadian history. This projected data represents the natural growth of a nation, the increase of life expectancy through health care improvement, and the large influx of births known as the 'Baby Boom. These three elements create a new type of society: one that must respond to an increasingly aging population with meaningful, affordable and timely answers.

One in every seven Canadians is a senior citizen $^{2}$. That means over $14 \%^{3}$ of public and private services are aimed towards meeting

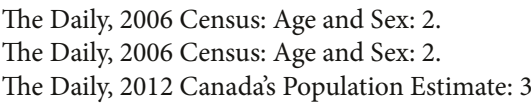

the needs of the senior population. This rate will only increase in the coming years since by 2036, the population of Canadians 65 and over will be doubled that of its population in $2009^{4}$. These seniors will represent the most rapid growth in Canadian population, and this growth will peak in $2031^{5}$

The strain on public and private services can most easily seen through the shortage of adequate housing for seniors. Often, private facilities are costly and are associated with the loss of independence and a disconnect from a greater community.

When choosing a senior housing facility, one large issue facing seniors is the associated cost.

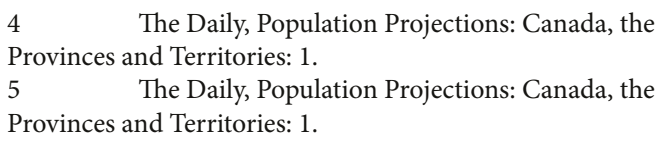


On average, single seniors have an annual income of $\$ 22000^{6}$. In metropolitan areas, the cost for a senior facility can average from $\$ 1000$ to $\$ 7000$ a month ${ }^{7}$. This simple observation in itself already identifies the need for low cost housing for seniors.

Yet, if costs need to be contained, where do these savings come from? One possible and worthwhile approach is to study how seniors can cohabitate with others. According to Statistics Canada ${ }^{8}$, the living arrangements of seniors is divided four ways: $63 \%$ of Ontario seniors live with family members, which includes spouses; $27.3 \%$ of Ontario seniors live alone; $6.4 \%$ of Ontario seniors live in institutions and $8 \%$ of Ontario seniors live with

\begin{tabular}{ll}
\hline 6 & Statistics Canada, Seniors in Canada Profile Series \\
$2001: 5$. & \\
7 & Krivel 2003: Z.14. \\
8 & Statistics Canada, Seniors in Canada Profile Series \\
2001: 13. &
\end{tabular}

extended family. Therefore, more than $77 \%$ of Ontario seniors are living with another person or have access to assisted living facilities. The option for dependence on another individual is highly needed among seniors in Ontario.

One option to provide dependent living is to reintegrate seniors backinto the family unit. The costs associated with this would be significantly lower than those associated with an assisted living facility. By having a multigenerational house, seniors can have all of their needs for assisted living met through the comfort and convenience of family. The family, in return, benefits from the additional social interaction with seniors. Therefore, by facilitating the reunion of seniors back to their families, seniors can maintain a more independent life style for a longer period of time, helping to save 
on cost and housing shortages. The seniors, in return, can potentially help with issues such as child care while parents and teens might also offer support to the senior members in their family. With a larger percentage of both parents returning to work after the birth of a child, the senior member could help to care for the child while the parents work.

A known design feature to solve this issue is to build an 'in-law-suite' in the family home. It gives both the family and the seniors independence but also easy accessibility to one another. The main disadvantage to this design is the typical setting in a suburban context: suburbia means living away from the city and thus a reliance on vehicles. For seniors, vehicle dependence can be detrimental to their ability to move as well as their access to various kinds of amenities and recreational activities.

An alternative to seniors living in the suburbs is to bring seniors back into the city. The city offers a much more walkable lifestyle than the suburbs. Seniors would be less dependent on their vehicle for transportation since amenities will often be within walking distance. Public transportation would also offer a reliable and affordable solution to mobility. In addition, the city provides for a more mature style of life, with access to things like museums, restaurants and cultural exhibits.

Although seniors may not need access to medical care at all times, as they age, the importance of being close to medical facilities, such as clinics and hospitals, increases. Del 
Webb $^{9}$, an American retirement community builder, explains,

"For current Del Webb residents, those who plan to move again consider both access to healthcare and cultural/ recreational amenities as the most important factors at 71 percent, with the cost of living a concern among 70 percent of these respondents."

Another aspect of location is proximity to alternative employment options. Although many seniors may retire and stay unemployed, a large group will choose to re-enter the workforce. This re-entry may not be towards traditional office jobs but rather part time positions that have a greater personal interest \begin{tabular}{ll}
\hline 9 & Del Webb http://www.delwebb.com/index.aspx \\
10 & Del Webb 2010B:2.
\end{tabular} to seniors. Living closer to a greater number of businesses and institutions increases the chances of seniors finding these new jobs.

Moving the multigenerational family into a more urban context has implications on all ages. A proper placement that can offer great schooling, easy availability of transportation and access to cultural amenities benefits the whole family unit.

The choice for a family to move to a multigenerational house would be a long term commitment. It would involve looking towards the future and understanding that the care of the senior is a priority and that it can be mostly accomplished through proper housing. If either the family or the senior chooses to move out of the housing complex, priority would be given 
to a complete multigenerational family for the affected units, while the remaining family or senior would be relocated within the complex if possible. Additional units would offer housing to single seniors and independent families. This allows for families and seniors to live within a multigenerational building and provide care to one another without living in the same unit.

Unfortunately sometimes the family will not be able to sustain adequate levels of care for the senior. If that point is reached, the option to transition to an assisted care facility might be appropriate.

Costing of the units would be income based rent. This allows for low income senior residences to have the opportunity to live in appropriate housing for seniors and receive care without the concern of high cost rent.

A new approach to multigenerational design is important and is offered in this thesis. Multigenerational living focuses mainly on the social aspects of cohabitation between generations and an architectural expression of this typology is important. This is found through three design aspects: shared spaces, dynamic movement of the residents, and the engagement of the greater community.

Multigenerational housing intends to provide the best life possible for families and seniors. By offering seniors the opportunity to live with individuals who can offer care, seniors are able to maintain relatively independent lives while receiving necessary care. 


\section{Seniors and Families in Ontario}

Statistics Canada reveals that the population of seniors, aged 65 and over, has more than doubled its population since $1956^{11}$. Although this can mostly be attributed to the large population of Baby Boomers reaching senior status, life expectancy is also increasing. In addition, there is a decrease in fertility rates, ${ }^{12}$ which affects the population ratio. People are living longer and maintaining senior status for longer periods of time. This creates an increasingly large group of seniors as time goes on.

The projection into the future for seniors in Canada is an exponential curve. The increase of seniors will forever have a slight increase because of issues of low fertility rates and better life expectancy; however, because of the Baby Boomer's age, this group front loads the senior statistics and carries forward an impact on the population statistics due to continued aging.

Due to the growing population of seniors in Canada, on July 1, 2012, children outnumbered seniors by less than 500,000 people; a small number compared to the almost 2.7 million children surplus in $1992^{13}$. This shift was created through two actions: a decrease in birth rates and the increase of senior population.

Ontario and Quebec have the largest population of seniors in all of Canada. The

13 The Daily, 2012 Canada's Population Estimate: 3. A Multigenerational Home 
majority of all seniors $(62.9 \%)^{14}$ live in these two provinces. This isn't surprising since over $62 \%{ }^{15}$ of Canada's population also lives in Ontario and Quebec. In 2012, $14.6 \%{ }^{16}$ of the population of Ontario was senior. That means $1,971,861$ people were 65 years of age or over in Ontario in 2012.

Family dynamics in Ontario are reflecting this change in senior population. In 2011, $92.1 \%{ }^{17}$ of seniors in Canada lived in private settings. This includes living with spouses, family or friends. In addition, in 2011, $2.7 \%^{18}$ of all households in Canada were multigenerational. This also accounts for

\begin{tabular}{ll}
\hline 14 & Statistics Canada, A Portrait of Seniors in Canada \\
$2006: 14$. & \\
15 & Statistics Canada, A Portrait of Seniors in Canada \\
$2006: 14$. & \\
16 & Statistics Canada, 2012 Census of Population Estimates \\
17 & Statistics Canada, 2011 Living Arrangements of \\
Seniors: 7. & \\
18 & Statistics Canada, 2011 Portrait of Families and Living \\
Arrangements in Canada: 14.
\end{tabular}

families who may be not be in biological relation to one another but still maintain similar roles to each other. Therefore it is clear that seniors presently occupy living arrangements within extended families or with their own spouses.

There are many benefits for families with a senior member within the household. Sharon and John Niederhaus, writers on the topic of multigenerational families, explain,

"Typically, all sides gain from the relationships: Parents of young children may receive help with child care from grandparents. The grandchildren obtain the gifts of time, unconditional love, and attention from their grandparents. In turn, grandparents get emotional A Multigenerational Home 7 
satisfaction form frequent interaction

with their grandchildren and from the responsibilities in helping them"19

This creates a level of dependency between all members of the family, creating a healthier and happier family unit where each generation is empowered in their role within the overall family structure. 


\section{Retirement Homes}

A retirement home $\mathrm{e}^{20}$ is a dwelling of at least six seniors that must provide at least two services. These services can range from meal cooking to bathing. It is entirely privately funded and is available to paying customers. There is no requirement for an approval from the Community Care Access Centre. In general, these homes provide minimal to moderate care and they are regulated through the Retirement Homes Regulation Authority.

The Community Care Access Centre (CCAC) is an Ontario health care organization that provides resources and tools for health care services for individuals of all ages. All

\begin{tabular}{l}
\hline $20 \quad$ ORCA Senior Living Options http://www. \\
orcaretirement.com/retirement-living/seniors-living-options/ \\
$21 \quad$ Champlain CCAC http://healthcareathome.ca/ \\
champlain/en.
\end{tabular}

provinces and territories offer these services, but through different organizations. In Ontario, the CCAC is funded by the Ministry of Health and Long-Term Care, ultimately being paid through OHIP. By educating individuals about the resources provided by the Ontario health care system and by private organizations, the CCAC ensures that all health needs are met with the necessary support. Within Ottawa, the Champlain CCAC states the mandate of the organization as follows:

"The Champlain Community Care Access Centre is a communitybased, not-for-profit corporation that is responsible for the assessment, care planning, care coordination and quality monitoring of publicly 
funded home-health services such as nursing, personal care, physiotherapy, occupational therapy, speech-language pathology, nutritional therapy, social work, and medical supplies and equipment. The Champlain CCAC endeavours to offer people a single point of access and connection to the most appropriate health care services to meet their individual needs"22

Therefore, since the CCAC focuses specifically on issues of health care, a referral to a retirement home - which does not solely focus on healthcare - is unnecessary.

The Retirement Home Regulation Authority sets out thirteen care services for the retirement home, two of which must be followed for regulation. The care services are: “(a) a prescribed health care service provided by a member of a College as defined in the Regulated Health Professions Act, 1991, (b) administration of a drug, as defined in the Drug and Pharmacies Regulation Act, or another substance, (c) assistance with feeding, (d) assistance with bathing, (e) continence care, $(f)$ assistance with dressing, $(g)$ assistance with personal hygiene, $(h)$ assistance with ambulation, (i) provision of a meal, or ( $j)$ any other service prescribed as a care service"23 
Essentially, if a senior does not have enough money to afford the monthly costs of the home, then care cannot be provided.

Retirement homes tend to focus on the social aspect of seniors lives whether that is through building wide initiatives or outings to greater community events.

As of 2011, in Ontario, there were $49,600^{24}$ total spaces available in retirement homes with an average vacancy rate of $15.7 \%{ }^{25}$, a decrease from the previous year ${ }^{26}$. The decrease of vacancy is due to the development of new facilities in Ontario as well as the increasingly stable economy ${ }^{27}$. Considering in 2012 there were $1971861^{28}$ seniors in Ontario this means that about $2.5 \%$ of seniors can ideally have access to a retirement home. This calculation solely compares the number of seniors to the number of spaces in retirement homes.

Retirement homes offer paying seniors access to minimum to moderate care with an emphasis on social activities and community engagement.

Canada Mortgage and Housing Corporation 2011: 1 . Canada Mortgage and Housing Corporation 2011: 1. Canada Mortgage and Housing Corporation 2011: 1. Canada Mortgage and Housing Corporation 2011: 3. Statistics Canada, 2012 Census of Population Estimates 


\section{Long-Term Care Facilities}

Long-term care facilities ${ }^{29}$ provide 24 hour moderate to advanced care for individuals who are unable to maintain an average standard of life for themselves. The Ministry of Health and Long-Term Care licenses and approves the facilities ${ }^{30}$. A person of any age can live within these facilities as long as there is approval from the Community Care Access Centre.

These facilities have a monthly fee, a copayment similar to the requirement of the retirement home, but if an individual cannot afford the co-payment then government subsidization is provided. Essentially, if a 29 ORCA Senior Living Options http://www. orcaretirement.com/retirement-living/seniors-living-options/ 30 Ministry of Health and Long-Term Care, Seniors' Care: Long-Term Care Homes http://www.health.gov.on.ca/en/public/ programs/ltc/15 facilities.aspx person needs to live in a long-term care facility, care will not be withheld because of financing. Government subsidization is organized through The Ministry of Health and Long-Term Care and is assessed and awarded to patients in need.

For example, if a person was able to afford copayment without any additional subsidization, the monthly co-payment would be between $\$ 1700$ and $\$ 2300^{31}$ depending on the type of accommodation

Although typically individuals who enter long-term care facilities remain in the facility for the duration of the individual's life, there are two other forms of stay: respite care and convalescent care. Respite care provides $31 \quad$ Ministry of Health and Long-Term Care, Seniors' Care: Long-Term Care Homes http://www.health.gov.on.ca/en/public/ programs/ltc/15_facilities.aspx 
care for a patient whose care giver needs temporary relief for up to 60 consecutive days. Convalescent care is offered to patients who need a space to recover and gather strength for up to 90 days. This care does not need to be funded by the individual.

Unlike retirement homes, long-term care facilities are governed through the Long-Term Care Homes Act. It sets out mandates ${ }^{32}$ on the topics of: residents' rights, care and services; admission of residents; councils; operation of homes; funding; licensing; municipal homes and first nations homes; compliance and enforcement; and administration.

Long-term care facilities ensure that
individuals have access to moderate to

advanced care so an average standard of life is maintained. These facilities are for individuals of all ages and focus more on health care than social activities.

$32 \quad$ Long-Term Care Homes Act 2007. 


\section{Low Income Seniors}

Seniors can be the most vulnerable to the dangers of financial instability. Seniors often have very little income. Money - especially through a steady source - is invaluable to everyday life. As life expectancy rises, cost of living increases, and seniors age further into their upper years, many often find themselves facing a financial short fall.

Seniors often fall below the Low Income Cutoff because of their lack of financial stability. Statistics Canada identifies the Low Income Cut-off as any person who spends a larger proportion of their income on shelter, food and clothing in comparison to the average family ${ }^{33}$.

$33 \quad$ Statistics Canada, Low Income Cut-offs for 2005 and Low Income Measures for 2004: 7
Reflecting inflation rates $^{34}$, the Low Income Cut-off for 2011 for a single senior after tax is about $\$ 18391^{35}$. Therefore any senior with an income after tax under this amount is spending a larger proportion of income than the average family on food, shelter and clothing. According to Statistics Canada, on average, a female senior's income is $\$ 22500^{36}$ while a male's income is $\$ 27800^{37}$. Therefore it is evident, that on average, a large percentage of seniors are below the Low Income Cut-off in Canada.

Many seniors that find themselves below the Low Income Cut-off in Canada have the

$34 \quad$ Bank of Canada Consumer Price Index http://www. bankofcanada.ca/rates/price-indexes/cpi/

35 Statistics Canada, Low Income Cut-offs for 2005 and Low Income Measures for 2004: 16.

36 Statistics Canada, Canada at a Glance 2013: 10. 37 Statistics Canada, Canada at a Glance 2013: 10. 
need to return to employment. Typically, seniors who retire stay out of the workforce. However, some choose - or are forced to re-enter the workplace to maintain a flow of income. In 2004, seniors made up only $1.7 \%$ of the labour force totalling about 300000 people $^{38}$. This income is normally less than their pre-retirement income. Reasons for returning to work can include rising cost of living, bad financial planning, and through the betterment of healthcare, a longer life expectancy.

For seniors who fall below the Low Income Cut-Off it can be extremely challenging to afford a monthly expense such as housing. According to Canada Mortgage and Housing Corporation's 2011 Seniors' Housing Report Statistics Canada, A Portrait of Seniors in Canada 2006: 115.

for Ontario, the average monthly rent for housing accommodation with minimum to moderate care is $\$ 3000^{39}$. An annual increase in this rent is due to the expectation from residents for expanded amenities within the residence ${ }^{40}$. This cost is unaffordable for those who fall below the Low Income Cut-Off and therefore they cannot have access to proper care.

Ultimately for seniors, income determines access to care and housing. For low income seniors, this accessibility is lacking and the issue of care is compromised. Low income seniors often do not have the access to the care that they need.

Canada Mortgage and Housing Corporation 2011: 1. Canada Mortgage and Housing Corporation 2011: 5.

A Multigenerational Home 15 


\section{Missing Option for Low Income}

\section{Seniors}

There is a missing option for low income seniors who wish to live in a retirement home. This is mostly due to the financial constraints placed on seniors who want to live in retirement homes but cannot afford the monthly costs. Where do these seniors go?

An option for these seniors is to remain in their current homes and have care brought to them in typical daily scheduled visits. This program, known as the Assisted Living Facility for High-Risk Seniors ${ }^{41}$, is provincially supported through the Ministry

$41 \quad$ Ministry of Health and Long-Term Care, Assisted Living Services http://www.health.gov.on.ca/en/public/programs/ ltc/13 housing.aspx of Health and Long-Term Care and run by Ontario's Local Health Integration Networks. It is specifically for high risk seniors who need daily care for things such as personal support, homemaking, reassurance services, care coordination and security checks. This program focuses on the health and well-being of the senior but allows the senior to maintain residency in their current home. It does not focus on the socialization of the senior in the community.

There is an alternative for low income seniors who do not want to or cannot physically maintain residency in their current homes. The Senior Affordable Housing program ${ }^{42}$ is offered to seniors as a rent-geared-to-income apartment normally rated at $30 \%$ of the $42 \quad$ Ministry of Health and Long-Term Care, Assisted Living Services http://www.health.gov.on.ca/en/public/programs/ ltc/13_housing.aspx

A Multigenerational Home 16 
senior's monthly income. Typically, there is a waiting list for accommodation. This option does not provide any elements of assisted care but promotes a sense of senior community. If assisted care was needed, the senior would be responsible for seeking out home treatment.

Alternatively, some seniors are taking issues of care into their own hands with a shared house $^{43}$. As a collective, multiple seniors live within one home and offer each other services of care and attention. Typically older members receive care from younger members. As the younger members age, they receive the care from newer members. Usually these homes are divided by gender in order to offer residents complete comfort, although both genders participate in this housing arrangement. Typically each resident pays rent to cover equal costs of the house. A potential issue may arise since one senior may have to take on the actual ownership and mortgage of the building which may not be possible for a low income senior.

This type of shared care is also found in adult lifestyle communities ${ }^{44}$. These communities are typically found within suburban neighbourhoods and include multiple homes within a relatively close distance marketed towards older adults. These homes, due to the projected clientele, deal with issues of mobility and social access and include single storey homes and community shared spaces. Unfortunately, these homes may not be financially feasible for low income seniors

$44 \quad$ Lahey 1998

A Multigenerational Home 17 
depending on the location and market price.

One option for low income seniors to find the care that would be provided from a retirement

home without the associated expenses would be to move into a multigenerational household. 


\section{Multigenerational Care}

Multigeneration includes more than one person from more than one generation. The relationship to one another is normally familiar, but it does not necessarily have to be in order to be considered multigenerational. The three typical situations of a multigenerational makeup are: parents to children, grandparents to grandchildren and children to parents to grandparents ${ }^{45}$.

A crucial feature of multigenerational care is understanding the terms of care. Between family members, care may be assumed to be provided for as long as the senior needs assistance. But often as the senior ages, this care may extend beyond the capabilities or interest of the caregiver. There needs to be a system of protection for both the senior and the caregiver to ensure that the multigenerational care is acceptable for both parties.

In order to facilitate this relationship, some seniors and caregivers are creating legal contracts which outline the expectation of care and possible compensation. As explained by Rachel Emma Silverman

"A small but growing number of families are setting up caregiver contracts, in which adult children or other relatives are hired, for modest salaries, to take care of elderly or disabled family members...They can also minimize battles between siblings 
and other family members. For many other families, the contracts simply help reward the significant amounts of time, effort and money that family members often spend watching over and taking care of an elderly relative" ${ }^{\prime 46}$

The contract's intent is to protect both parties from both mismanagement of care and from possible family disagreements over compensation.

Multigenerational care intends to allow a group of people, whether it is a family or not, to live with one another and provide care between all members. This care ensures that the living situation is beneficial to all members and that a shared lifestyle provides the necessary care that an independent lifestyle may lack.

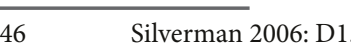




\section{Precedents Analysis}

Figure 1. Torre Julia front elevation.

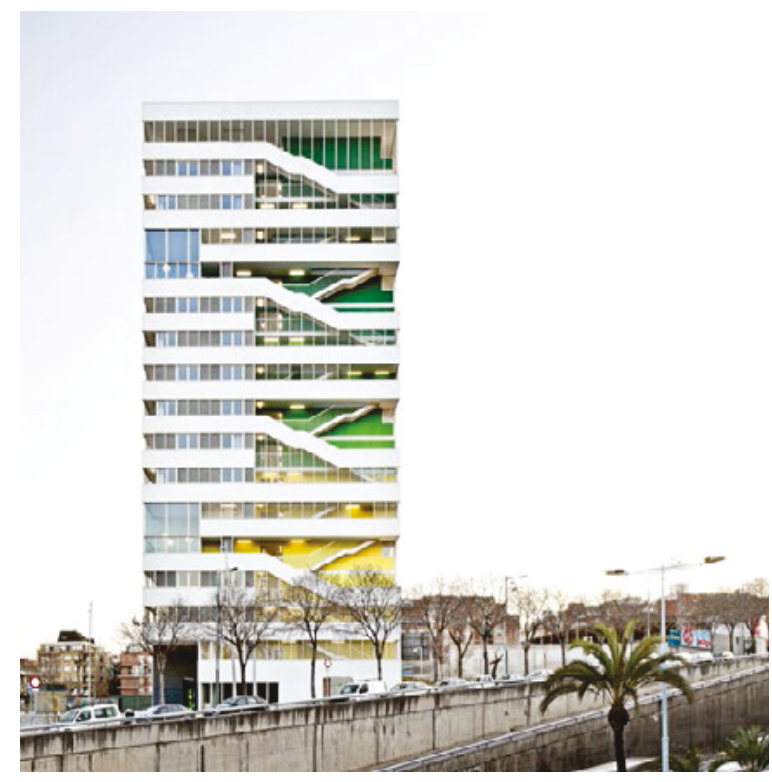

Figure 2. Torre Julia front entrance.

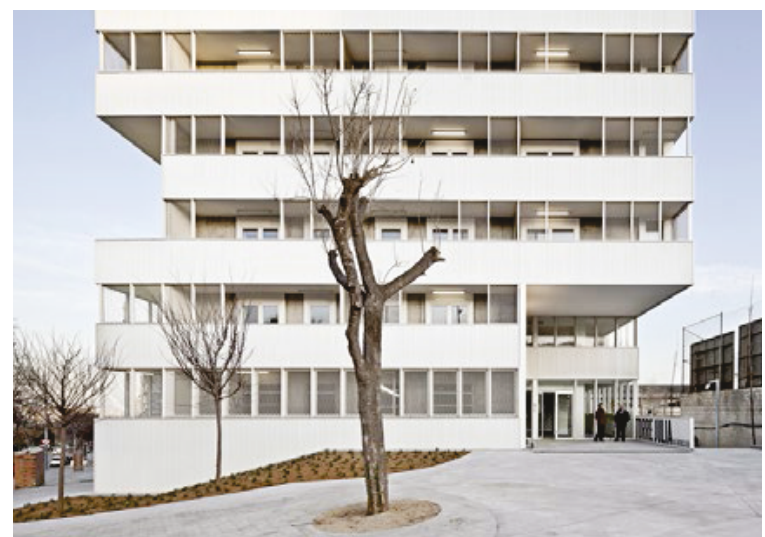

\section{Retirement Communities}

Retirement homes offer residential accommodation for seniors with the option for minimum to moderate care and programmed activities. Typically, additional spaces such as dining rooms and common living rooms allow for residents to interact outside of individual units. These homes are privately run and therefore require all residents to have adequate finances to maintain residency.

The retirement home Torre Julia ${ }^{47}$ by Pau Vidal, Sergi Pons and Ricard Galiana (figures 1 and 2), completed in 2011, is a high rise housing complex in Barcelona, Spain. In

$47 \quad$ Julia Tower http://www.archdaily.com/283113/ A Multigenerational Home 
Figure 3. Armstrong Place Senior Housing facade.

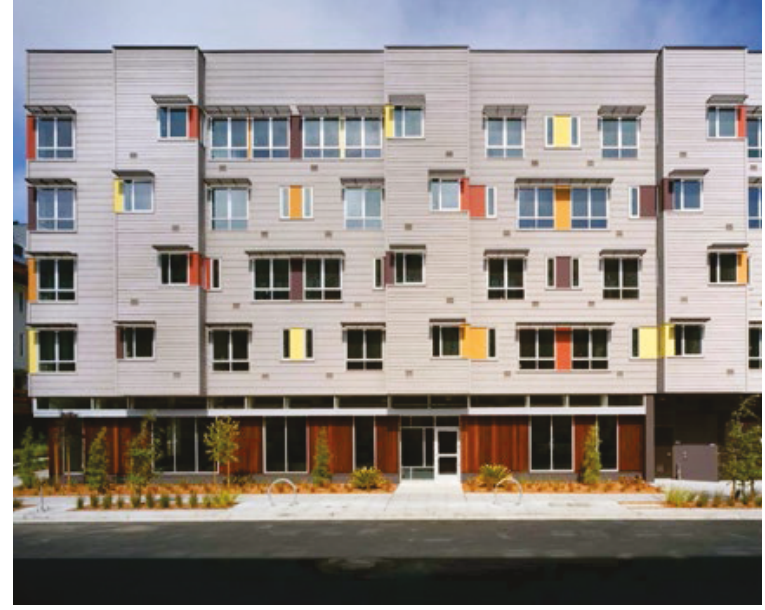

Figure 4. Armstrong Place Senior Housing courtyard.

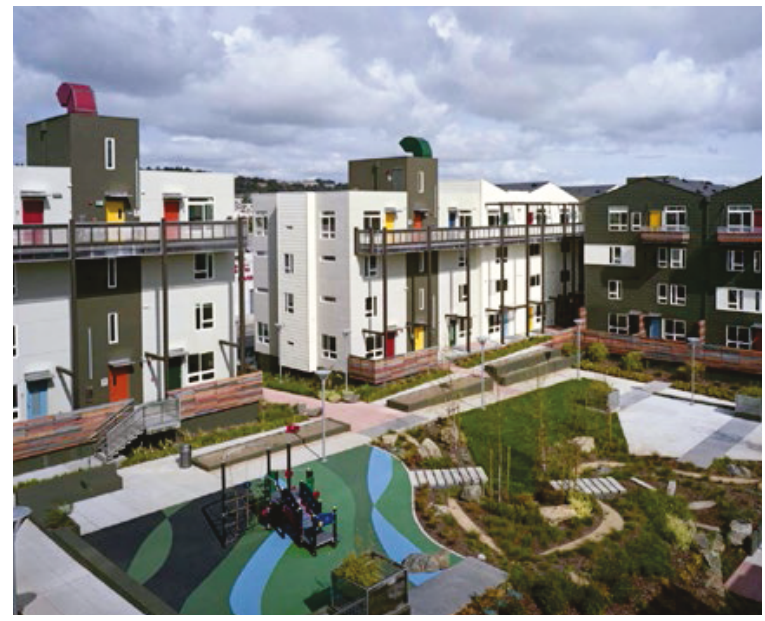

order to connect its residents together, the home uses the main circulation stair to join interior courtyards. These courtyards then become places of interaction for the residents. Although thislevel of connectivity is important, the reliance on a stair is not practical for aging residents. The challenge then becomes how to connect people between floors who may not have strong mobility skills. An element that can be used from Torre Julia for the proposed multigenerational home is the concept of vertical shared space. By providing spaces for interaction on multiple levels, it gives residents the chance to completely engage in the surrounding space.

Armstrong Place Senior Housing ${ }^{48}$ by David Baker and Partners (figures 3 and 4), $48 \quad$ Armstrong Place Senior Housing http://www.archdaily. com/153359/armstrong-place-senior-housing-david-bakerpartners/ 
completed in 2011, is a housing community in San Fransisco, California, that provides houses for all ages. The main idea is to allow residents of this community to age in place: as needs change, people can move into more accessible homes with additional care. This community is focused around an internal courtyard which encourages all residents to interact with one another. Ideally, residents could move from one home to another which prevents a large disruption to their sense of community and belonging. Unfortunately, Armstrong Place distinguishes buildings based on age groups and family sizes and therefore misses out on truly integrating people of different ages and families. A mix within one building would provide for a more integrated life. An element that can be used from Armstrong Place Senior Housing for the proposed multigenerational home is the ability for residents to age in place. By offering units for all age groups, residents can maintain residency in the same building throughout their life, which reinforces a sense of belonging and community.

\section{Multigenerational Housing}

Multigenerational housing is the habitation of more than one generation in a single household. Typically, this is confined to one family lineage which includes grandparents, parents and children. Some cultures view multigenerational housing as an accepted norm while other cultures view it as an option for sickened family members. 
Figure 5. Kidosaki House floor plans.
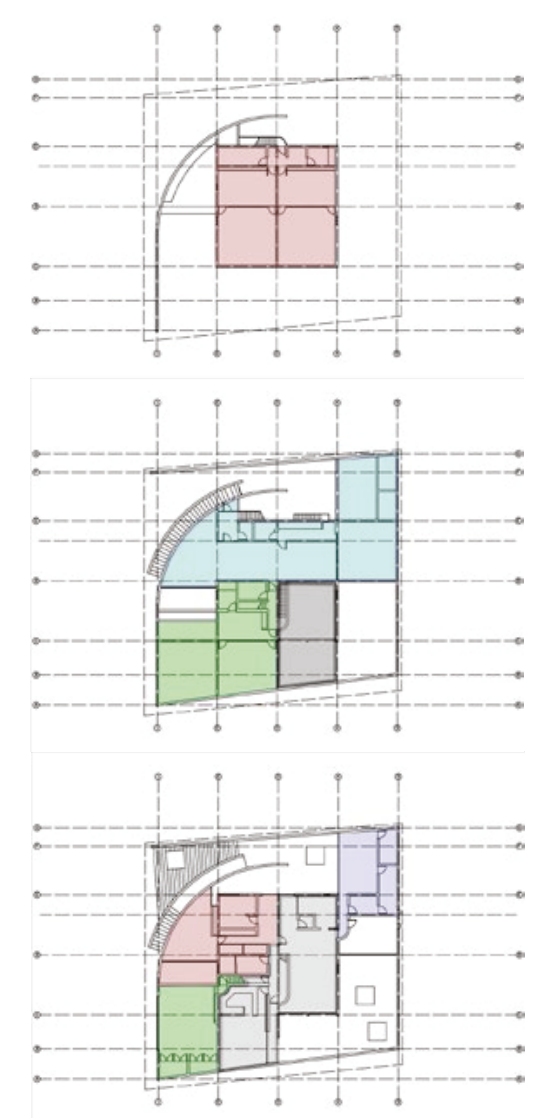

Figure 6. Kidosaki House entrance.

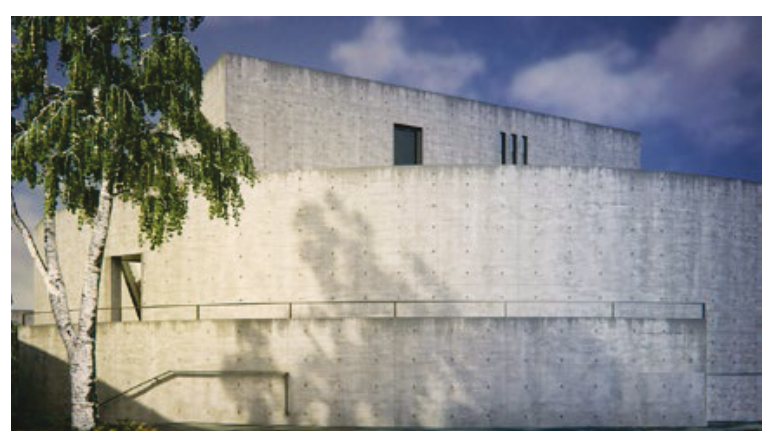

The Kidosaki House by Tadao Ando ${ }^{49}$ (figures 5 and 6), completed in 1986 in Tokyo, Japan, combines private and communal spaces for an extended family. Designed for a married couple and their two sets of parents, the home divides the three separate houses between three floors. The extension of a privacy wall around the home creates a sense of community for the three families. This precedent demonstrates the concept of multigenerational living within a confined space. The level of independence is quite high for all three couples. Looking into the future, this may cause some issues of accessibility if any of the parents need additional care. Perhaps the presence of their spouses mitigates this concern. However, this house keeps the families completely separate

$49 \quad$ Andao 1996: 234.

A Multigenerational Home 
Figure 7. Miss Sargfabrik facade.

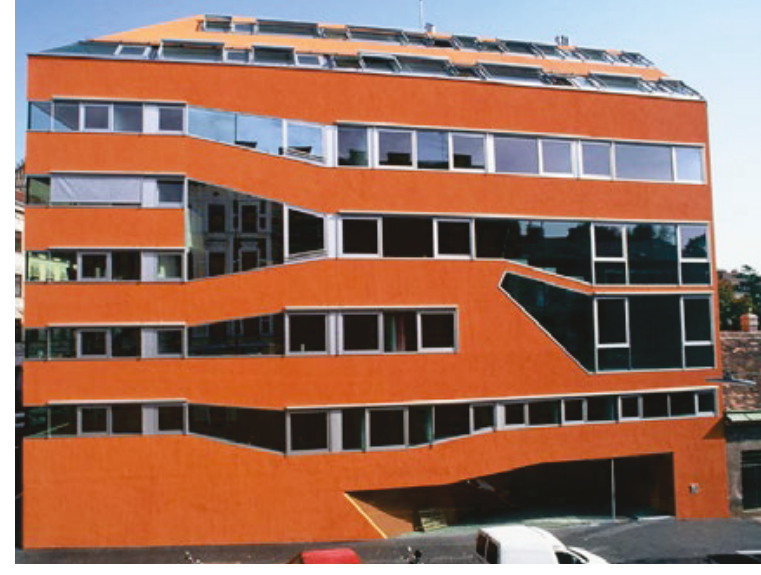

Figure 8. Miss Sargfabrik exterior living space.

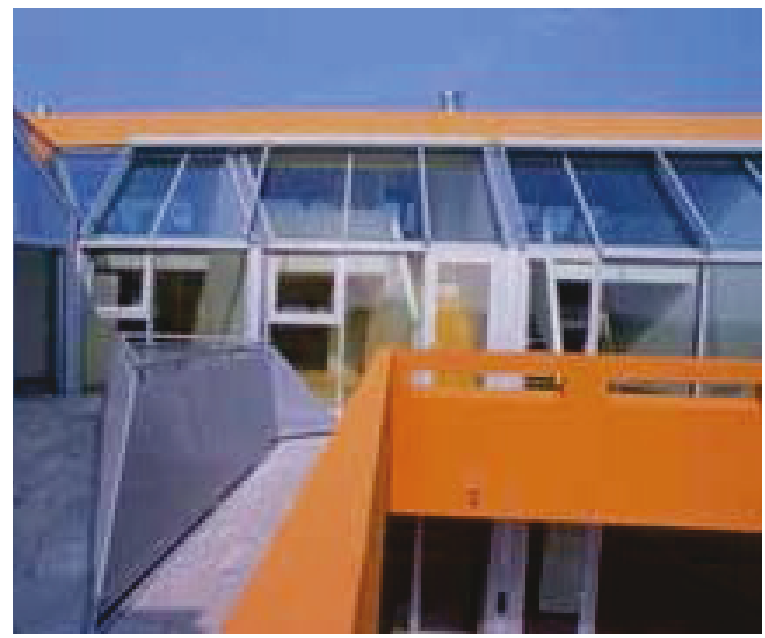

without any internal connection or shared space which essentially directs the families to live near but not together. An element that can be used from the Kidosaki House for the proposed multigenerational home is the ability to house many families within a small footprint without compromising their privacy.

Miss Sargfabrik ${ }^{50}$ by BKK-3 (figures 7 and 8), completed in 2000, is a single building composed of 39 apartments with individual layouts in Vienna, Austria. These apartments vary from one storey to two and are joined through an exterior balcony. The most striking feature of this building is the orange façade which is an attempt to make a statement in the neighbourhood, giving residents a unique

$50 \quad$ BKK-3 http://www.bkk-3.com/BUILDINGS/MISS LIVING/miss-living.html. 
place to live $e^{51}$. Unfortunately, the unique shaping of each unit may cause issues with mobility for residents who need clearance for wheelchairs. Especially since each unit has a unique shape, easy movement could be sacrificed in the building. An element that can be used from Miss Sargfabrik for the proposed multigenerational home is the striking façade finish of the building as compared to the local architecture. A unique façade allows for the building to be read as something that is unique in both its form and program which would engage both residents and the greater community.

\section{Multigenerational Communities}

Multigenerational communities include housing units of varying sizes that offer accommodation to families, seniors and/or a combination of both. Therefore the building itself houses people of many generations while individual units may have multiple generations within them as well.

The Steinacker Residential Complex ${ }^{52}$ by Hasler Schlatter Partner (figures 9 and 10), completed in 2004, is a project of five low rise apartments designed for varying family structures in Zurich, Switzerland. The units themselves have the ability to be expanded into adjacent spaces to provide needed space for families. The project also focuses on the outdoor space around the buildings ensuring that pathways connect each building, and play

$52 \quad$ Hasler Schlatter Partner http://www.hsp-architekten.ch/ hsp_referenzen.php?read_article $=11$. 
Figure 9. Steinacker Residential Complex

facade.

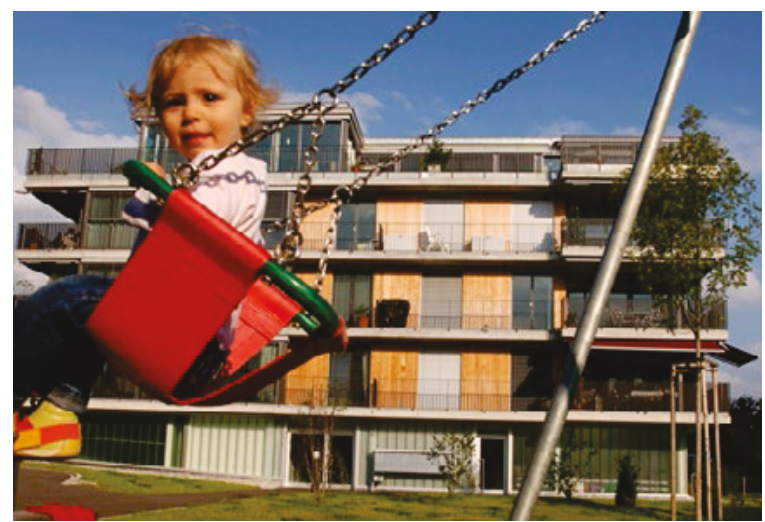

Figure 10. Steinacker Residential Complex courtyard.

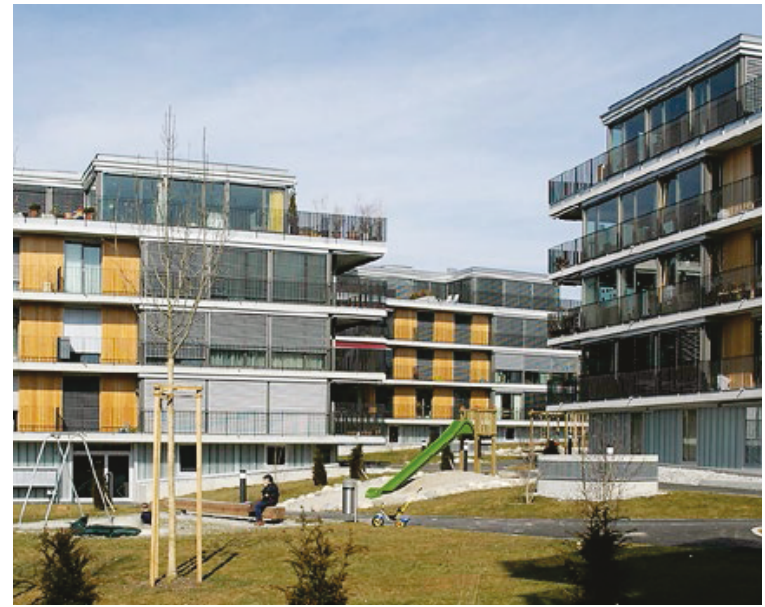

space is provided for children ${ }^{53}$. Regrettably the design of five separate buildings creates a disconnect between residents of each building which may further isolate residents from one another. An element that can be used from the Steinacker Residential Complex for the proposed multigenerational home is the integrated green space through the complex.

By ensuring that there is a continuing narrative of exterior space, residents extend individual units into the greater community through green space.

The Social Housing Complex - Wiesbaden ${ }^{54}$ by Dietz Joppien Architekten AG (figures 11 and 12), completed in 2001, is a complex of

$53 \quad$ Sustainable. Inter-Generational. Living http:// sieplcoatesstudio.weebly.com/steinacker-residential-complex.html. 54 Dietz Joppien Architekten AG http://www. dietz-joppien.de/projects/projekt-datenspeicher/residentaldistrict-sauerland $/ 1$.html? $\mathrm{L}=1$ \&no_cache $=1$ \&sword list $\% 5 \mathrm{~B} 0 \% 5 \mathrm{D}=\mathrm{Gemeinn} \% \mathrm{C} 3 \% \mathrm{BCtzige}$. 
Figure 11. Social Housing Complex Wiesbaden exterior living space.

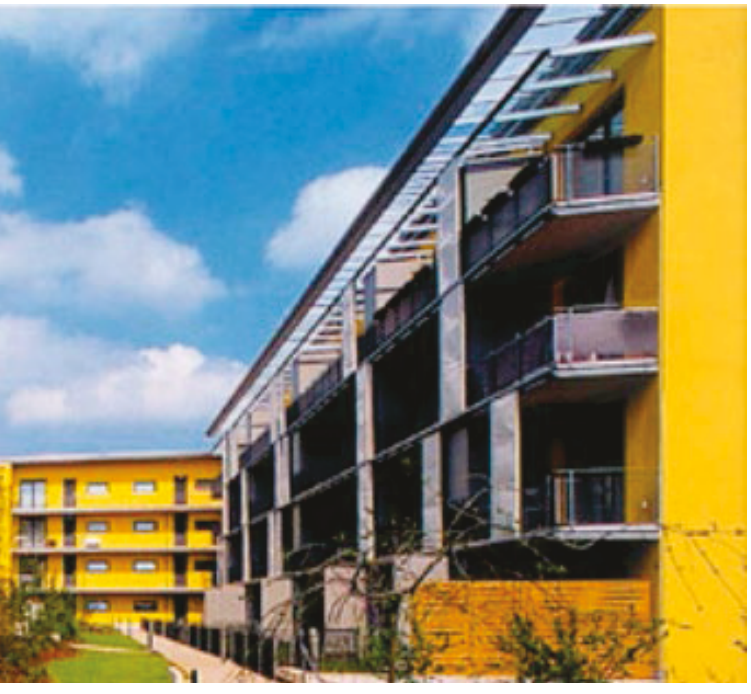

Figure 12. Social Housing Complex Wiesbaden facade.

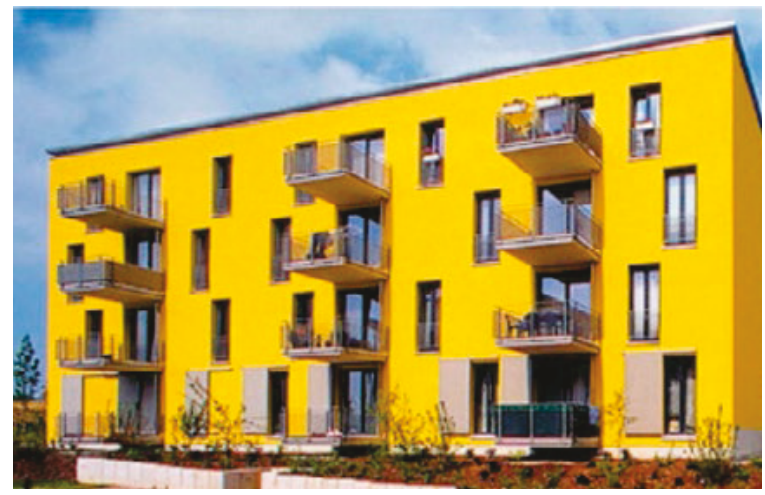

two low rise apartment buildings composed of different types of units in Wiesbaden, Germany. These units vary in size to attract people from different age groups in order to have a mixed population within the building. Due to its location in a dense residential neighbourhood, the connection to the adjacent green space was emphasized through balconies and walking paths ${ }^{55}$.

Much like that of the Steinacker Residential Complex, the Social Housing Complex Wiesbaden separates residents between two facing buildings which may cause a loss of immediate physical connection between residents. This is especially worrisome for senior residents with mobility issues. An element that can be used from the Social

$55 \quad$ Sustainable. Inter-Generational. Living http:// sieplcoatesstudio.weebly.com/housing-development.htm 
Figure 13. Courier Place front elevation.

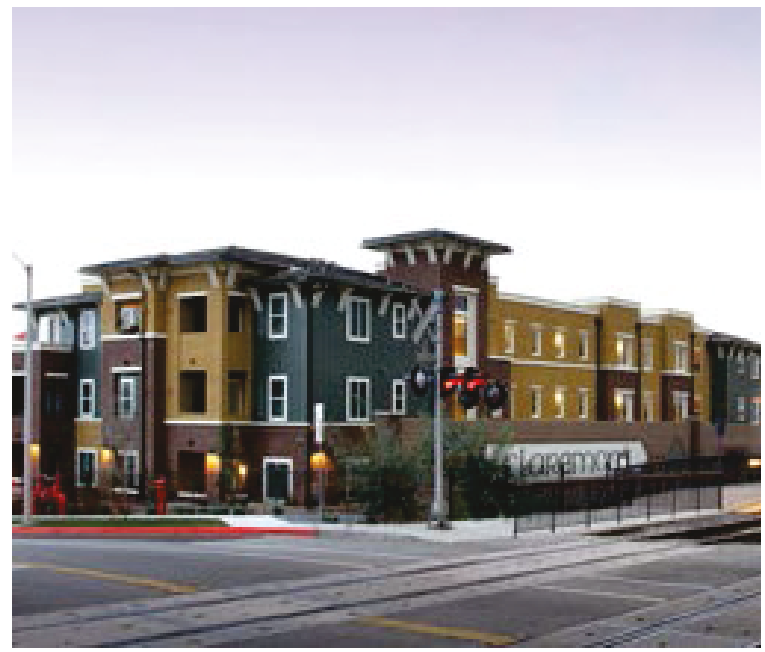

Figure 14. Courier Place site plan.

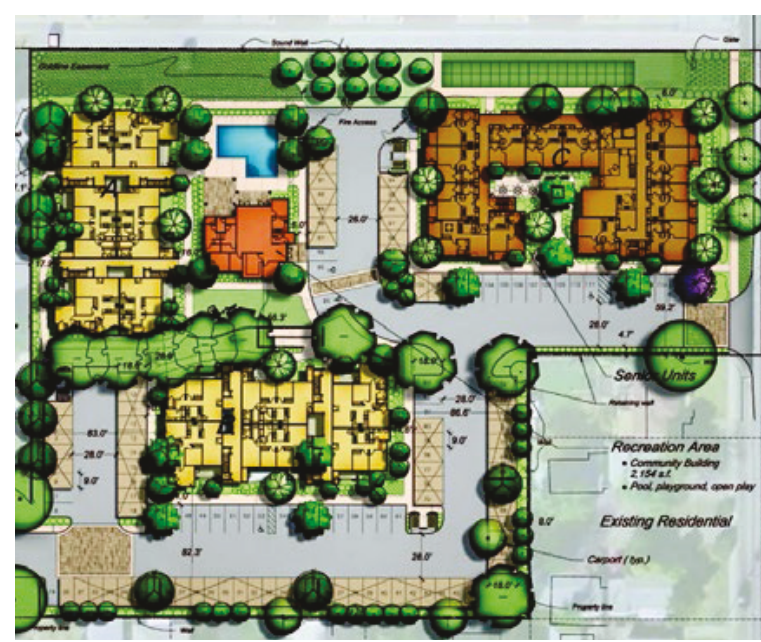

Housing Complex - Wiesbaden for the proposed multigenerational home is the use of balconies on individual units to connect to the greater green space. The provision of individual exterior space allows for residents of all mobility the option to experience both interior and exterior space.

Courier Placeisa multigenerational apartment community (figures 13 and 14), completed in 2012, in Claremont, California ${ }^{56}$. It contains three apartment buildings on a site: two dedicated to two and three bedroom, for rent, apartments marketed towards families; and one building with single bedrooms, for lease, marketed towards seniors. There are 38 single bedroom apartments for seniors and 36

56 Jamboree Courier Place http://www. jamboreehousing.com/index.php?option $=$ com content\&view $=$ category\&layout $=$ blog\&id $=16 \&$ Itemid $=\&$ properties $=$ detail \&property $\_$id $=62$ 
apartments for families. The units surround an internal courtyard that includes green space and a pool. Amenities, walkability and affordability were three main focuses of the project. Ensuring that the residents of the three buildings had space to run activities within the site was crucial to creating a sense of community amongst residents. The ability to easily leave site by foot was also crucial for seniors who may face mobility issues and for families with small children. Finally, although multigenerational housing is becoming more prevalent in design it often comes at a high cost. This project aimed its units to families who earn between $30-50 \%{ }^{57}$ of the area median income. Although this precedent claims to be multigenerational, the examination of individual units clearly shows that families $57 \quad$ PR Web Jamboree Housing Corporation http://www. prweb.com/releases/JamboreeHousing/CourierPlaceClaremont/ prweb9271411.htm and seniors live independently. The concept of multigenerations is only introduced through community shared spaces. An element that can be used from Courier Place for the proposed multigenerational home is the shared space between the different residents of the complex. Ensuring that this shared space provides opportunities for socialization, exercise and child play is crucial for a multigenerational home. 


\section{Design of a Multigenerational}

\section{Home in Ottawa, Ontario}

The design of a multigenerational home for families and seniors begins with the design of the unit. Next, the design of additional spaces within the building should reflect the need for social and support spaces. Since this building is rooted in its own typology, siting becomes a secondary study. Through the understanding of the site, a greater connection to the neighbourhood and community is possible.

\section{Process - Multigenerational Unit}

A multigenerational house brings together two independent groups, the family and the senior, and creates a shared housing situation (figure 15). Each generation requires separate spaces such as bedrooms and bathrooms. As explained by Susan Newman, a writer on multigenerational families, "Bedroom privacy, once defined, draws a crucial boundary line for the living arrangement"58. Although these generations have chosen to live with one another, privacy is necessary in the bedroom. The area in which privacy can begin to be altered is within the living space: the kitchen, dining room and living room. Sharon and John Niederhaus state that:

"There are many helpful ways to live together and apart at the same time. By far, the two most important considerations are a separate entrance and kitchen. It may be a cliché, but the

$58 \quad$ Newman 2010: 25. 
kitchen really is the heart of the home and is traditionally run by the female head of the household...two women trying to manage one kitchen can present serious problems" $"$.

Therefore bedrooms must be provided as private spaces, the kitchen must be designed to provide separate spaces for each generation, and main entrances must give all generations a sense of independence.

The unit must provide for three different types of spaces: private, semi private and public (figure 16). Much like the greater building, there needs to be areas that provide a sense of place, transition and privacy. While containing two front doors, the entry

$59 \quad$ Niederhaus 2007: 77. 
represents the public space of the unit. The language of the front door identifies the difference between the family and the senior. By designing the front door for families to be parallel to the hall and the door for seniors to be perpendicular, the architecture allows for residents and visitors to have a greater sense of place with each unit. By withholding views into the rest of the unit, the entry is a buffer area restricting movement into the semi private space only to those who are invited in. The living room, dining room and

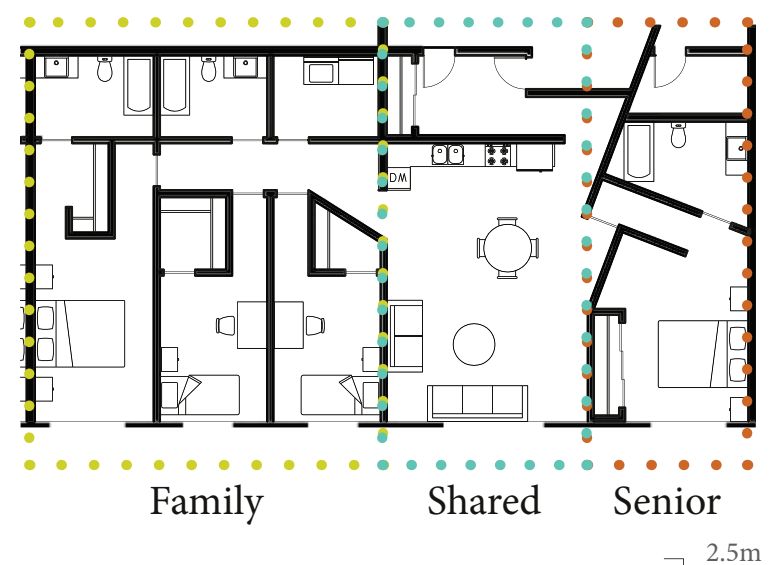

kitchen - located off of the entry - represent the semi private area of the unit. This area is the main location for interaction between family members. Similarly, the view to the private sections of the unit, the bedrooms, is withheld from the space. The bedrooms are located off of the semi private area which 


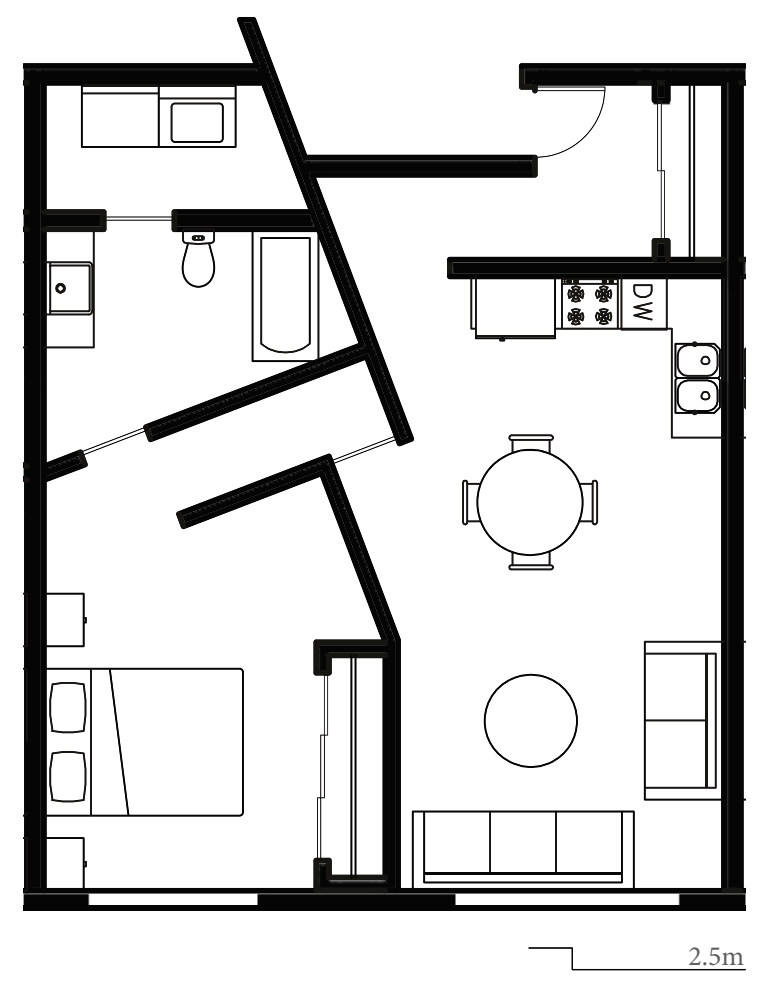

provides for a high level of privacy. The bedrooms and bathrooms for the family feed from one hallway with an adjoining laundry area. The senior bedroom and bathroom are on the opposite side of the semi private space with its own hallway. The physical separation of the two hallways insures that both the family and the senior have an increased level of privacy in their own bedrooms. Both the senior and the family share a locker which is accessible from the hall. It can be used to store things like outdoor equipment.

\section{Process - Senior Unit}

The senior unit (figure 17) is a one bedroom unit with a private bedroom, bathroom, and laundry room. The three levels of spaces are still present within the space, with views 
being withheld between the private, semi private and public spaces. The front door of the senior unit is perpendicular to the hall which continues the language developed by the multigenerational unit.

\section{Process - Family Unit}

The family units (figure 18) vary between two and three bedroom units with one to two bathrooms respectively. The entry way is a public area of the unit; the living room,

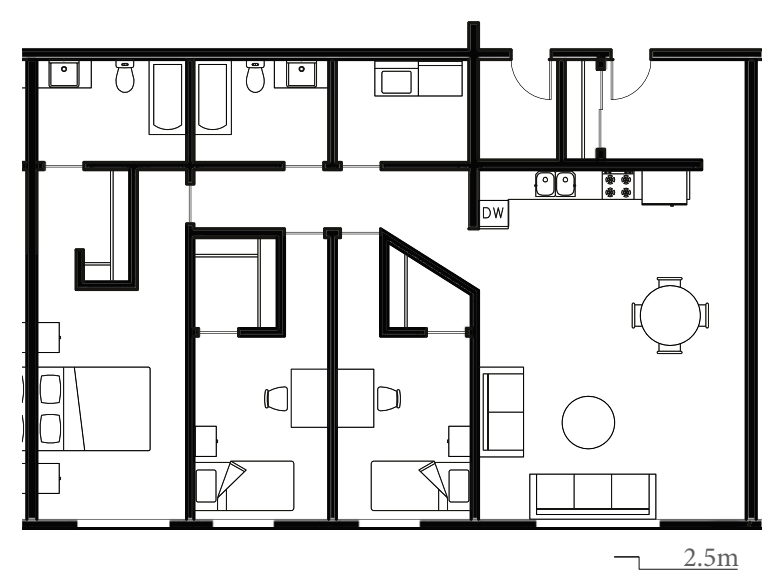

dining room and the kitchen form a semi private space; and the bedrooms, designed off of a hallway, are private. The front door of the family unit is parallel to the hall, a continuation of the established language. While a locker with access from the hallway offers space for things like outdoor equipment. 


\section{Building in Plan}

Within the residential floors (figure 19), the movement of residents through the hallways mimics that of the movement in the front yards of traditional single family homes. Each unit maintains a separate façade from other units which provides both visual interest and an increase of privacy between units. The setback of the door for each unit also allows for privacy for each resident. A single loaded corridor ensures that all residential units

Figure 19. Building axonometric describing the internal programs of residential private, residential shared and community space.

Residential Private

Residential Shared

Community

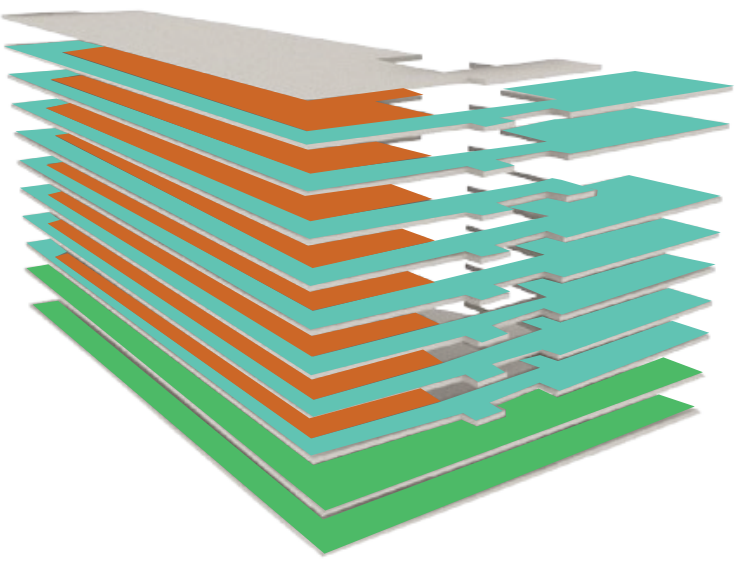

face west, towards the building's courtyard.

This allows for a greater visual connection to outdoor activities, such as watching children as they play. In addition, this corridor protects the smaller residential buildings to the east of the site from constant viewing. The windows in the corridors are placed opposite 
of the front doors of each unit. This allows for a greater visual indication of the location of doors along the hallway as a resident walks through the hall.

\section{Building in Section}

The building itself must facilitate an appreciation for the workings of a multigenerational household within both the units and within the building as a whole. The building integrates three types of units within the space: a multigenerational unit, a senior unit, and a family unit. By providing three types of units there is a reinforcement of the mutual relationships between the generations. A senior who does not have a family to care for them can choose to live in the building with the understanding that the families who do not have a senior in their units can offer that care. In return, seniors can provide assistance to the families (figures 20 and 21). This care can be achieved within the family and senior units or within other spaces in the building. This mutual relationship will be defined and regulated through the New Horizons for Seniors Program as explained later in the legal section. The multigenerational relationship then extends beyond the traditional familiar bond and approaches the bond between the building's residents. By offering these three types of units within one building, it allows each generation to expand their own social network and feel more comfortable within the space.

The ground floor of the building holds public programs in order to engage with the greater 
Figure 20. Diagram showing the relationship between family units, multigenerational units and senior units in the building.

Figure 21. Diagram axonometric depicting the relationship between residential units.
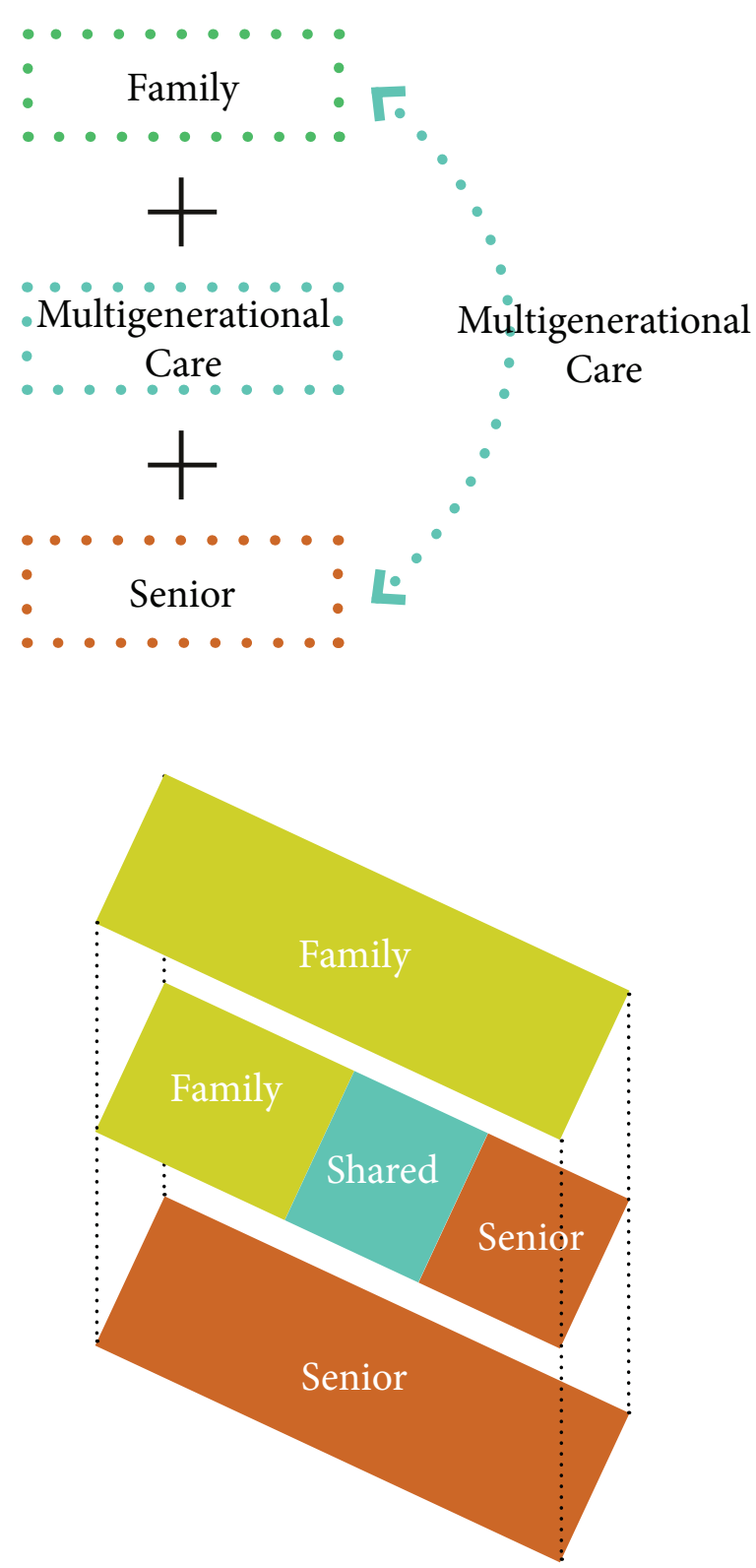

community. The next eight floors are private residential floors. The second and third storey are senior residential units and shared spaces. The fourth to sixth floor are multigenerational units and shared spaces. Finally, the seventh to ninth floor are family units with shared spaces. In total, there are 33 units within the building: 12 senior, 9 multigenerational and 12 family. The ratio of generations is also crucial to the running of the building. In order to guarantee care for seniors and families there must be a dedicated relationship between a family and a senior. Therefore the building maintains a 1:1 ratio of seniors to families. The residential units are located along the east of the site with the main circulation and shared spaces along the north (figures 23 through 28).

The main circulation core bridges the gap 
between the shared spaces and the residential spaces on each floor, becoming a buffer zone. The circulation in this area provides all residents the ability to freely move between shared spaces without interrupting the more private areas of the residential units.

\section{Shared Spaces and the Residents}

The building facilitates relationships not only between multigenerational families within one unit but between residents of all ages with one another. By providing shared spaces within the building, these relationships can begin to develop into greater connections and create a sense of community in the building. By offering a space for seniors to gather, that generation becomes more involved in the building and thus with other residents. In return, assigning children a specific shared space allows the younger generations to play and exercise without disrupting the older generations. It also ensures that the generations have specific spaces that can be used for personal activities that relate to different age groups. Locating the shared spaces on each floor ensures that there is a constant movement of residents between levels which increases communication and creates a sense of community.

Beginning on the first floor of the residential levels (the second floor of the building) is the library. This space offers building residents space to read quietly and interact with other residents who share similar literary interests. The following floor has a meeting room. This space is intended to be used as 


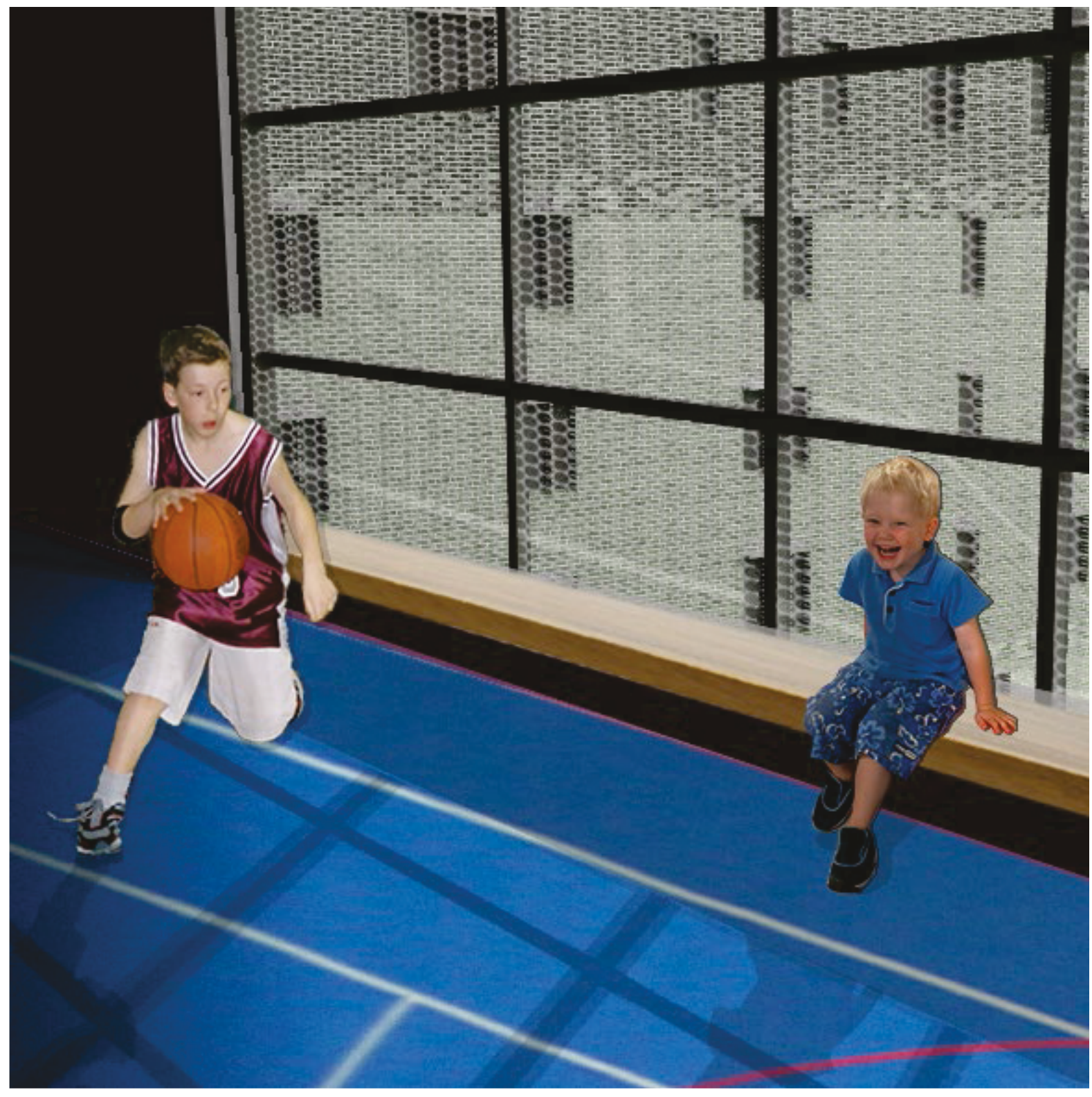


a social gathering area for all residents for activities such as building-wide meetings or shared meals. On the fourth floor is a large shared kitchen. Since an aspect of living in a multigenerational building is the guaranteed care of other residents, this kitchen provides space for families to cook for seniors or for seniors to cook for families. Therefore, although the care of providing food may be needed by different residents, the preparation of the food can be made in a shared space. It also gives families and seniors an option for a separate kitchen as suggested by Sharon and John Niederhaus. Located on the fifth floor is a day care. This day care is self-run by the residents of the building. Although children are being cared for in the space, both adults and seniors can provide the actual duty of care. Above the day care is a double height gym space (figure 22). This area allows children to play within the building. It is an active space and reflects the needs of children to be playful. On the eighth floor is the final interior shared space. Its designation as a kid's space provides an area for children to gather, socialize and interact. The ninth floor has an exterior shared space - a communal garden - which provides all residents with the opportunity for growing fresh vegetables within the building.

The locations of the shared spaces intends to meet the social expectations of the floor each space is located on. Therefore kid friendly spaces are found on the upper floors where kids live while spaces that promote adult socialization are located on the lower floors where seniors live. These shared spaces are 
Figure 23. Floors two through three which

include senior residential units and shared

spaces. The shared spaces include a library

on the second floor and a meeting room on

the third floor.

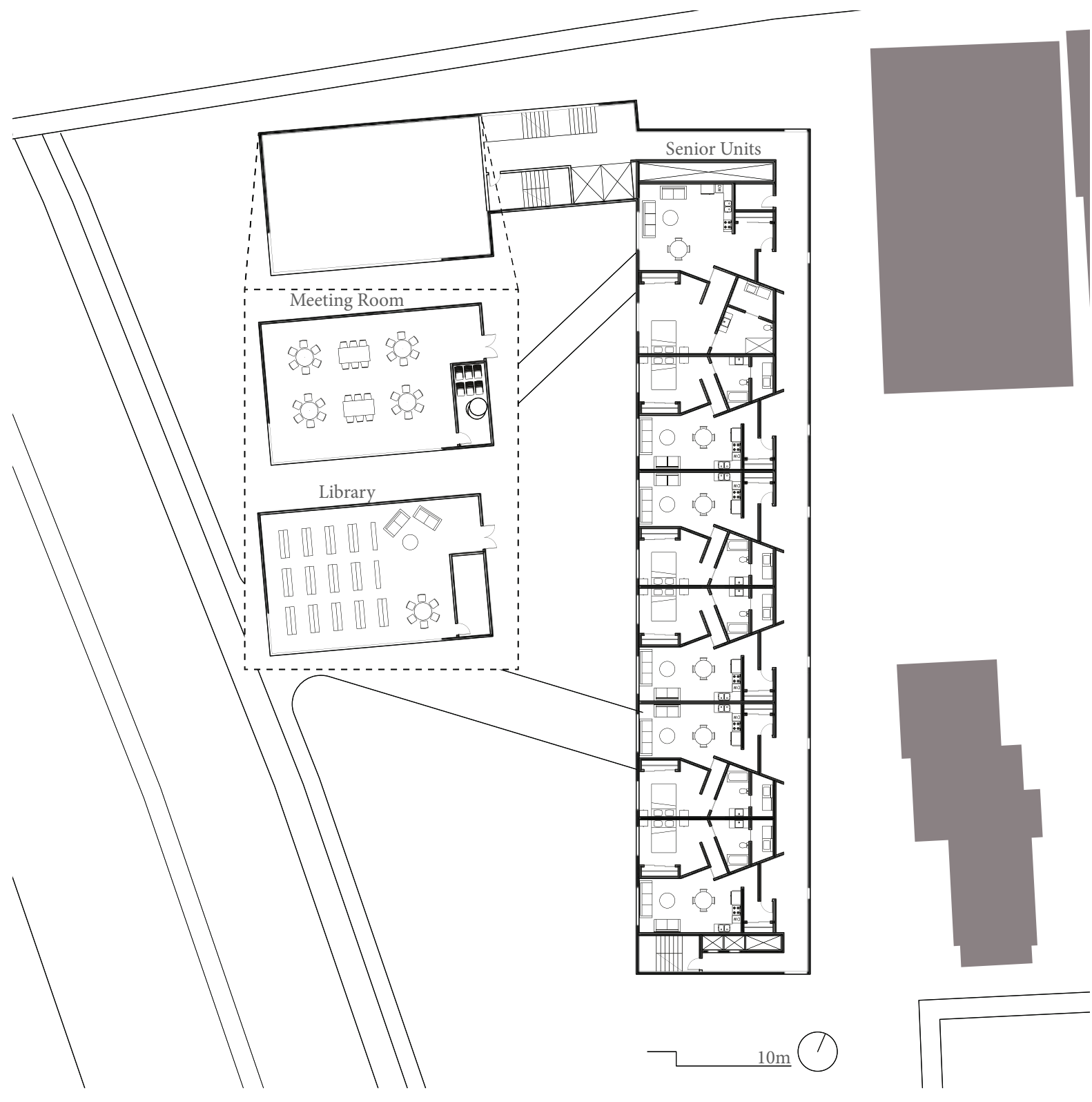


Figure 24. Diagram showing the unit bedroom breakdown on floor two through three.

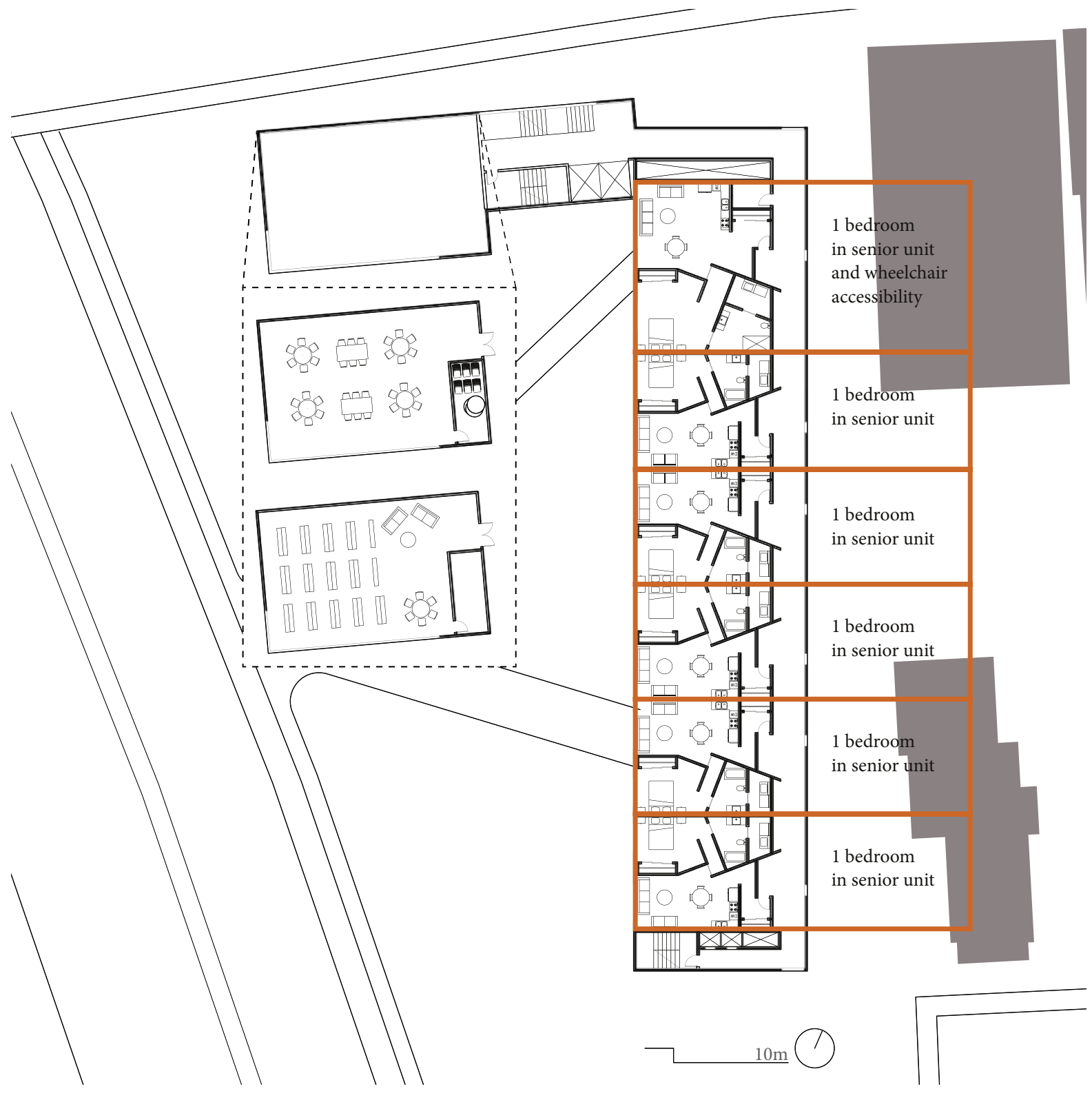


Figure 25. Floors four through six which

include multigenerational residential units and shared spaces. The shared spaces include

a shared kitchen on the fourth floor, a daycare on the fifth floor and a gymnasium room on the sixth floor.

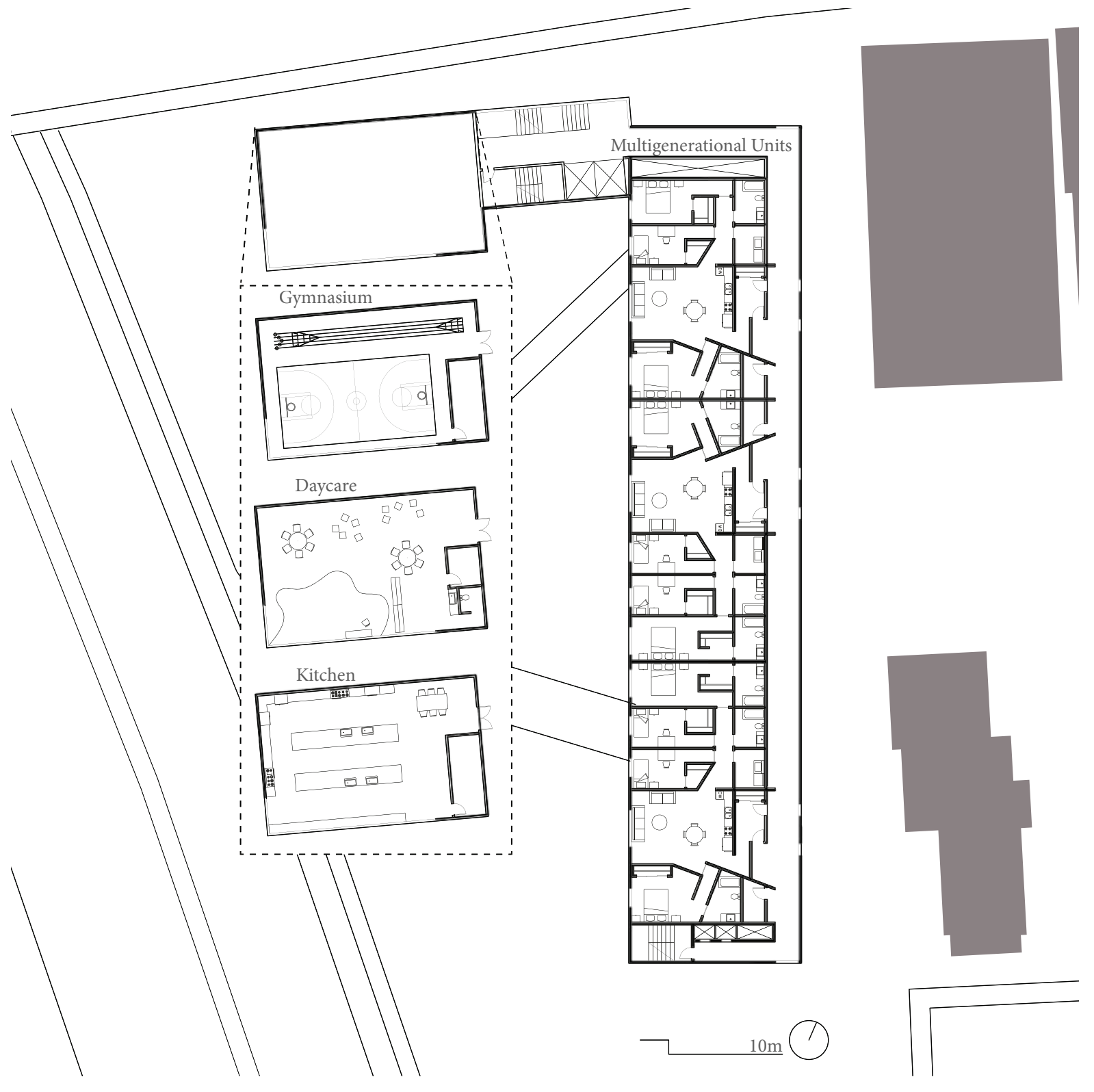


Figure 26. Diagram showing the unit bedroom breakdown on floor four through

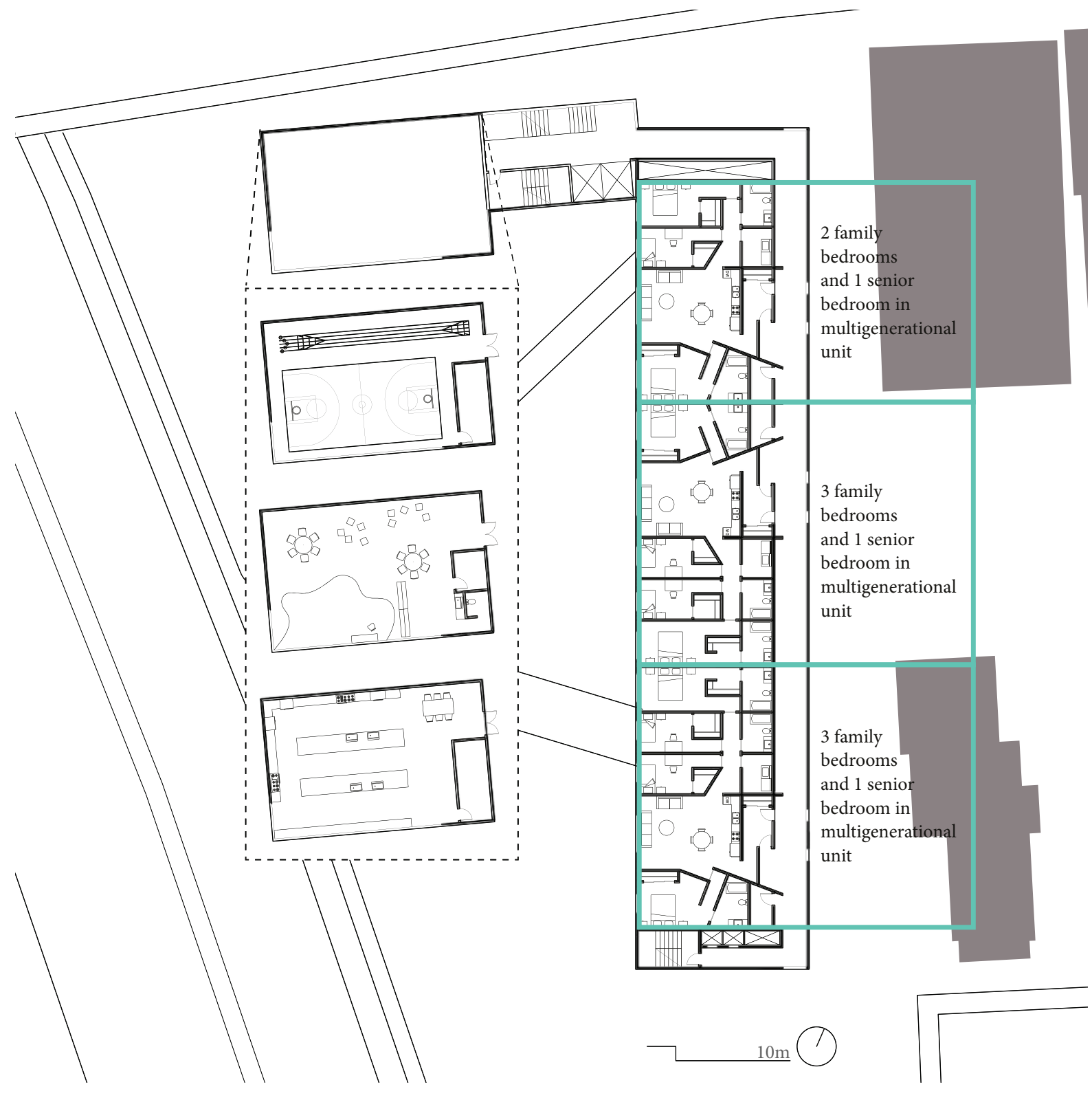


Figure 27. Floors seven through nine which

include family residential units and shared

spaces. The shared spaces include an open to

below space to the gym on floor seven, a kids

only area on floor eight and an exterior green

space on floor nine.

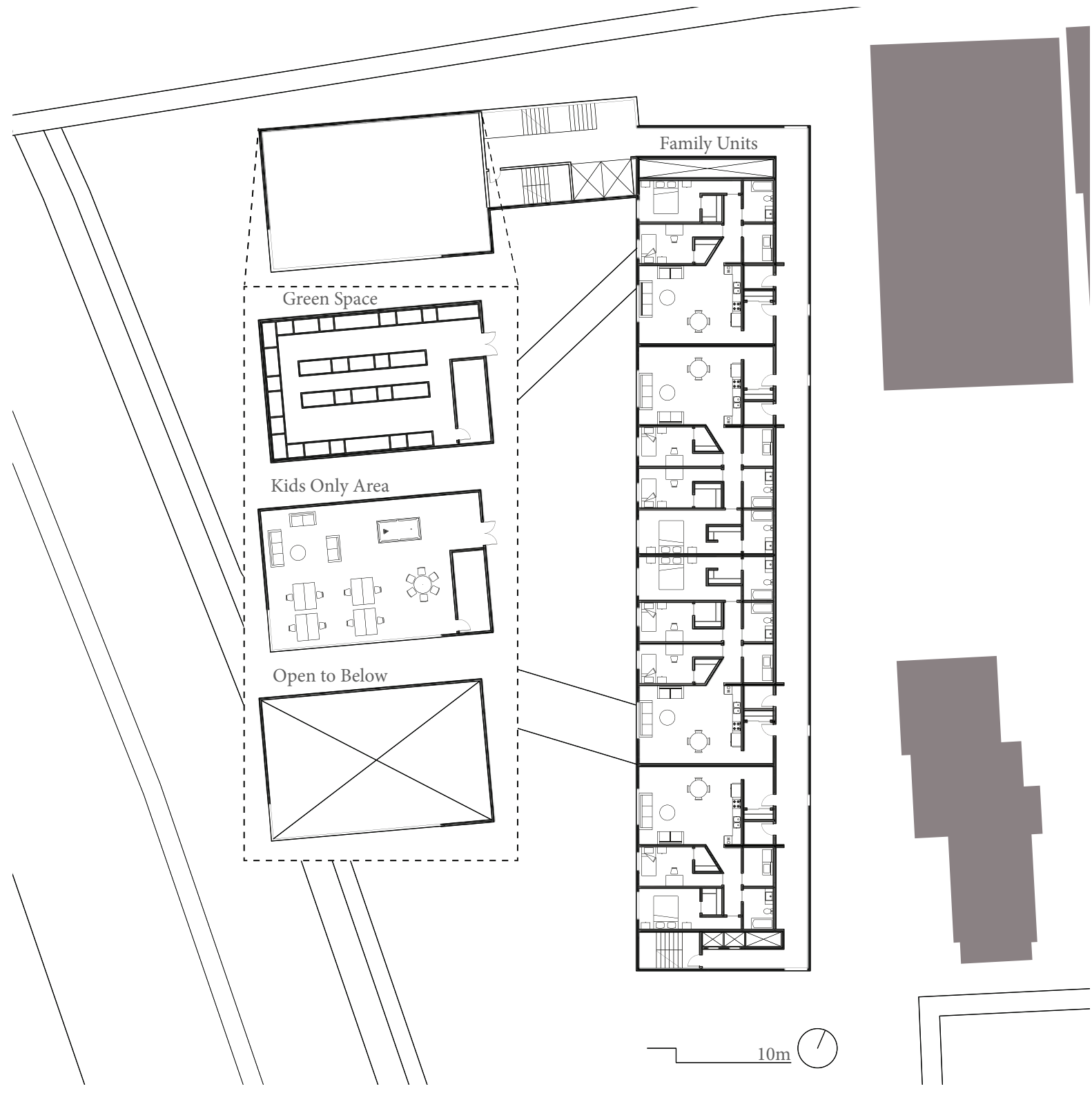

A Multigenerational Home 


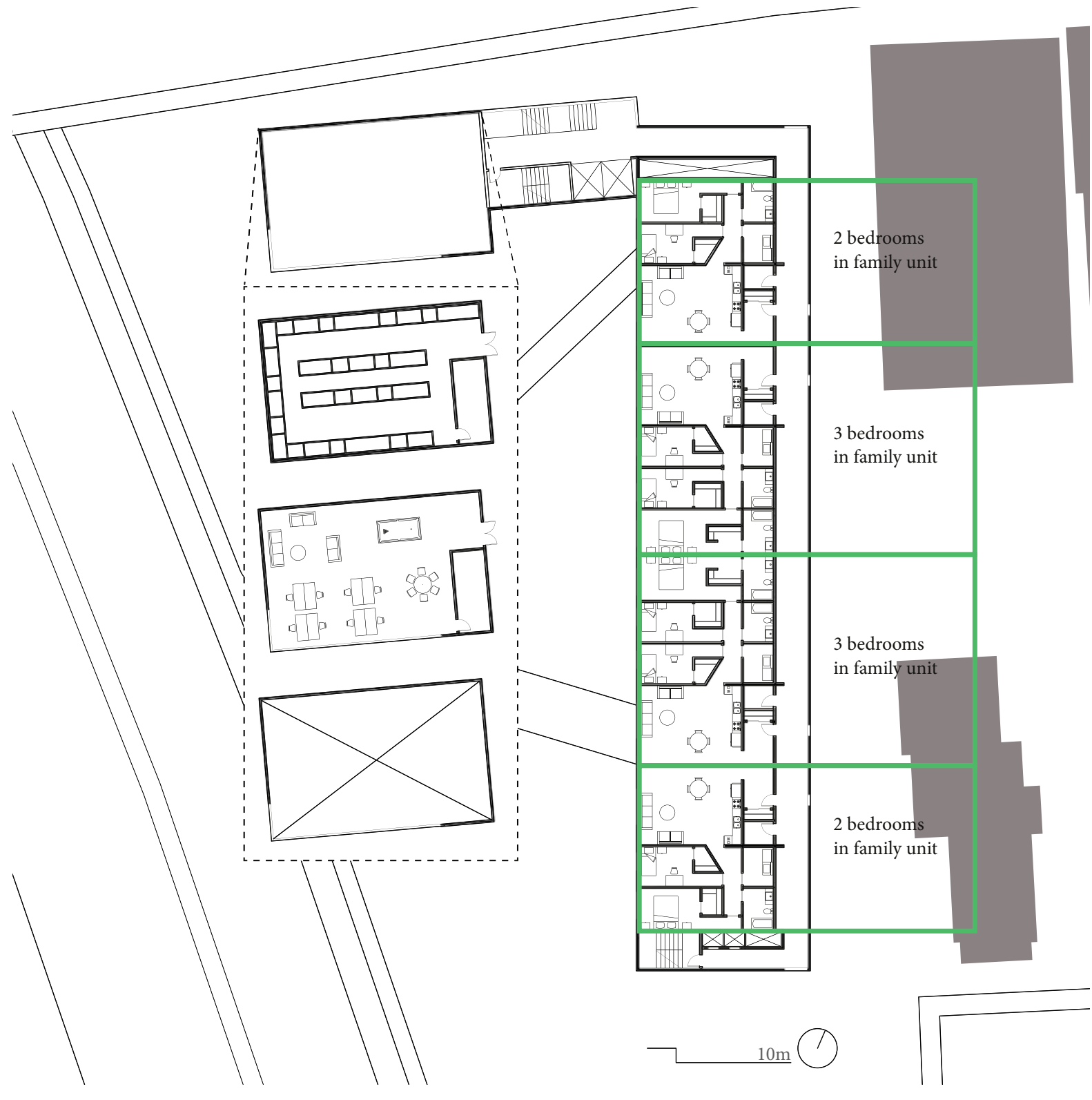


also located off of the residential area of the building. This location allows the residential space to maintain a level of noise that is acceptable for living.

\section{Site}

In order to facilitate a building that provides accommodation for all ages, the location of the building must be respectful to the needs of every generation. This includes access to schools, green space, hospitals and shops. Due to the varying scale of the physical abilities of the residents, close access to public transportation and walking routes is crucial.

The site, located in Little Italy to the south west of the intersection of Gladstone Avenue and Preston Street, offers all of these accommodations. It is adjacent to the Ottawa River Pathway, a pedestrian pathway that connects the neighbourhood to nearby communities, and is accessible by bus routes on both Gladstone Avenue and Preston Street. The site is also within a 10 minute drive from the Ottawa Hospital Civic Campus. In addition, the site is close to multiple schools ${ }^{60}$ for both children, adolescents and adults (figures 29, 30, 31 and 32).

The O-Train, a light rail transit system, runs perpendicular to Gladstone Avenue and parallel to the site to the west. Currently the City of Ottawa projects that a stop at Gladstone Avenue could be built after $2018^{61}$, 60 Devonshire Community Public School, St. Anthony School, Cambridge Street Community Public School, Adult High School, St. Mary Elementary School, Urban Aboriginal Alternate High School, École Élémentaire Catholique Saint-François-d'Assise, Connaught Public School, Richard Pfaff Secondary Alternate Program, Glashan Public School, Dominican University College 61 Transit Services. Feasibility Study of O-Train Extension to Leitrim and Riverside South. 
Figure 29. Site map of the greater Little Italy area showing the site, bus routes, education facilities and public green spaces. Please

note, the Ottawa Hospital - Civic Campus is located just south west of the map.
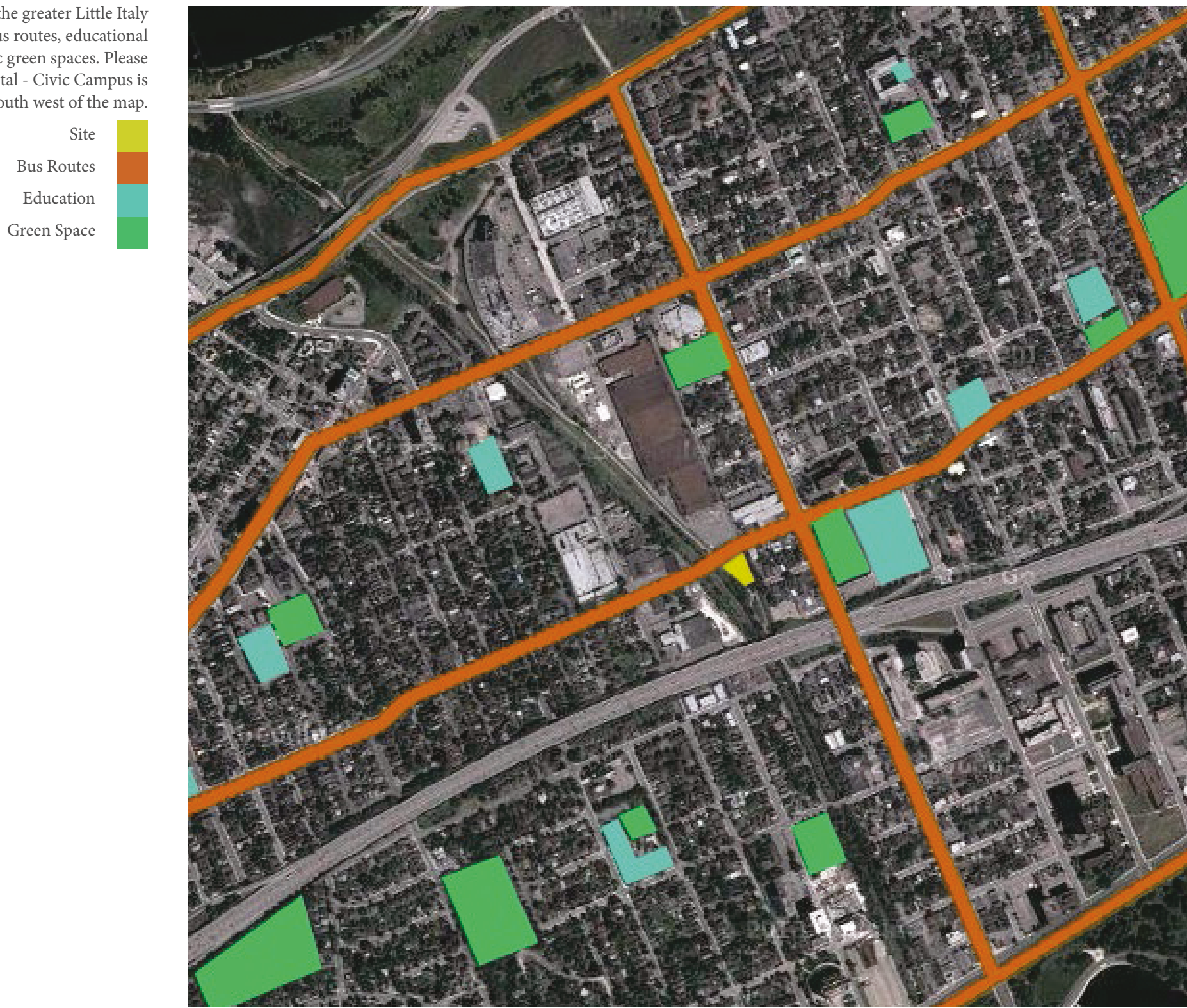
Figure 30. Current condition of the site as a City of Ottawa infrastructure testing area.

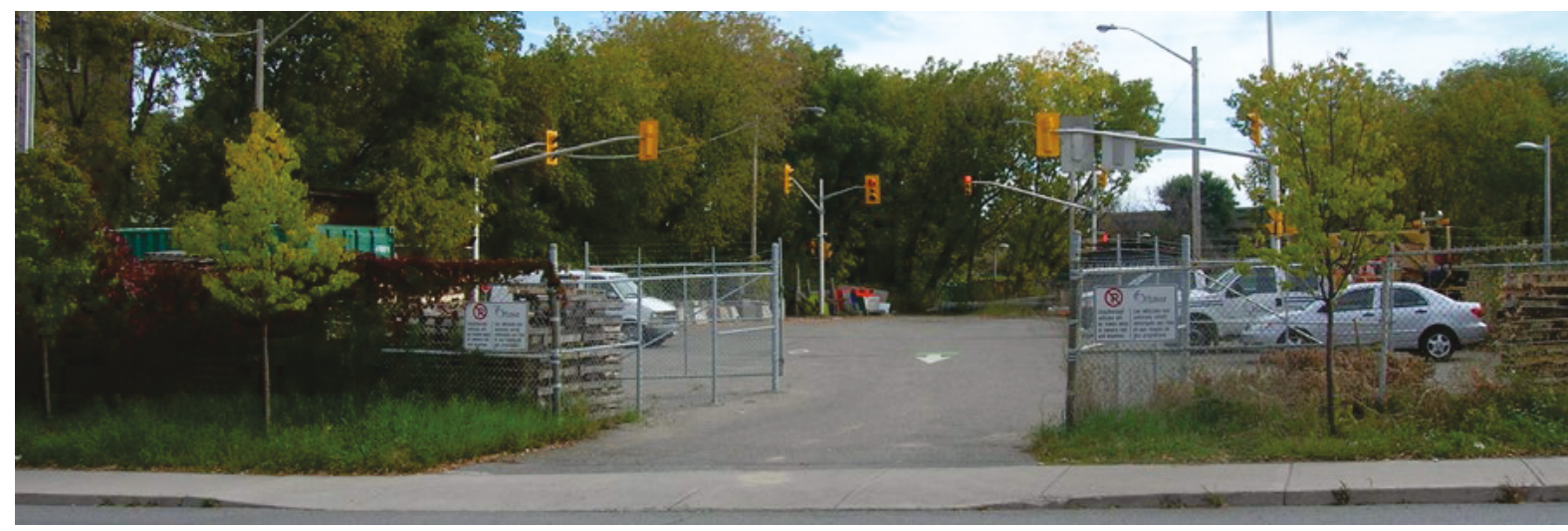

Figure 31. Site map showing the locations of the O-Train, the Ottawa River Pathway and Gladstone Avenue.

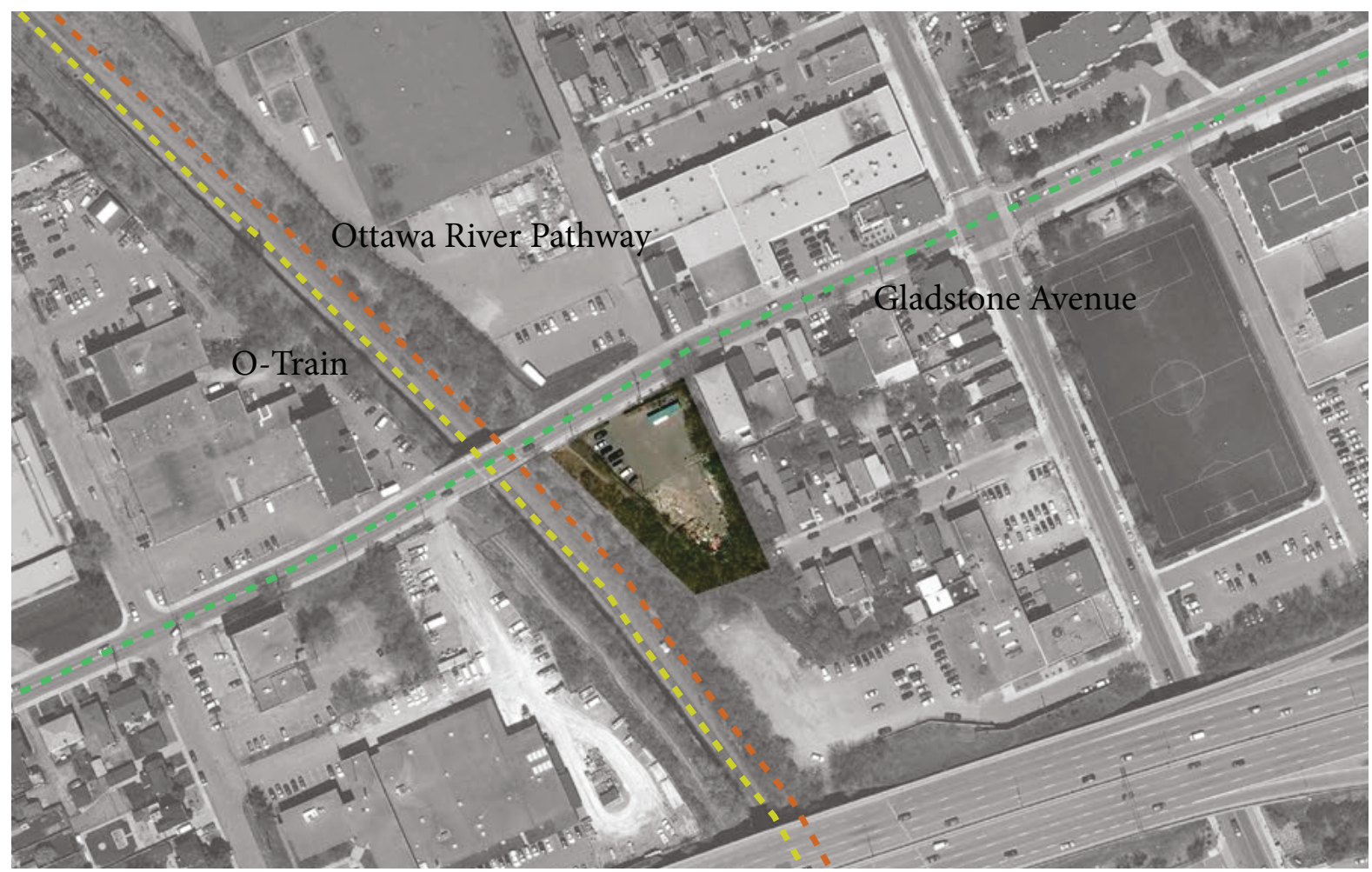




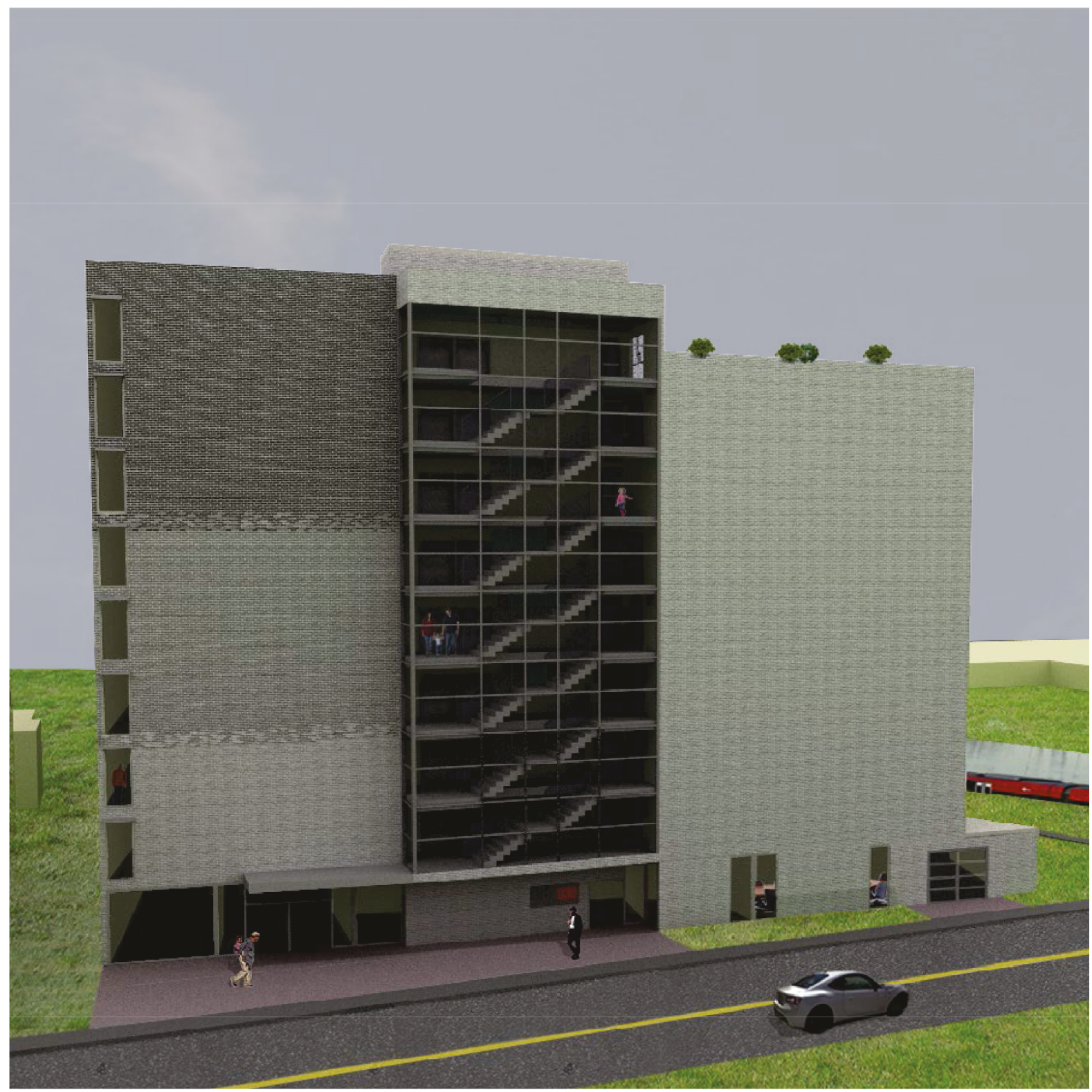

A Multigenerational Home 51 
in its larger scheme to extend the O-Train

further south. Additional passing sidings to the track are proposed to be in the Gladstone

Avenue area, which began design in $2012^{62}$.

Directly to the north of the site is a large two storey building owned by the Government of Canada. Public Works and Government Services Canada and Health Canada are within the building. Directly east to the site are a small theatre, various businesses and one to three storey homes. An Italian soccer club's parking lot is located to the south of the site.

The City of Ottawa zones the site as a mixeduse centre zone $e^{63}$. This zoning intends to

62 Transit Services. Feasibility Study of O-Train Extension to Leitrim and Riverside South.

63 MC - Mixed-use Centre Zone (Sec. 191-192) http:// ottawa.ca/en/residents/laws-licenses-and-permits/laws/city-ottawazoning-law/mc-mixed-use-centre-zone-sec-191-192 utilize the land with transit-supportive uses including community recreation, day care centres, and high and medium density residential programs. The intent is to utilize the ease of access to the transit system to aid in pedestrian oriented programs. Parking for community and residential access must be provided on site. The area located to the east of the O-Train and to the immediate west of the site is zoned as a general industrial zone $e^{64}$. Programs on this site include low to moderate impacting programs such as day cares, parks and recreational programs.

\section{Shared Spaces and the Community}

Within Little Italy there are very few grocery

\begin{tabular}{l}
\hline $64 \quad$ IG - General Industrial Zone (Sec. 199-200) http:// \\
ottawa.ca/en/residents/laws-licenses-and-permits/laws/city-ottawa- \\
zoning-law/zoning-law-2008-250-consolidation-70.
\end{tabular} A Multigenerational Home 52 


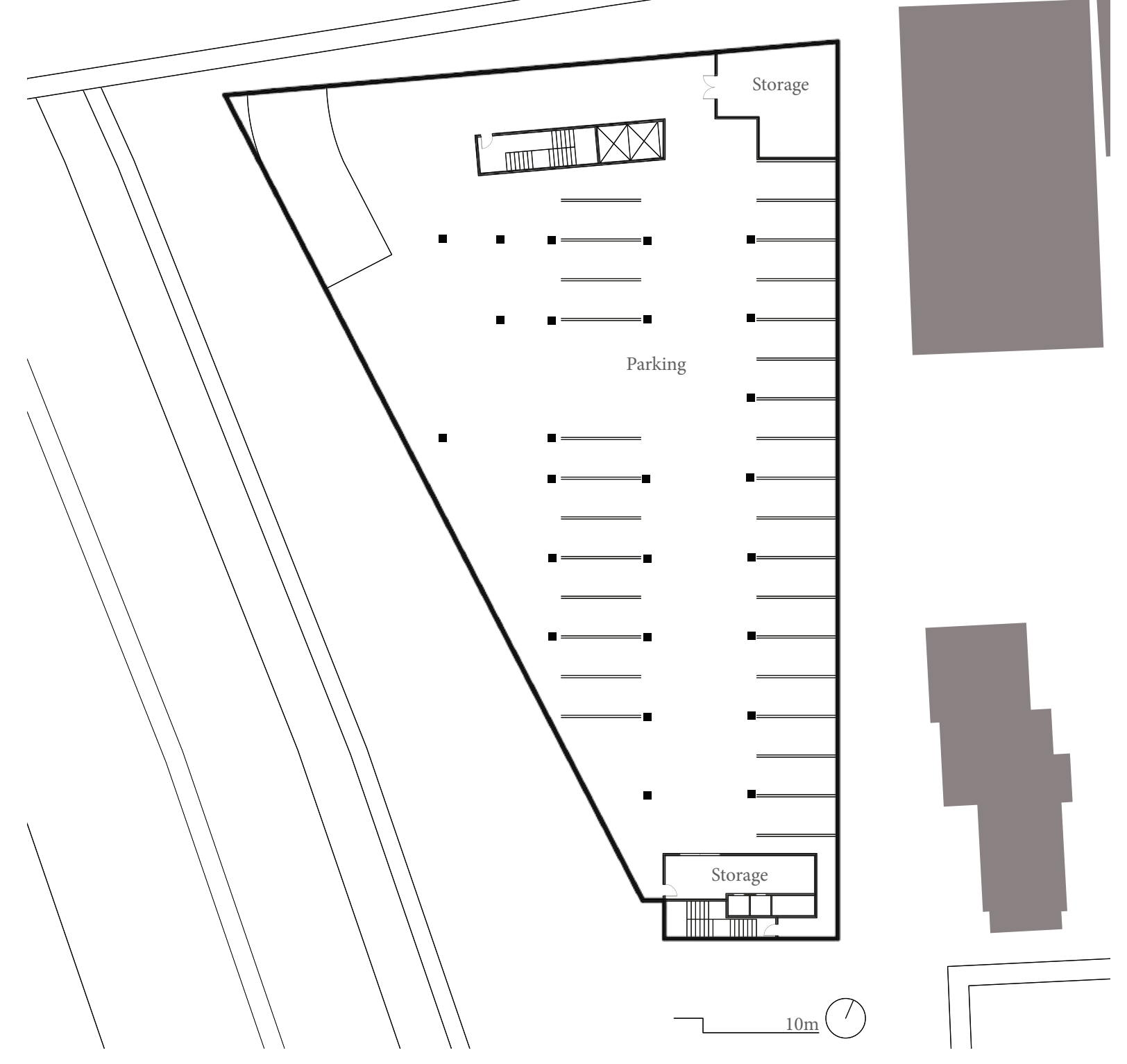

A Multigenerational Home 53 


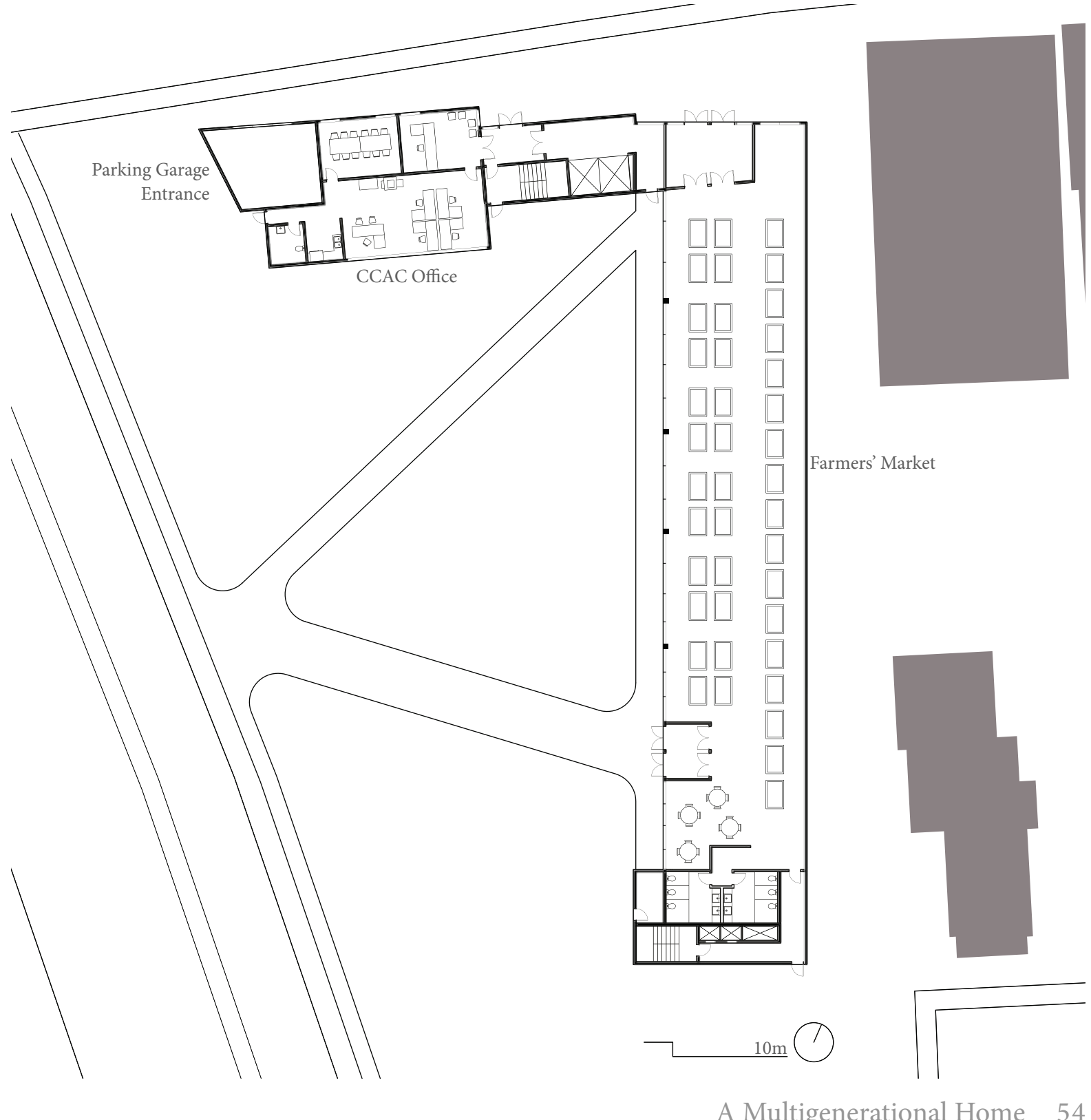



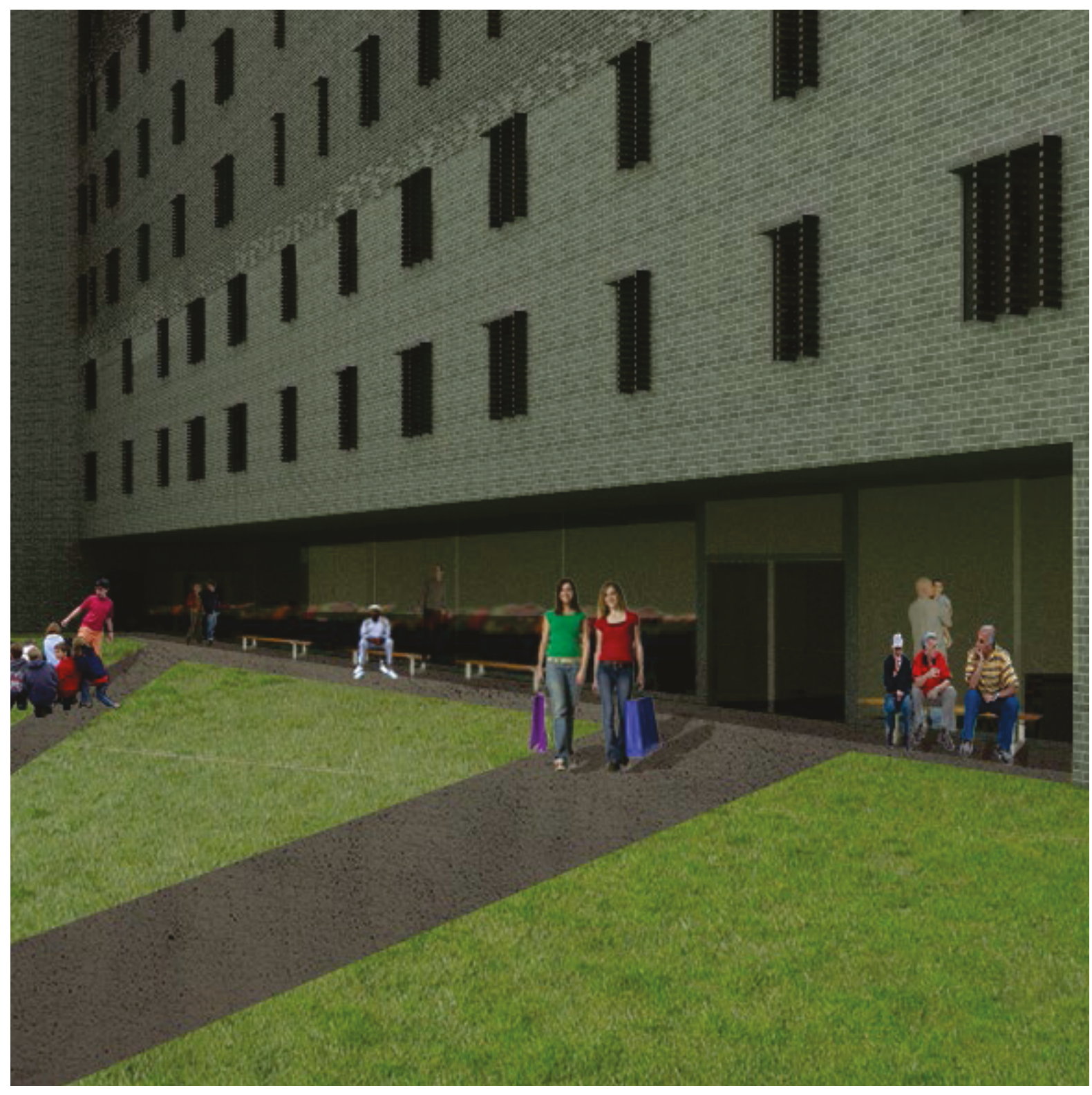
stores. Although smaller stores are an option, the choice for a larger store with greater variety and selection is not found in the neighbourhood. In addition, the farmers' market in Little Italy is seasonal and located in a parking lot just south east of the building site.

The placement of permanent farmers' market on the ground floor and parking on the basement level for this proposed multigenerational home (figure 33, 34 and 35) ensures that Little Italy's market is maintained while providing both building residents and the greater community a place for a large selection of fresh food and accessible parking. Within the farmers' market, seating areas offer the community a place to gather, eat and socialize with both the community and building residents. In addition, it provides a space for teaching the community and residents techniques for cooking and healthy eating. The market engages both the residents and the community while also providing a space for a neighbourhood practice.

\section{Materiality}

The materiality of the building represents the internal program of the building. Therefore the residential and shared spaces all have individual materiality represented on the façade of the building. This provides an external ability to locate units, increasing the residents' connection to the building. The materialityalso uses this identification method on the interior through its continuation of materials for separate spaces. Senior units, 
Figure 36. Diagram of the brick materiality of the residential facade.

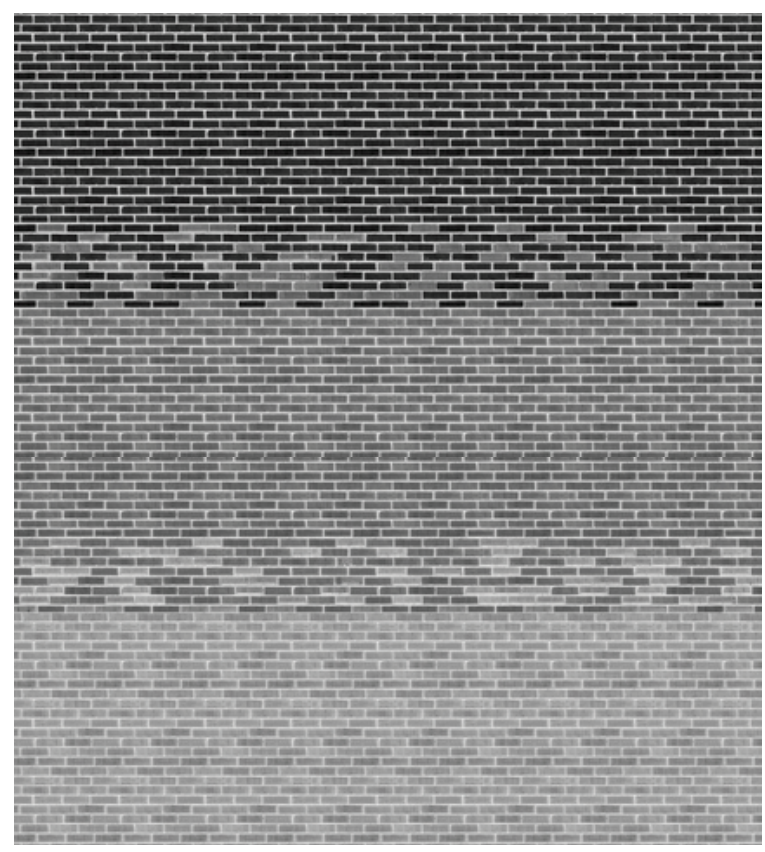

multigenerational units, family units and shared spaces all have different interior materials to extend this understanding.

The materiality of the facade is a textured brick. In order to maintain individual readings of the three units, the brick's colouring changes slightly (figure 36 ). Beginning on the senior floors, the brick is a light grey. Moving into the multigenerational floors, the brick fades into a darker shade. Finally on the family floors the brick fades into a dark grey. This fading between floors demonstrates that even though the senior, multigenerational and family floors are separate, ultimately they work together to maintain a sense of community within the building. The texture on the brick helps to blur the visual fading between the floors so the facade isn't read 
Figure 37. View of the entrance to the farmers' market, residential units and the CCAC office.
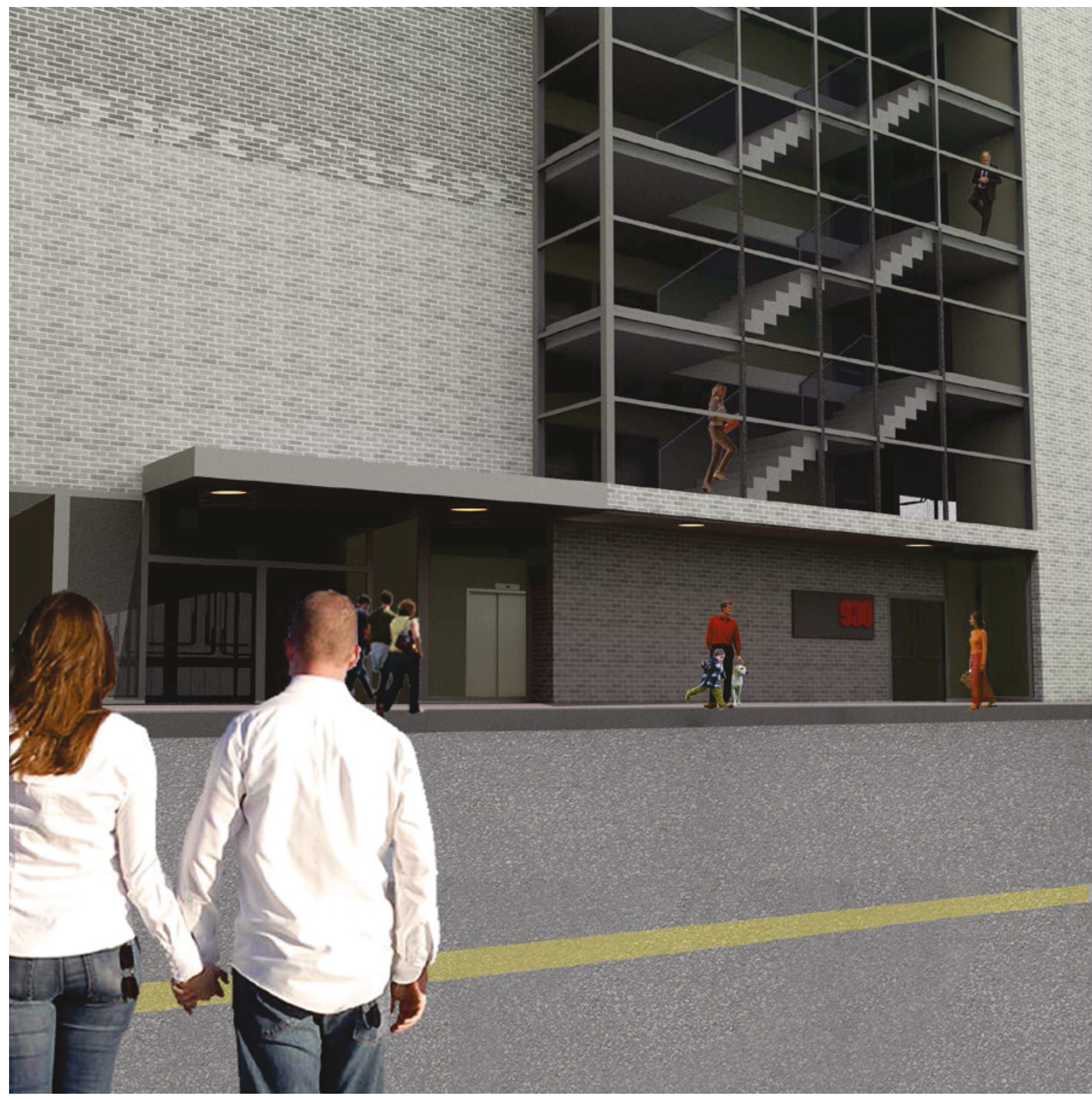

A Multigenerational Home 58 


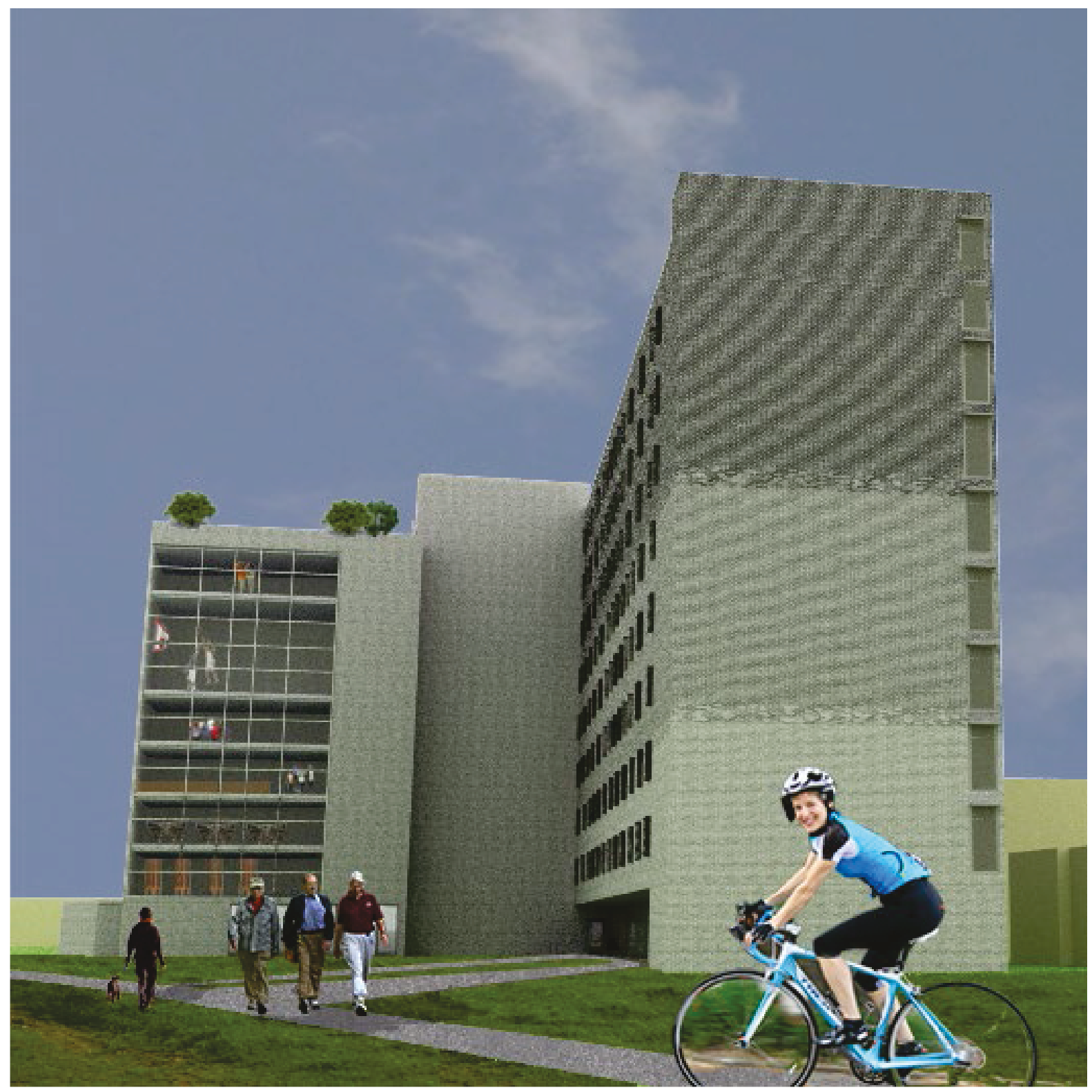


as one solid face but a compilation of many pieces. The shared spaces of the building is clad in the lightest grey brick to visually show a connection.

In addition, the ground floor of the building, which holds the office for the New Horizons for Seniors Program and the community farmers' market, intends to invite members of the greater community into the building. This is accomplished through the use of glazing and high transparency. This invitation is then extended into the courtyard which abuts the Ottawa River Pathway.

This level of high transparency, as shown through glazing, is extended into the main circulation core and the shared spaces. This allows for the community to have a greater understanding of the dynamic relationships between all members of the building. It is through this movement of people between floors that the relationships of multigenerations are explained and explored to the public (figures 37 and 38).

\section{Legality and Architectural Design}

A multigenerational household can only function if each generation agrees to the style of life of this living situation. Issues arise when one generation fails to provide the necessary care for another generation. Due to its rise in popularity, many families choose to write a legal contract about the expectations of the generational care in order to protect each member and ensure that proper care is received for each person. These contracts protect the wellbeing of both the family and the senior. 
for seniors to maintain a sense of social

Although multigenerational housing is typically constrained to one household for the care of the senior, this multigenerational housing complex looks at the program in terms of its greater application to an entire building. By integrating multiple multigenerational housing units together, a sense of communal responsibility is spread amongst all members of the building. Therefore, the care for a senior extends beyond the unit and into the building. In return, relationships are formed amongst residents of the same generation which reinforces a sense of greater responsibility to other generations.
A large aspect of multigenerational care is the interaction between members. The Government of Canada recognizes the need

inclusion within both their own generation and amongst other generations. Through Employment and Social Development Canada, the federal government funds a project called New Horizons for Seniors Program (NHSP). This program is a community grant awarded to companies who intend to provide one or more of the following objectives:

“...promoting volunteerism among seniors and other generations; engaging seniors in the community through the mentoring of others; expanding awareness of elder abuse, including financial abuse; supporting the social participation and inclusion of seniors; and providing capital assistance for new and existing community projects and/or

A Multigenerational Home 61 


\section{programs for seniors"65}

A multigenerational care complex focuses on "...engaging seniors in the community through the mentoring of others..."66 and “...supporting the social participation and inclusion of seniors..." ${ }^{67}$ Since the NHSP grant needs to be run through an existing company, the Community Care Access Centre is best suitable to take on this responsibility. This centre, with the New Horizons for Seniors Program grant, can financially support the multigenerational housing complex and its residents. Currently in Ottawa there are

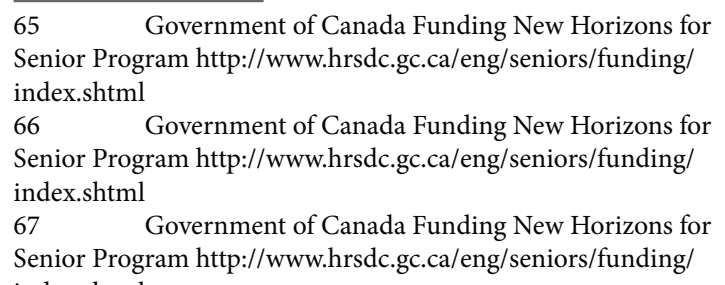

two CCAC offices ${ }^{68}$ : one located in the west end and one in the east end of the city. The placement of a CCAC office in central Ottawa allows centre city residents easier access to the offered services.

Within the proposed building, all residents are required to go through an application process, run by the New Horizon for Seniors Program, to determine if the individuals meet the requirements for living in a multigenerational house. Through interviews, potential residents are questioned on individual abilities to assess the care they can provide, or require. Successful applicants are then required to sign a contract outlining the issues covered in the interview. This means contracts are signed between the family, the senior and the New Horizon for $68 \quad$ Champlain CCAC Office Locations http:// healthcareathome.ca/champlain/en/contact/Pages/Officeaddresses-and-phone-numbers.aspx 
Seniors Program. This contract sets out the responsibilities of the family and the senior in terms of care. It also defines the expectations of the family and senior if one generation were to choose to leave the multigenerational unit or the complex.

In order to run the program successfully, coordinators are required to maintain continuity between the caregiver and the senior. These coordinators are necessary to ensure that adequate care is being provided to the senior and that the relationship between the family and the senior is healthy. Therefore, the coordinators do not provide the care but ensure that care is being offered and provided to the family and the senior. If a multigenerational family chooses to create a legal contract for care, the coordinators are available to act as an arbitrator between the family and the senior. Additional money is used for activities for residents in order to create a sense of community between the families and the seniors in the building. By offering tools to successfully maintain a multigenerational household, both the families and seniors can easily create a sense of community in the building. Finally, the coordinators take on the responsibility of monitoring the well being of the senior residents and, if needed, helping the seniors gain access to additional resources or helping with a move to a long-term care facility.

The costing of a multigenerational unit is shared in proportion between the family and the senior. Therefore, a unit with a family of two parents and one senior would split the rent two thirds for the family and one third for the 
senior. This type of ratio is applied to other unit layouts in order to maintain an appropriate level of responsibility between all members of the multigenerational unit. The costing of the family only and senior only units reflects the incomes of the respective families and seniors to ensure that the units are affordable for all residents.

Since this multigenerational housing complex is intended for low income seniors, government subsidies for its construction are necessary. The intent of the building is to house individuals who cannot afford market based rent. Therefore the units themselves are not sold for a profit to a private developer. This means that the building needs to be funded. The running and maintenance of the building will be through rent and the New Horizons for Seniors Program grant. Ultimately - even though it is not run directly by the government - it is a property of the government, and through grants it will have a large association.

The commitment to living in a multigenerational house or within a multigenerational housing complex brings along the potential for great responsibility and scrutiny. There needs to be a commitment from the residents to look after one another; either through individual multigenerational unit contracts or for families and seniors living independently. The contracts for multigenerational units ensures that within the unit necessary care is provided. For families and seniors living independently within the complex, a commitment to participate in monthly events and activities will be necessary 
for residency. This ensures that all residents are committed to bettering the lives of one another.

If residents fail to maintain contract standards, or cannot maintain the expected monthly activity commitment, the residential unit will be offered to a new potential resident. 


\section{Conclusion}

Over the next 50 years, the shift of demographics to a population with a large number of seniors requires a response for both senior care and senior housing. Although a large percentage of seniors maintain residency in independent homes, some choose to live in a home that can provide additional services and care.

Traditional facilities such as retirement homes and long term care facilities can provide some of the needed assistance. Retirement homes provide minimum to moderate care but come at a high cost to the resident. Long term care facilities ensure that individuals who need moderate to advance care are provided to with government subsidy, but lack a focus on social participation. In addition, these facilities are intended for individuals whose medical condition prohibit them from living independently. Therefore, a senior requiring minimum to moderate care - such as care from a retirement home - must be wealthy enough to pay for those services. This alienates seniors who are not wealthy enough to afford to live in a retirement home. Many seniors fall below the Low Income Cut-off and therefore a retirement home (and its services) are not feasible.

Fortunately there are some options for low income seniors. The Government of Canada offers both scheduled in house care and rent geared apartment for seniors. These programs, the Assisted Living Facility for High-Risk Seniors and the Senior Affordable Housing 
program respectively, ensure that seniors can live independently in affordable housing with care. Yet the care must be scheduled, while the apartments are exclusive of any services. In addition, shared housing allows for groups of seniors to buy into a home and share both the responsibilities and care of the members and the home with one another. Similarly, adult lifestyle communities are homes within a designated area with a suggested resident age, allowing for seniors to live close together. Unfortunately, the last two options are only viable if a senior has the means to afford a mortgage. The final option for seniors is to receive the needed care through multigenerational housing.

A multigenerational house is made up of people from at least two generations, choosing to live with one another in order to better each other's lives. This type of house has an implied responsibility of care for each member. Therefore, each member takes on different responsibilities and expects care in return. For low income seniors, care can be provided by families. In return, these families create a relationship with the senior and can have expectations for care from the senior too.

The multigenerational housing complex is made up of three types of units: senior, family and multigenerational. The multigenerational unit provides a space for a senior and a family to live together within one unit. The senior only units allow for seniors who want to participate in a multigenerational home to do so without the requirement of having to live 
with a family. This also encourages seniors who may not have a family and can offer care to live in the building. This allows the senior to ultimately get care from a nonrelated family. Similarly, family only units allow families to live in the building without a senior but with the guarantee of care to a senior in a senior only unit.

The introduction of the community into the multigenerational housing complex is crucial. As much as the relationships between members of the building create a network of care, extending this into the community promotes an even greater web of support. Through the farmers' market on the ground level, community members and building residents have the space to interact with one another. In addition, the green courtyard facing the Ottawa River Pathway encourages residents of the building to use the green space and move into the greater neighbourhood.

The Government of Canada offers a grant the New Horizons for Seniors Program - to ensure that seniors have the opportunity for social participation and are not victims of neglect. This grant, as run by the Community Care Access Centre within the first floor of the building, ensures that the building maintains the expectations of all residents. This includes outlining the expectations of each family and senior in terms of care and responsibility. The complex is intended to be a choice for families and seniors. That choice includes a commitment to the care and well-being of all residents within the building. 
Upon defending the thesis, questions were raised about the architectural expression of multigenerational housing. The post script addresses these questions and explores the physical manifestation of multigenerational architecture.

This development of a new architectural typology explores three aspects of design: shared space, dynamic movement of residents, and a connection to the community. These design aspects attempt to engage residents and provide spaces that support and aid in care. Care is often a personal matter so a high level of adaptation offered in these spaces accommodates all residents. By designing a physical form to respond to a social issue, this architecture facilitates multigenerational care.
Ultimately, a solution for low income seniors is to rethink traditional housing complexes so that these complexes can become places of care for all generations. By providing housing for all generations in one building, and multiple generations within one unit, the residents of the building can create a network of care for one another. It is through this multigenerational housing complex that the children, their parents and seniors can live together and provide the needed care. 


\section{Appendix I - Design Development}

Throughout the development of the building, a strong focus is placed on the design of the shared wall within the multigenerational unit. This wall is both a physical barrier within the space and a social barrier between the family and the senior. It allows for the shared space to be read as one unified area while also providing the option to break that space into smaller segments for privacy. The development of this wall took on four iterations before finalizing the completed design.

\section{Process - Wall}

Design development includes the design of a main customizable panel system that would

run through the kitchen, dining room, and living room of the multigenerational unit. This panel system ensures that both the family and the senior have private space within the shared common area of the unit.

The process to develop this shared space begins by studying the shared wall (figure 39). If the shared space was separated in half, giving both the family and senior space independence from each other, the separating wall becomes the main focus. This wall provides opportunities for interaction or for privacy. Since these families and seniors choose to live in a multigenerational house, the understanding is that space will be shared for the betterment of the generations. Susan Newman explains: 
Figure 39. Diagram of the multigenerational units' development of the wall from a physical barrier to a moveable and interactive wall.

Figure 40. Diagram of the creation of a retractable wall between the family and senior shared space.
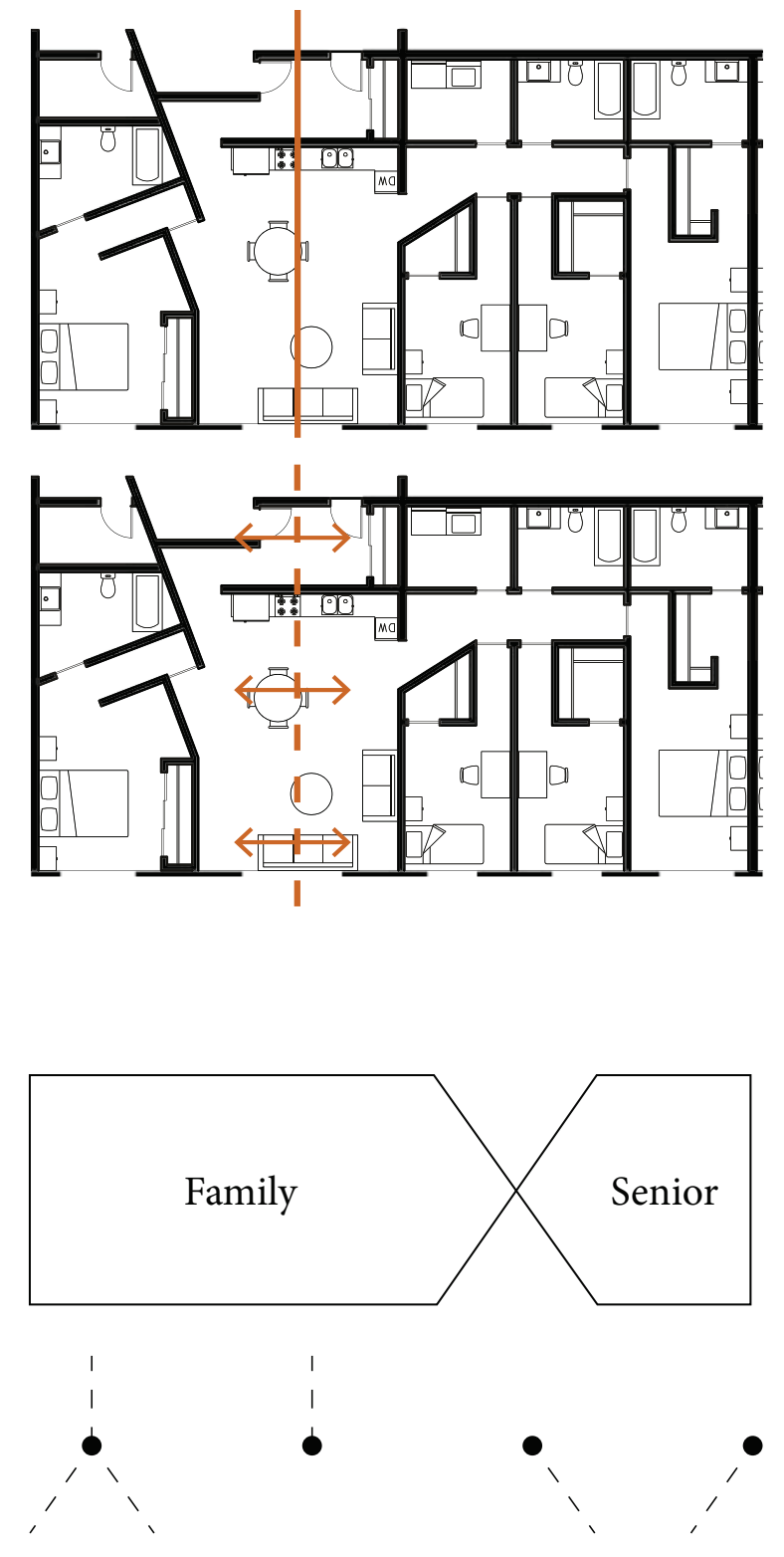

"Privacy is hard to come by in a fill house, or one that feels full...Lack of privacy - giving it and getting it - is a real issue for parents, as well as their adult children, especially when sharing a small apartment or house"69

Therefore designing a fully separated kitchen, dining room and living room prevents proper multigenerational living. However, a level of separation might be desired. Openings and movement of the wall allow for interaction while still maintaining an option for privacy.

The initial design development (figure 40) studies the wall as a retractable feature that separates the shared space into multiple sections allowing the various generations to $69 \quad$ Newman 2010: 105.

A Multigenerational Home 71 
Figure 41. Diagram of the creation of private space.

Figure 42. Diagram of the creation of permanent walls to divide the shared space into smaller, more private spaces.
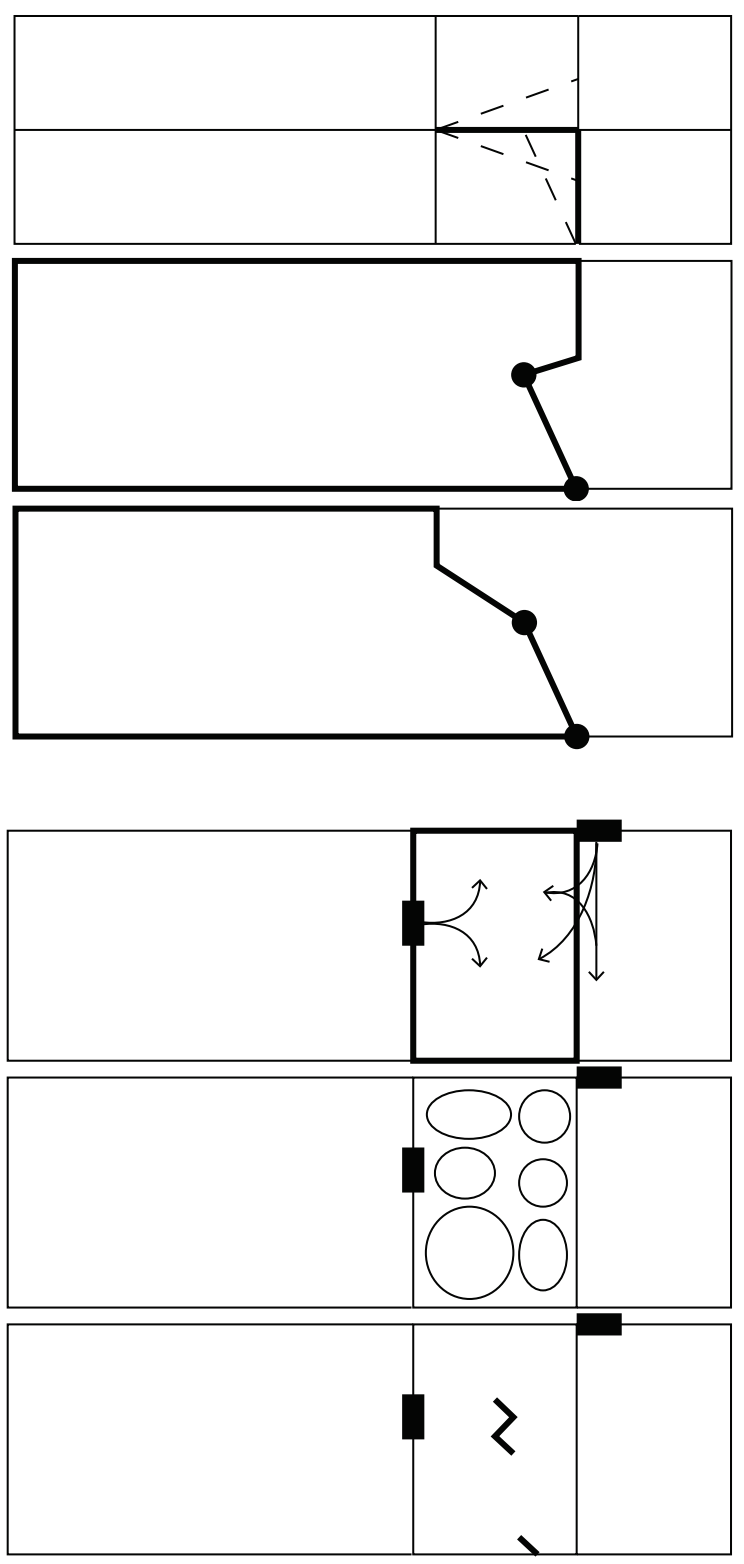

determine how the shared space would be used every day. The retractable walls originate from structural columns within the shared space.

The second design development (figure 41) studies how the walls of the private spaces the bedrooms - could rotate into the shared space in order to create an extension into the shared space. The senior bedroom, through this rotating wall, would then transform into a bachelor apartment, giving the senior even more private space.

The third design development (figure 42) examines the placement of walls in a permanent layout by analyzing the social spaces that results from their placement. This includes providing separate spaces for dining 
Figure 43. Diagram of the creation of a pane and track system, hung from the ceiling to create smaller private areas within the shared

Figure 44. Diagram of the movement of the panel and track system through the shared space.
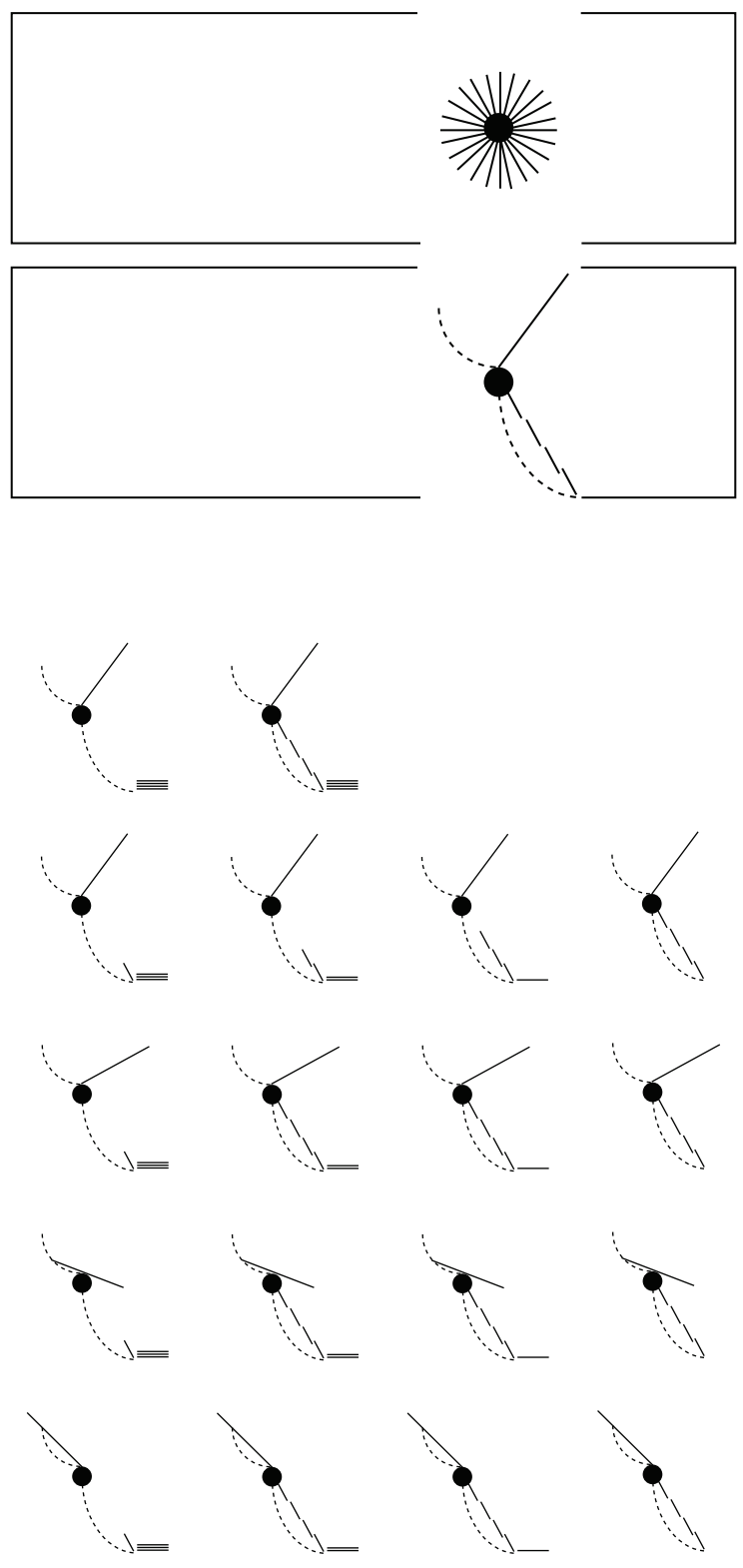

and living for the family and senior while still maintaining a larger shared space between the generations. Unfortunately, the separation from the walls becomes too extreme and the understanding of the shared space is lost.

The fourth and final design development (figures 43 and 44) takes ideas from all of the previous designs. It studies how panels, suspended on a ceiling track, would allow for the space to be shared while also providing the option for separation. The three panel system creates different spaces depending on the chosen placement and are easily movable by any generation.

In all of these designs, the wall becomes a point of social interruption. The intention of the wall is not to create defined separate 
spaces but to allow the generations the option

to create spaces that reflect their lifestyle. Each multigenerational family would use the shared space differently, and the intention of the wall is to customize the space to their needs. Since it is customized to each family, the movement of the panels would become less frequent and most likely set to a specific wall layout on move in. The use of the wall panel system after an occupancy change allows for the new tenants to customize the space to their needs. Therefore, units can provide the basic framework for multigenerational families and the wall panel system creates a greater sense of belonging for the family and the senior.

Ultimately, because of the design of shared spaces located on each floor, the wall system is replaced with the independence gained through these shared spaces. Generations can chose to leave the unit and engage in the various shared spaces instead of creating additional physical boundaries within the multigenerational unit while also interacting with other residents of the building. 


\section{Post Script (Appendix II)}

A further development of the typology of multigenerational housing explores what 'multigenerational' means in architecture. Although multigenerational is defined as a collection of socially related people, the concept of multigenerational architecture extends beyond the social realm. This extension is studied through the post script.

The physicality of multigenerational living is seen through various elements; all which aid in both the giving and receiving of care. Firstly, the element of shared space allows for care without the intrusion into more private space. This shared space needs to reflect the various users of the space and therefore should involve a component of flexibility. This flexibility provides a shared space that can accommodate different types of relationships and therefore respond to different levels of care. Secondly, multigenerational architecture should allow for dynamic movement through the building. This movement of residents ensures that there is a greater social flow and connectivity between all involved. This movement allows for the care to extend from the residential unit to the entire building. This in turn allows residents of the building to take on a greater role for one another instead of just limiting their role of support to people within their own residential units. Finally, multigenerational architecture should play an active role in the larger community. This can be accomplished through public programming and is most often found through ground floor intervention. Through engaging the 
community, the building residents gain social connectivity to the surrounding community. This prevents social isolation of all generations and extends relationships beyond those found in the building. These three physical elements of multigenerational architecture intend to engage, aid and support the lifestyle of multigenerational living.

The design exploration of this post script includes the study of a family and a senior residential unit, a multiple senior residential unit, a typical residential floor plan, the ground floor plan, and a building section. The defined elements of multigenerational architecture needed to be reflected in all aspects of design.

Re-evaluating the residential unit allows for an increased focus on the concept of shared space and its influence on a private space. Considering that multigenerational living is a choice which involves the sacrifice of many traditional residential rules - such as complete privacy and independence in areas like the bedroom and the kitchen - shared spaces begin to blur into the more private areas. This blurred area is where multigenerational living can most easily be seen.

In order to accomplish this blurred area between shared space and private space, an exploration of a panel system was conducted (figure 45). These panels intend to aid in the day-to-day running of a multigenerational household. They include seven different types of panels: privacy panel, low visibility panel, high visibility panel, storage panel, fold 
Figure 45. Elevations of the seven panels including a privacy panel, a handrail panel, a fold out table panel, a high level of visibility panel, a storage panel, a fold out chair panel, and a low visibility panel as read from left

$$
\text { to right }
$$
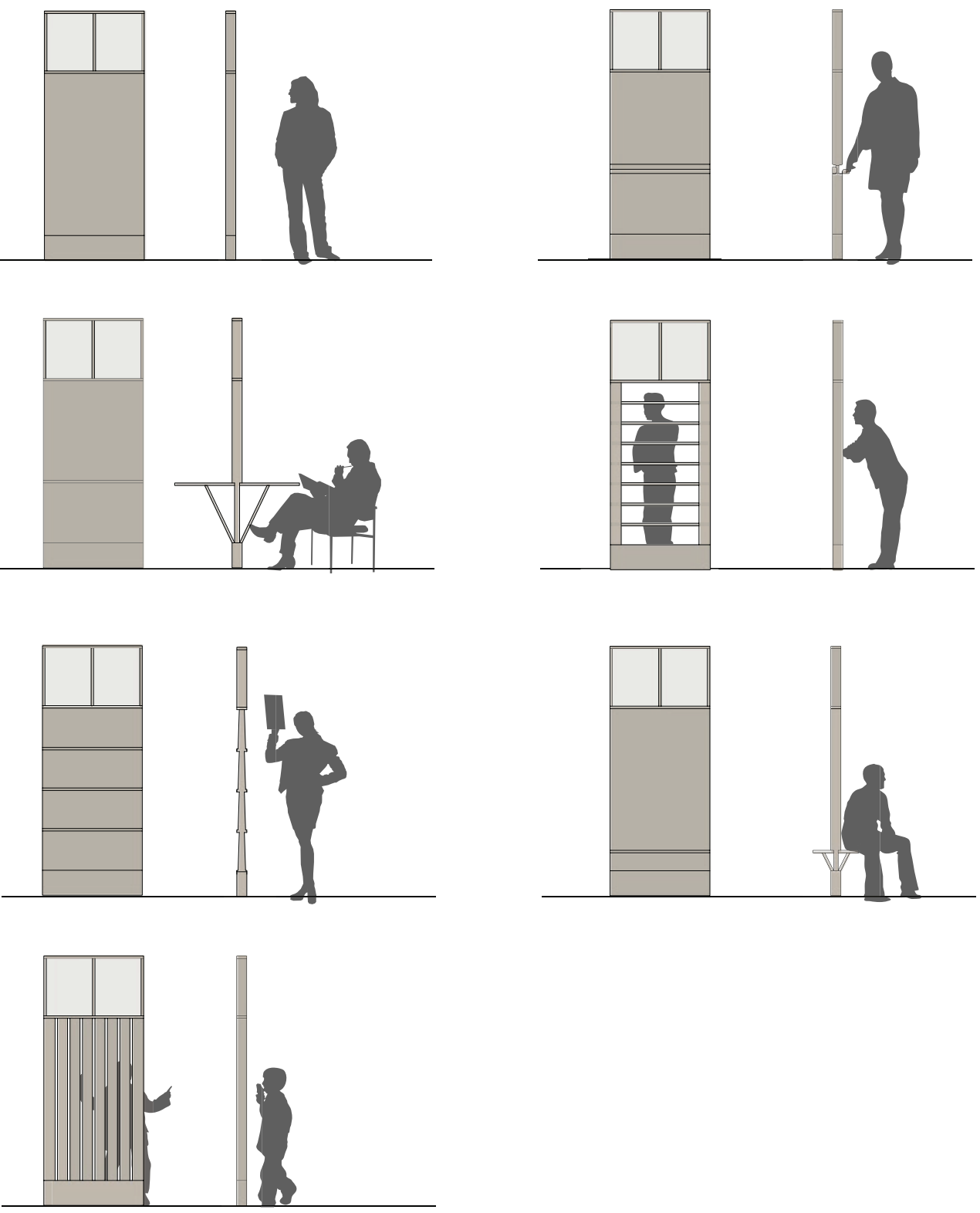
out chair panel, fold out table panel, and a panel with a handrail. These different types of panels help with various social situations and respond to different types of physical needs that residents of all ages may require. For example, panels between a grandparent and their grandchildren may include a high level of visibility so that the kids can be watched throughout the night. Also, a fold out chair panel can be used in the living room for additional seating. Overall, these panels intend to help with multigenerational living and can be used as a tool for better care between residents.

Through the panels, the physical layout of the family and senior residential unit was explored. This exploration included redefining the boundaries between private and public within a unit and how, through the implementation of the panel system, these two spaces could blend together. Therefore, all bedrooms are located along one side, while the kitchen, dining room and living room are located along the opposite side. The bathrooms exist in between these spaces. This layout allowed for a minimal amount of permanent walls to be designed, providing an optimal opportunity for spaces to be customized to the residents' needs. Although all spaces can be separated using the panel system, giving residents this choice in their layout provides a residential unit that reflects the workings of that specific multigenerational group.

The exploration of a multigenerational unit resulted in two types of units: a unit for a 
family and a senior to live together and a unit for multiple seniors to live with one another. The multi senior unit, although not explored in previous designs, is another type of unit that can provide care for all residents. Its programming is different than a family and senior unit because all bedrooms have a small kitchen, living room, and dining room off of their respective bathrooms. A larger shared kitchen, living room and dining room is located at the end of these units which allows for seniors to gather together in a communal area. Similar to the family and senior unit, the panels in this unit are used to distinguish between private and public space and facilitate care between residents. The panels provide the seniors the option of privacy between bedrooms. They also extend into the individual kitchen, living room and dining room spaces allowing for seniors to maintain independence from each other. The seniors have the choice to open these spaces to one another to create a larger shared space. Even though there is a sacrifice of private space for these seniors, helping and caring for other seniors is of more importance.

Moving from the individual unit, a typical residential floor plan was developed in both plan and section simultaneously (figures 46 and 47). This design implemented both the elements of shared space and the dynamic movement of a multigenerational building. By placing stairs in alternating areas on each floor, residents engage the entire floor area in order to change floors. This zig-zagging of residents through the building encourages additional social interaction not only through 
Figure 46. Plan of a typical residential floor

in a closed condition with a multiple senio unit to the west, two multigenerational units, and a kids only shared space

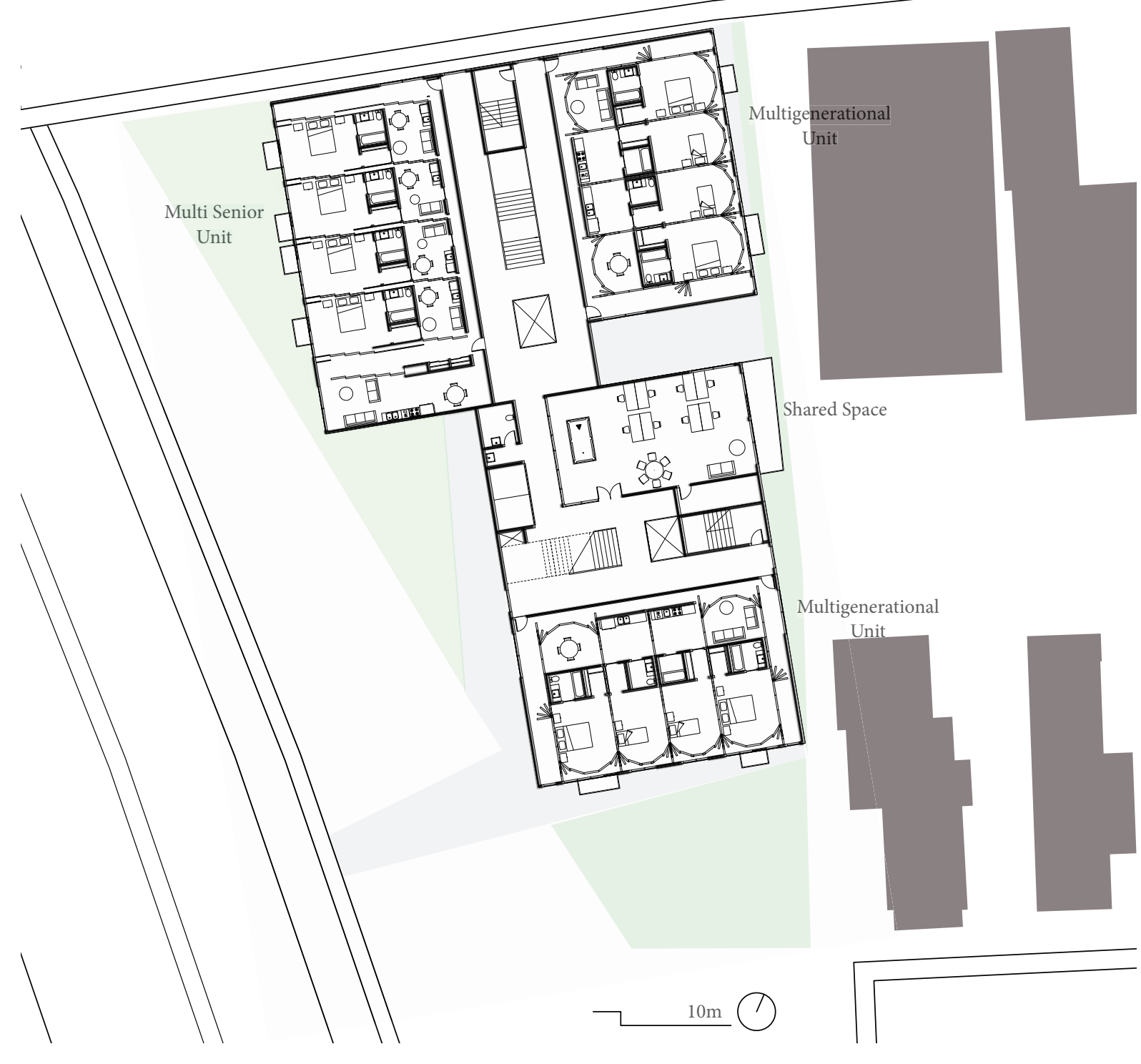


Figure 47. Plan of a typical residential floor

in an open condition with a multiple senio

unit to the west, two multigenerational units, and a kids only shared space

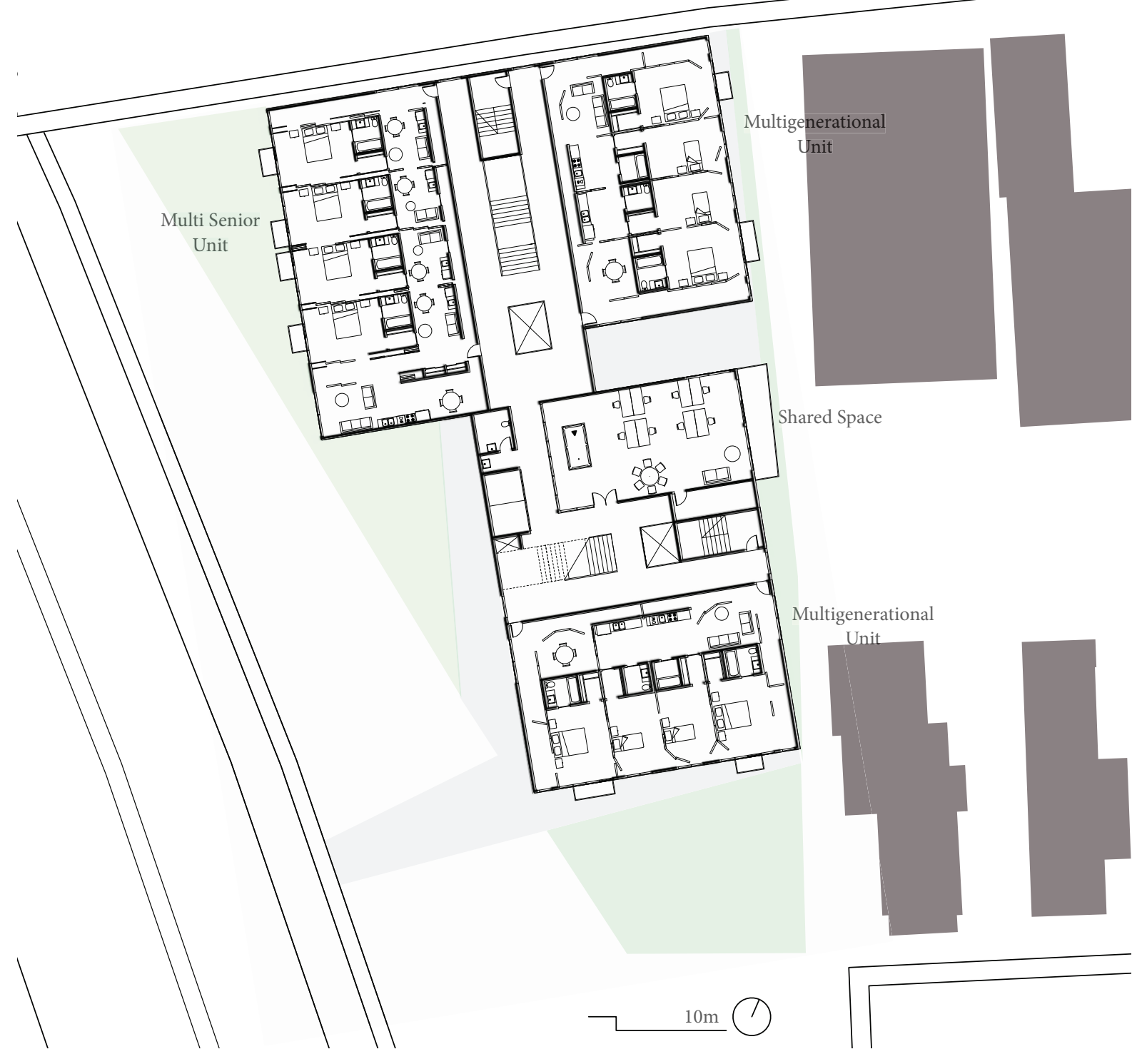


Figure 48. Diagram of the movement through the building. Yellow represent vertical movement, orange represents movement on one floor, and green represents movement on the alternating floor 
Figure 49. Diagram of the movement through the building. Yellow represents

vertical movement, green represents

movement from the stairs, and orange represents movement to residential units

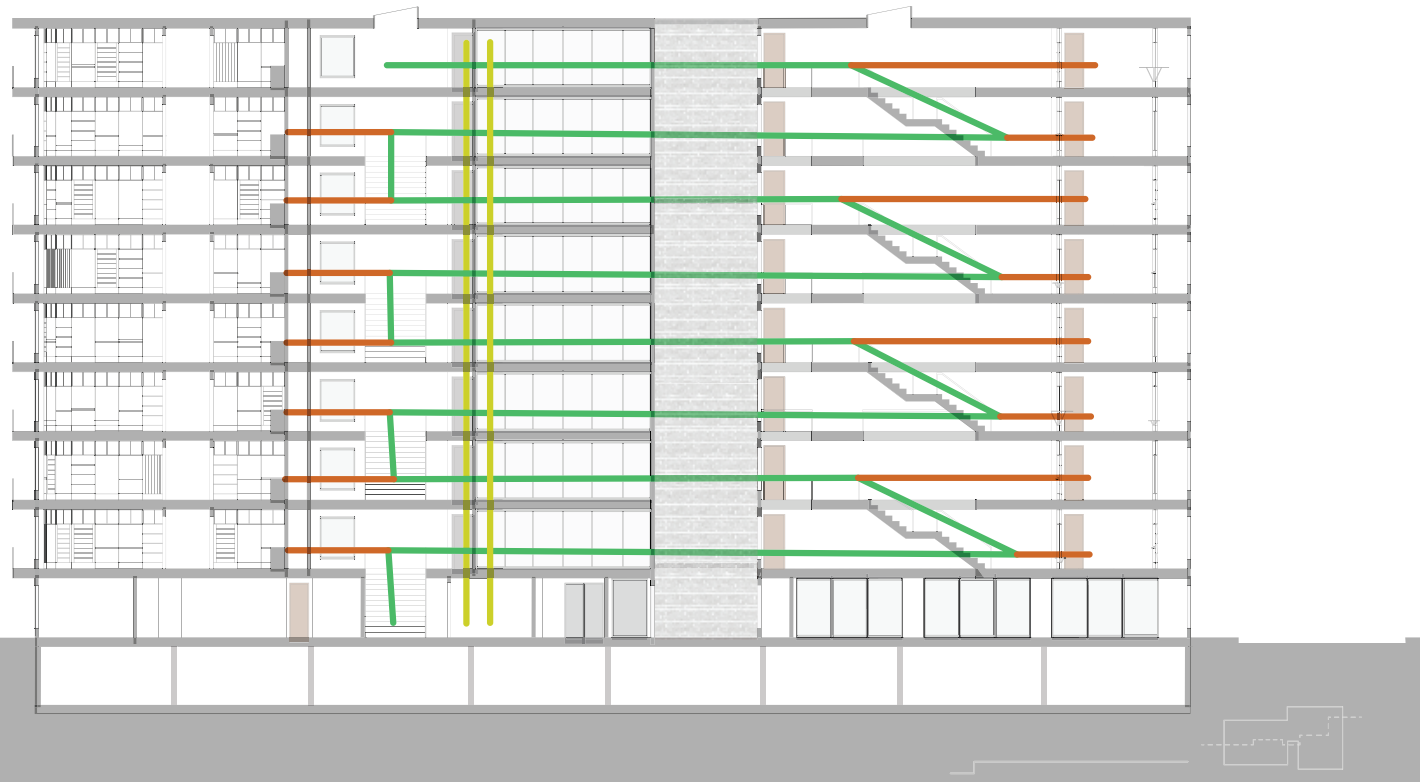


the large hallways but also through the centrally located shared spaces (figures 48 and 49). The shared spaces on each floor are centrally located. This ensures that residents experience the total floor as they move from one floor to another using the main stairs (figure 50).

The final element of multigenerational living that was studied was the ground floor and its connection to both the site and the greater community (figures 51 and 52). Although the programming of the farmers' market and an office space for the CCAC is maintained, the connection of these two spaces to the site is further explored.

In order to better connect the farmers' market to both the site and to the community, it is placed against the public sidewalk. This engages people as they walk by the market. In addition, both the west and east wall of the market can open to the exterior area through large glass doors. These doors operate seasonally to connect the exterior garden to the west and the pathway to the east. By opening up the ground plane to the community, it encourages people to interact with the space and utilize the market to its full potential. The west wall of the market has two layers of operable glass doors; this allows for a transition area that can be further programmed for events involving either the market or the community.

Directly to the west of the farmers' market is a small community garden. This space is intended to be used by local community 


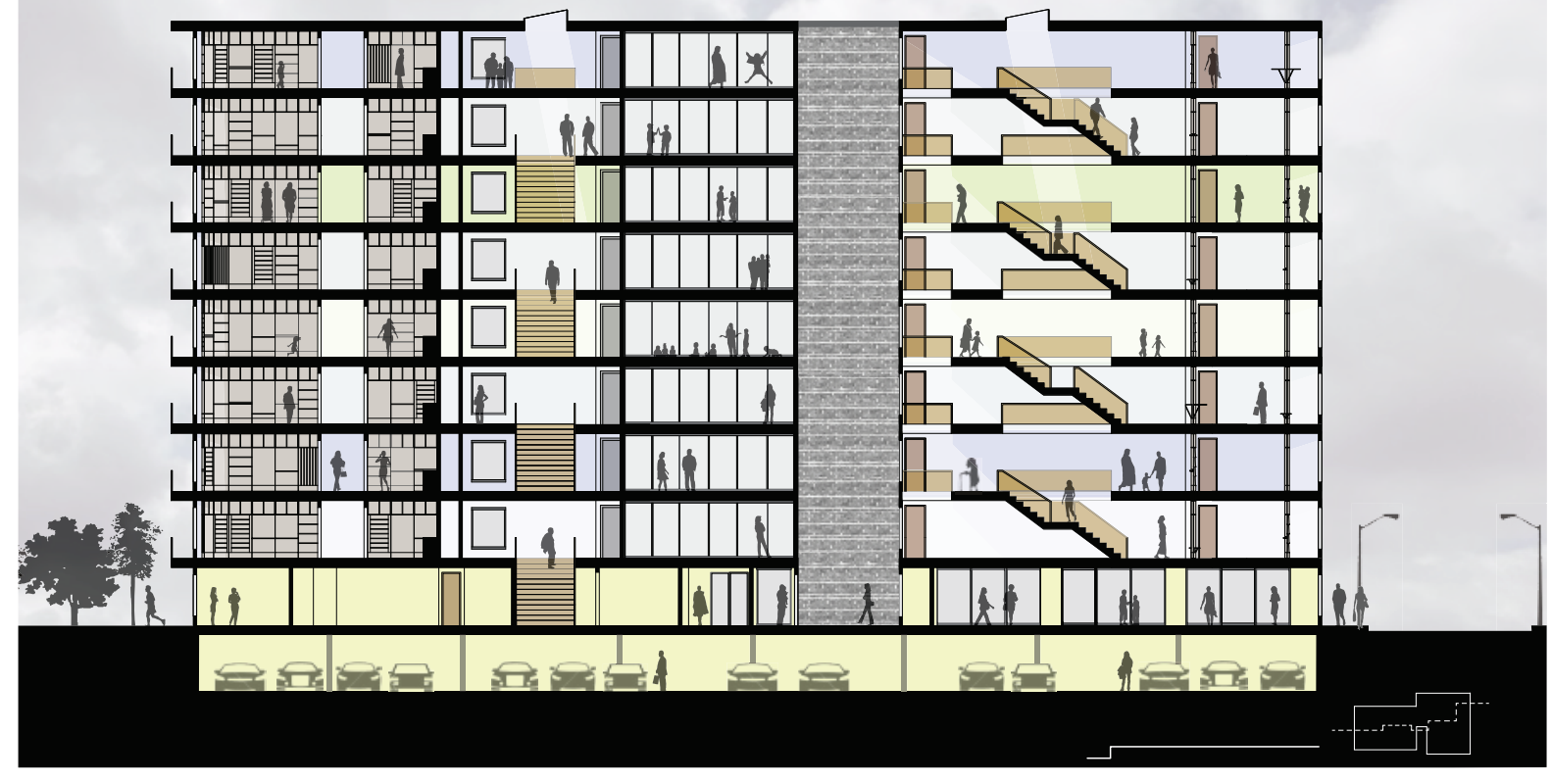


Figure 51. Plan of the ground floor in a

closed condition including the farmers' market, residential entrance, and the CCAC

$$
\text { office }
$$
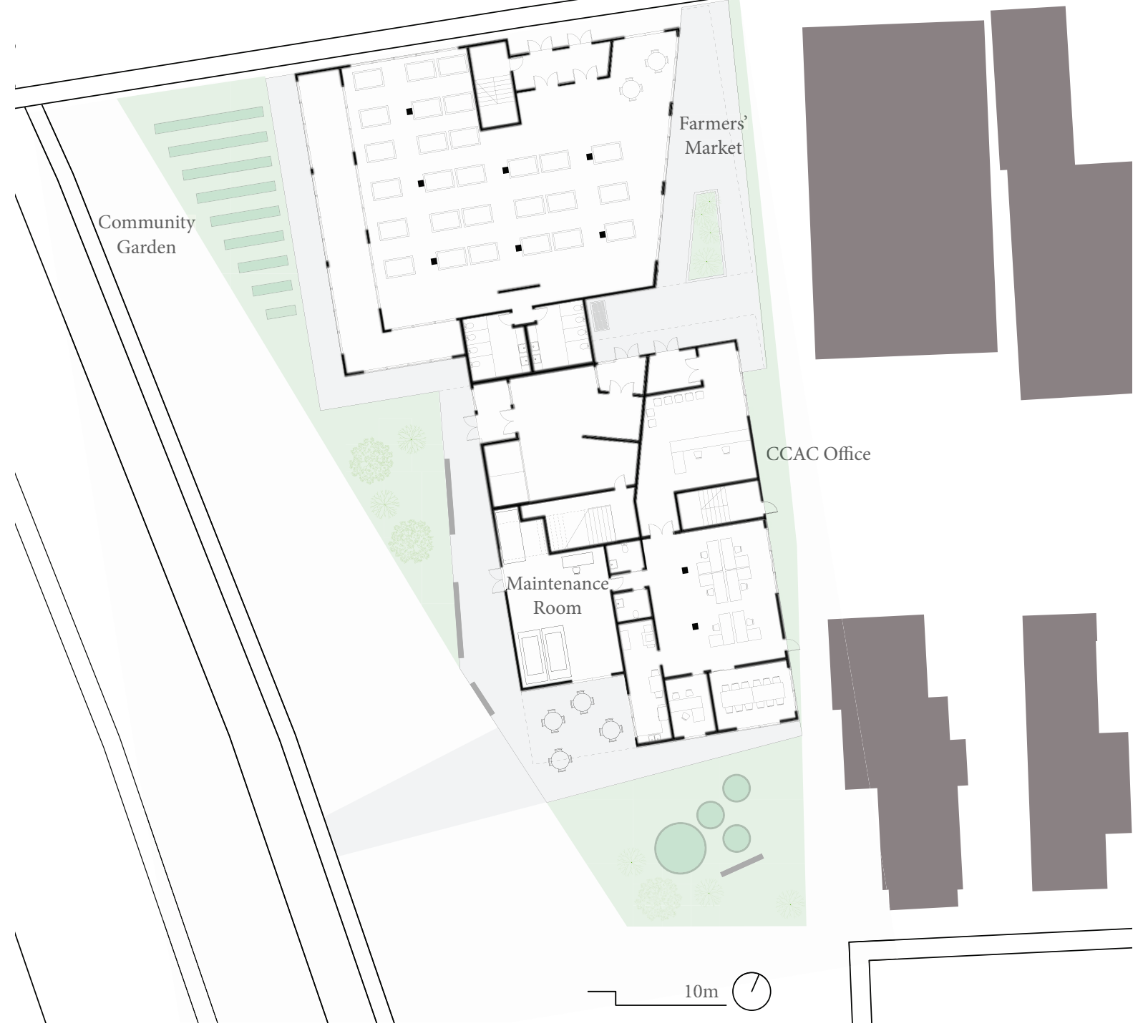

A Multigenerational Home 
Figure 52. Plan of the ground floor in an

open condition including the farmers' market, residential entrance, and the CCAC

$$
\text { office }
$$

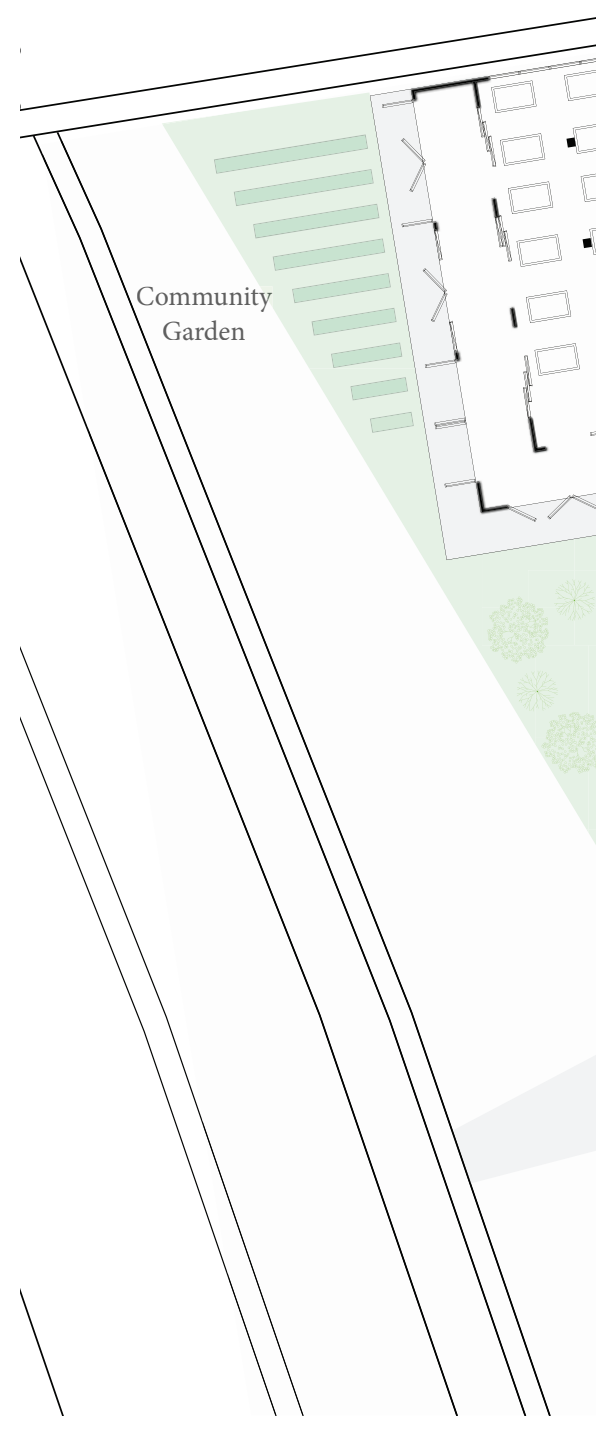

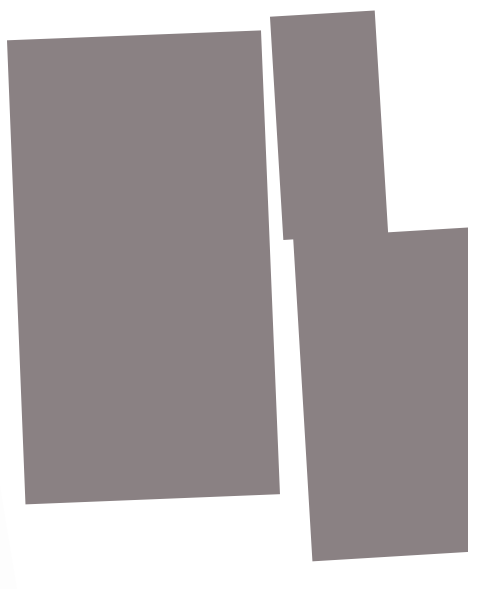
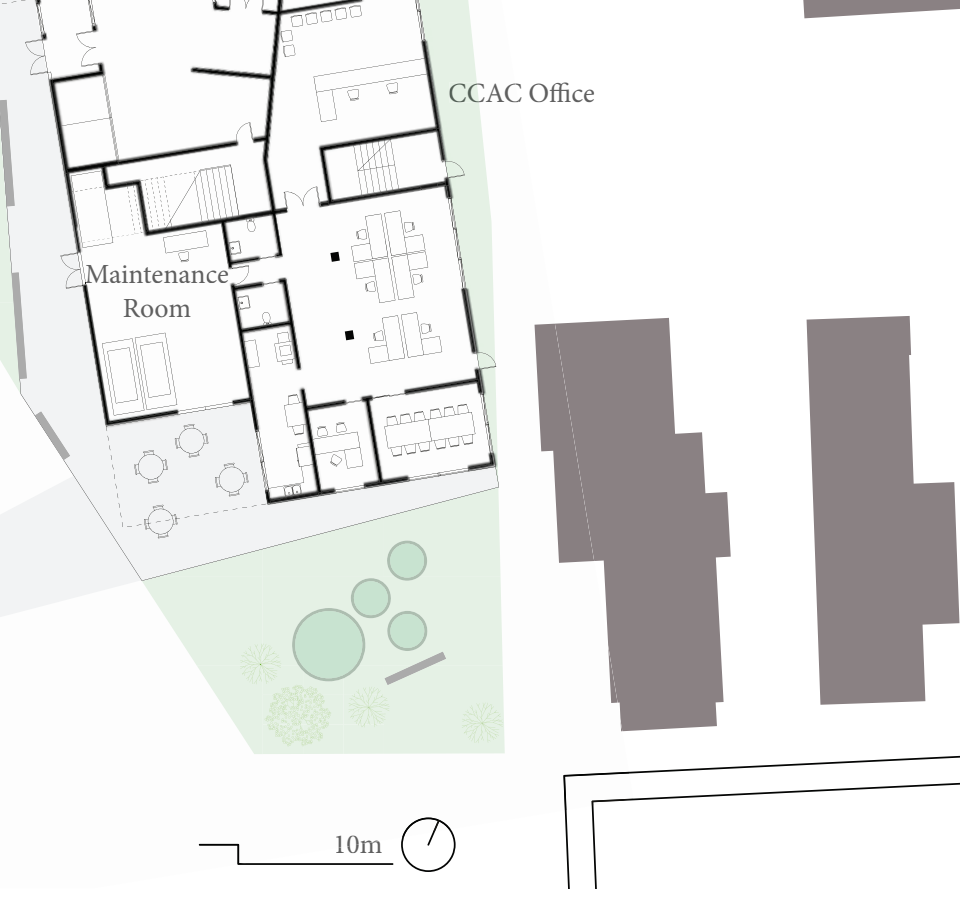
members and building residents to grow fruits and vegetables. It is also a location where farmers can teach gardening and engage the community further.

The office of the CCAC is located towards the south of the site. This location was chosen for two reasons: to encourage the community to use the entire length of the site, and to give the CCAC a level of privacy that would not be possible if it was placed along Gladstone Avenue. Since the CCAC can deal with issues of a personal matter, a level of privacy is required. A presence on Gladstone Avenue is also important, however. This is accomplished through a large pathway along the east side of the site leading to the entrance. This pathway is lit from the operable wall of the farmers' market and is also the pathway for building residents to enter the building.

The residential entrance is located between the farmers' market and the CCAC office. Its central location ensures that building residents engage the site while also maintaining a sense of identity independent from the farmers' market. The pathway acts as a more private area to be used by building residents and CCAC office users. In addition, the central location of the residential entrance allows for building residents to engage the exterior green space for both areas of social gathering and a children's play area to the south of the site.

Overall, this additional design study intended to explore the greater meaning of multigenerational architecture in its physical 
manifestation. Although multigenerational

living is a very social activity, the physicality

of the space that it exists within can help

various relationships succeed and provide the

necessary spaces for care to be implemented. 


\section{Bibliography}

The bibliography includes primary and secondary sources that have collectively contributed to the thesis.

The Boomer Boon Generating Ideas about Engaging Baby Boomers in the Nonprofit Sector 2010. Ottawa, Ont: HR Council for the Nonprofit Sector.

Adams, Michael and Amy Langstaff. 2010. Stayin' Alive : How Canadian Baby Boomers Will Work, Play, and Find Meaning in the Second Half of their Adult Lives. Toronto: Viking Canada.

Andåo, Tadao and Richard Pare. 1996. The Colours of Light. London: Phaidon.

ArchDaily. “Armstrong Place Senior Housing.”, accessed January 1, 2014, http://www. archdaily.com/153359/armstrong-place-senior-housing-david-baker-partners/. “Julia Tower., accessed October 31, 2013, http://www.archdaily.com/283113/.

Archinect People. “Regenerate: Multigenerational House.”, accessed December 10, 2013, http://archinect.com/people/project/21750526/regenerate-multigenerationalhouse/23030017.

Ball, M. Scott. 2012. Livable Communities for an Aging Population: Urban Design Solutions for Longevity. Hoboken, N.J: John Wiley \& Sons, Inc.

Bank of Canada. "Consumer Price Index., accessed October 31, 2013, http://www. bankofcanada.ca/rates/price-indexes/cpi/. 
BKK-3. “Miss Sargfabrik.”, accessed December 10, 2013, http://www.bkk-3.com/BUILDINGS/ MISS-LIVING/miss-living.html.

Brown, Mary and Carol Orsborn. 2006. Boom: Marketing to the Ultimate Power Consumer-the Baby Boomer Woman. New York: American Management Association.

Canadian Mortgage and Housing Corporation. 2001. "Retirement Homes Report."

-_- 2011. Seniors' Housing Report Ontario.

Champlain CCAC. 2011. 2011 - 2013 Strategic Plan.

- - - "Champlain CCAC.", accessed January 10, 2014, http://healthcareathome.ca/ champlain/en.

_-_. "Champlain CCAC Office Locations.", accessed January 10, 2014, http:// healthcareathome.ca/champlain/en/contact/Pages/Office-addresses-and-phonenumbers.aspx.

City of Ottawa. "IG - General Industrial Zone (Sec. 199-200)., accessed January 10, 2014, http://ottawa.ca/en/residents/laws-licenses-and-permits/laws/city-ottawazoning-law/zoning-law-2008-250-consolidation-70.

_-_. “MC - Mixed-use Centre Zone (Sec. 191-192).”, accessed January 10, 2014, http:// ottawa.ca/en/residents/laws-licenses-and-permits/laws/city-ottawa-zoning-law/mcmixed-use-centre-zone-sec-191-192.

Claremont Insider. “Affordable Housing Update., accessed December 10, 2013, http://4. 
bp.blogspot.com/_iFIDdxibrTg/TIpKyToiu9I/AAAAAAAAESs/Ecp3cIlvHOI/s1600/

Courier+Place+site+plan1.jpg.

Cravit, David. 2008. The New Old: How the Boomers are Changing Everything... again. Toronto: ECW Press.

Del Webb. 2010. 2010 Del Webb Baby Boomer Survey.

-_- 2010. Baby Boomers on the Move: Snuggling in Or Launching Out?.

_-_. “Del Webb Retirement Communities.", accessed December 10, 2013, http://www. delwebb.com/index.aspx.

Dietz Joppien Architekten AG. “Social Housing Complex - Wiesbaden., accessed December 10, 2013, http://www.dietz-joppien.de/projects/projekt-datenspeicher/residentaldistrict-sauerland/1.html?L=1\&no_cache=1\&sword_list $\% 5 \mathrm{~B} 0 \% 5 \mathrm{D}=$ Gemeinn\%C3\%BCtzige.

Dr. Samir K. Sinha. 2013. Living Longer, Living Well: Highlights and Key Recommendations from the Report Submitted to the Minister of Health and Long-Term Care and the Minister Responsible for Seniors on Recommendations to Inform a Seniors Strategy for Ontario.

Feldman Rotenberg, Jessica. 2011. "Integrated Ageing: An Architectural Strategy for the Ageing Baby Boomers." Master of Architecture, Ryerson University.

Google Maps. "Little Italy Map., accessed December 10, 2013, https://maps.google.ca/ 
maps?q=little+italy\&ie=UTF-8\&ei=shIzU4e_NKiM2QX3kIHICg\&ved=0CAYQ

AUoAQ.

Government of Canada. "Funding: New Horizons for Seniors Program., accessed November 10, 2013, http://www.hrsdc.gc.ca/eng/seniors/funding/index.shtml.

Government of Ontario. 2007. Long-Term Care Homes Act 2007.

_-_. 2010. Ontario Retirement Homes Act.

Graham Niederhaus, Sharon and John L. Graham. 2013. All in the Family: A Practical Guide to Successful Multigenerational Living. United Kingdom: Taylor Trade Publishing.

_-_. 2007. Together again: A Creative Guide to Successful Multigenerational Living. United Kingdom: M. Evans.

Gruchala, Adam. 2010. "Integrational Structuring: A Holarchic Strategy for Housing the Aging Population." Master of Architecture, University of Waterloo.

Harrigan, John E., Jennifer M. Raiser, and Phillip H. Raiser. 1998. Senior Residences : Designing Retirement Communities for the Future. Wiley Series in Healthcare and Senior Living Design. New York: Wiley.

Hasler Schlatter Partner. “Steinacher Apartments., accessed December 10, 2013, http://www. hsp-architekten.ch/hsp_referenzen.php?read_article=11.

Hodge, Gerald. 2008. The Geography of Aging : Preparing Communities for the Surge in Seniors. Kingston, Ont: McGill-Queen's University Press. 
Horgan, David and Shira Block. 2009. When Your Parent Moves in: Every Adult Child's Guide to Living with an Aging Parent. United States: Adams Media.

Jacobs, Jerry. 1974. Fun City: An Ethnographic Study of a Retirement Community. Case Studies in Cultural Anthropology. New York: Holt, Rinehart and Winston.

1975. Older Persons and Retirement Communities : Case Studies in Social Gerontology. Springfield, Ill: Thomas.

Jamboree. “Courier Place., accessed November 10, 2013, http://www.jamboreehousing.com/index.php?option=com content\&view=category\&layout $=$ blog\&id $=16 \&$ Itemid $=\&$ properties $=$ detail\&property_id=62.

KOKO. “Fahle House.”, accessed October 31, 2013, http://www.koko.ee/new21/index.php/ projects?projekt=7.

Krivel, Peter. 2003. "Retirement Living Options are Many and Varied." The Toronto Star, Z.14.

Lahey, Anita. 1998. "Marketing the Leisure Life: Adult Lifestyle Communities are Booming as Seniors Embrace a Promised Life of Ease.” Marketing Magazine 103 (32): 20.

Litchfield, Michael. 2011. In-Laws, Outlaws and Granny Flats The Taunton Press.

Lucy, William H. and David L. Phillips. 2006. Tomorrow's Cities, Tomorrow's Suburbs. 1st ed. ed. Chicago: American Planning Association. 
Ministry of Health and Long-Term Care. "Assisted Living Services in Supportive Housing Overview.", accessed November 10, 2013, http://www.health.gov.on.ca/en/public/ programs/ltc/13_housing.aspx.

_- - “Seniors' Care: Long-Term Care Homes., accessed October 31, 2013, http://www. health.gov.on.ca/en/public/programs/ltc/15_facilities.aspx.

Newman, Susan. 2010. Under One Roof again: All Grown Up and (Re)Learning to Live Together Happily. United States: Lyons Press.

Nicol, Heather N. and Greg Halseth. 2000. (Re)Development at the Urban Edges : Reflections on the Canadian Experience. Department of Geography Publication Series, no. 53. Waterloo, Ont: Dept. of Geography, University of Waterloo.

Ontario Retirement Communities Association. "Senior Living Options., accessed October 31, 2013, http://www.orcaretirement.com/retirement-living/seniors-living-options/.

Perkins, Bradford. 2004. Building Type Basics for Senior Living. Building Type Basics Series. Hoboken, N.J: Wiley.

Pew Research Center. 2010. The Return of the Multi-Generational Family Household.

PR Web. “Jamboree Housing Corporation Complete Courier Place Apartment Homes in

Claremont, California., accessed November 10, 2013,http://www.prweb.com/releases/ JamboreeHousing/CourierPlaceClaremont/prweb9271411.htm.

Rose, Mary. “Liveable Communities: Shared Houses for Older Women.”, accessed January 10, 
2014, http://www.steppingstonestays.com/shared_houses.htm.

Schriener, Judy and Mike Kephart. 2010. Building for Boomers : Guide to Design and

Construction. McGraw Hill Construction. New York: McGraw-Hill.

Schwartz, Barry. 1976. The Changing Face of the Suburbs. Chicago: University of Chicago Press.

Silverman, Rachel Emma. 2006. “Who Will Mind Mom?” Wall Street Journal, D1.

Statistics Canada. 2012. 2012 Census of Population Estimates.

-_-. 2013. Canada at a Glance 2013.

-__. 2006. The Daily: 2006 Census: Age and Sex.

-_- 2012. The Daily: 2012 Canada's Population Estimate.

-_- 2010. The Daily: Population Projections: Canada, the Provinces and Territories.

-_- 2011. Living Arrangements of Seniors.

_-_. 2006. Low Income Cut-Offs for 2005 and Low Income Measures for 2004.

-_- 2011. Portrait of Families and Living Arrangements in Canada.

-_- 2007. A Portrait of Seniors in Canada 2006.

-_- 2001. Seniors in Canada Profile Series 2001.

Sustainable. Inter-Generational. Living. “Miss Sargfabrik., accessed December 10, 2013, http://sieplcoatesstudio.weebly.com/miss-sargfabrik.html.

_-_. "Social Housing Complex - Wiesbaden.", accessed December 10, 2013, http:// 
sieplcoatesstudio.weebly.com/housing-development.html.

“Steinacher Apartments.”, accessed December 10, 2013, http://sieplcoatesstudio. weebly.com/steinacker-residential-complex.html.

The Ontario Seniors' Secretariat. 2013. Independence, Activity and Good Health: Ontario's Action Plan for Seniors: Queen's Printer for Ontario.

This is 3D. “Kidosaki House.”, accessed December 10, 2013, http://thisis3d.com/2011/03/10/ kidosaki-house-in-osaka-japan/.

Transit Services. 2012. Feasibility Study of O-Train Extension to Leitrim and Riverside South: City of Ottawa.

Wakan, Naomi. 2012. A Roller-Coaster Ride: Thoughts on Aging. Hamilton, Ont: Poplar Press.

-_- 2012. A Roller-Coaster Ride: Thoughts on Aging. Hamilton, Ont: Poplar Press.

Wheeler, W. Michael. 1995. Elderly Residential Experience; the Evolution of Places as Residence. New York: Garland Publishing Inc.

Whitehand, J. W. R. and C. M. H. Carr. 2001. Twentieth-Century Suburbs : A Morphological Approach. Planning, History, and the Environment Series. London ; New York: Routledge. 